\title{
Effekt der Beta-Blocker-Therapie auf die Infektionsrate nach einem ischämischen Schlaganfall
}

\author{
INAUGURAL-DISSERTATION \\ zur Erlangung des Doktorgrades \\ der Medizinischen Fakultät der \\ Georg-August-Universität zu Göttingen
}

vorgelegt von

Johannes Becker

aus

Salzgitter

Göttingen 2019 
Dekan:

\section{Betreuungsausschuss}

Betreuer/in

Ko-Betreuer/in:

\section{Prüfungskommission}

Referent/in

Ko-Referent/in:

Drittreferent/in:
Prof. Dr. rer. nat. H. K. Kroemer

Professor Dr. med. J. Liman

Professor Dr. med. R. Wachter
Prof. Dr. Jan Liman

Prof. Dr. Rolf Wachter

Prof. Dr. Margarete Schön

Datum der mündlichen Prüfung: 12.05.2021 
Hiermit erkläre ich, die Dissertation mit dem Titel „Effekt der BetaBlocker-Therapie auf die Infektionsrate nach einem ischämischen Schlaganfall“ eigenständig angefertigt und keine anderen als die von mir angegebenen Quellen und Hilfsmittel verwendet zu haben.

Göttingen, den 


\section{Inhaltsverzeichnis}

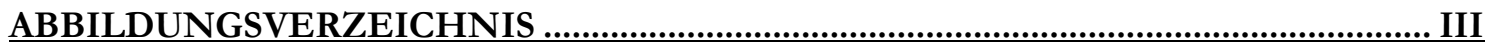

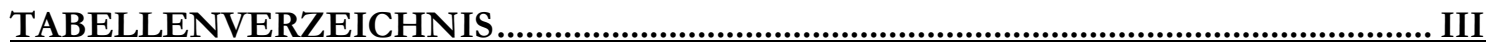

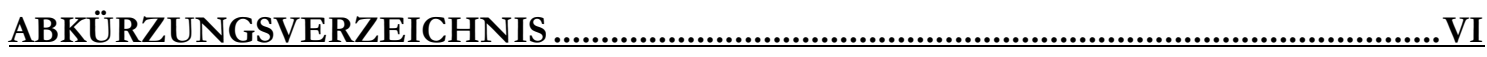

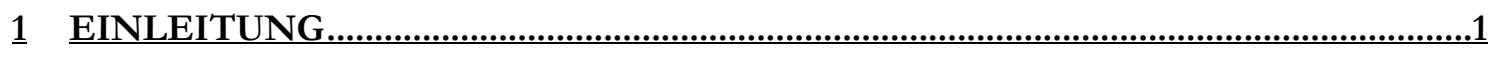

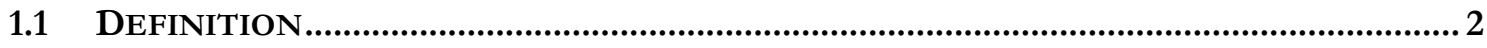

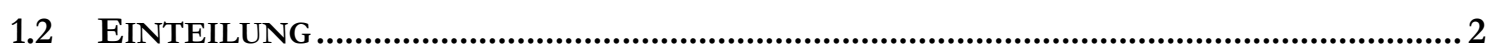

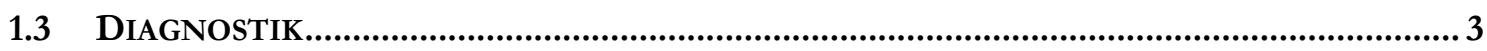

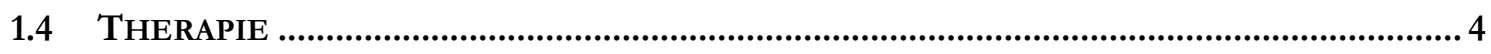

1.5 INFEKTIONEN UND INFEKTIONSRATEN NACH SCHLAGANFALL .................................. 6

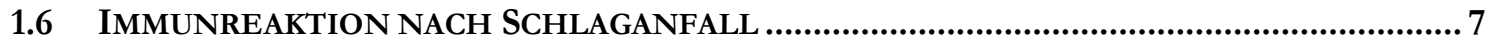

1.7 SYMPATHIKUS-AKTIVIERUNG UND IMMUNSUPPRESSION .........................................9

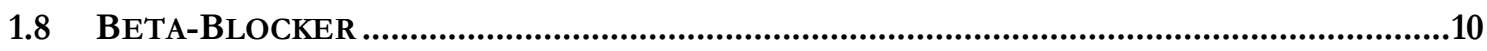

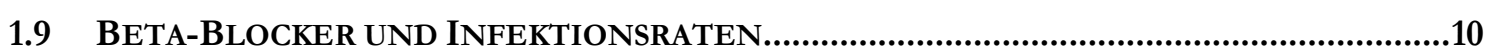

1.10 BISHERIGE IMMUNMODULATORISCHE THERAPIEANSÄTZE ..................................11

1.11 EINFLUSS DER LOKALISATION DES SCHLAGANFALLS ............................................12

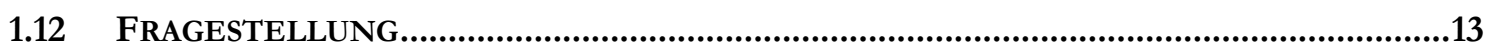

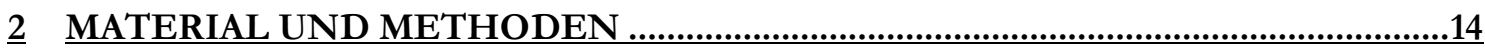

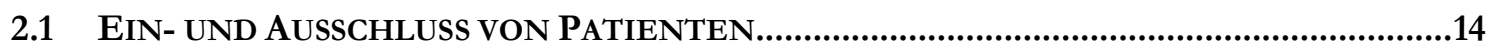

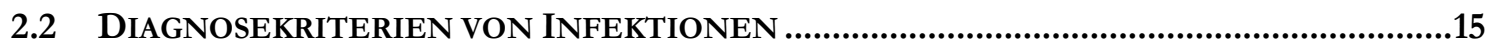

2.3 ERFASSUNG VON MÖGLICHEN INFEKTIONSEINFLUSSFAKTOREN …............................16

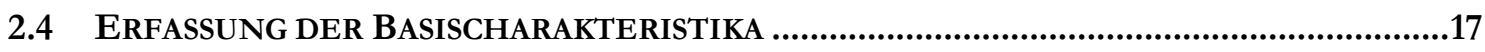

2.5 ALBERTA STROKE PROGRAM EARLY CT-SCORE (ASPECTS) ......................................17

2.6 NATIONAL INSTITUTES OF HEALTH STROKE SCALE (NIHSS) ..................................19

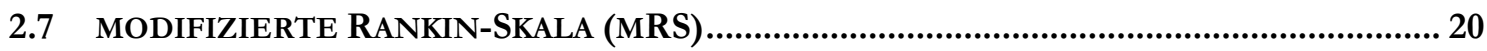

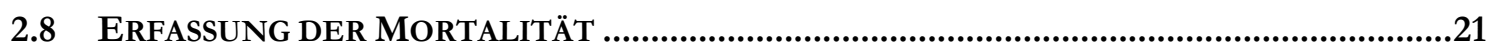

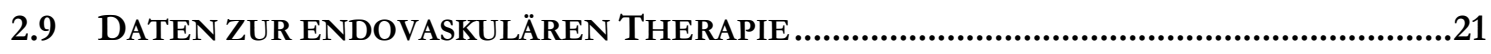

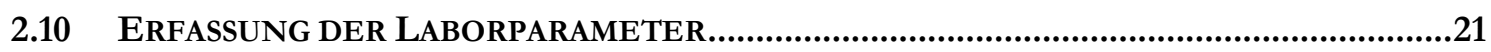

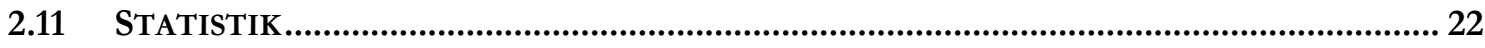

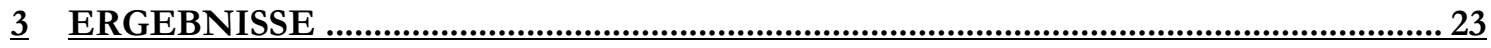

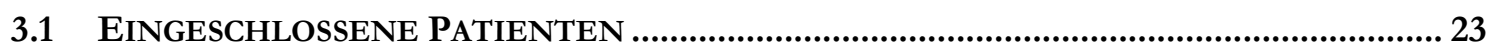

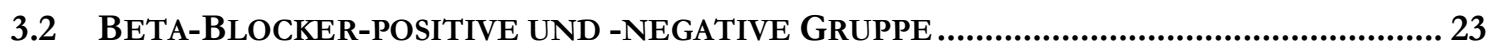

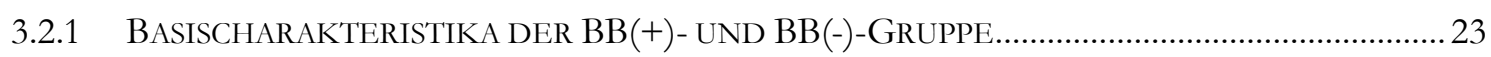

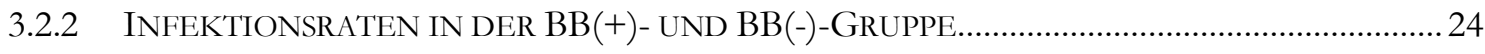

3.2.3 VERTEILUNG VON EINFUSSFAKTOREN IN DER BB(+)- UND BB(-)-GRUPPE........................26

3.3 ANALYSE DER INFEKTIONS- UND MORTALITÄTSGRUPPEN.......................................... 28 
3.3.1 EINFLUSS AUF DIE ENTWICKLUNG EINER PNEUMONIE................................................28

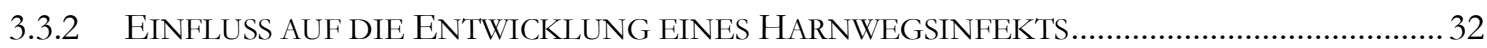

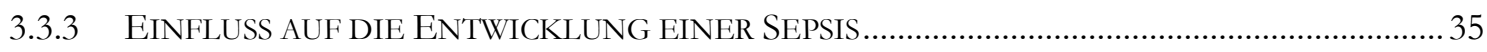

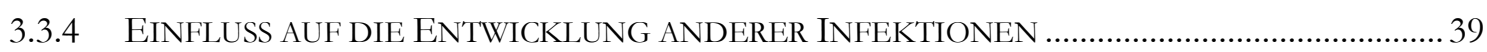

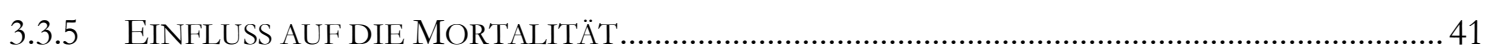

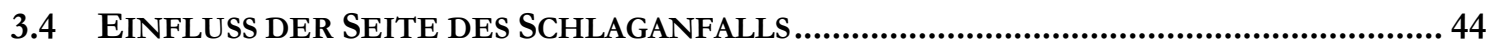

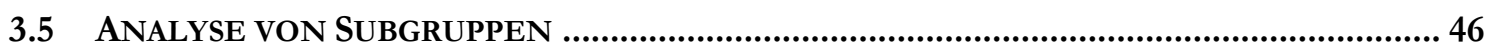

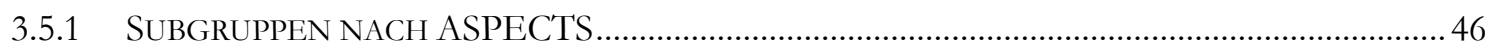

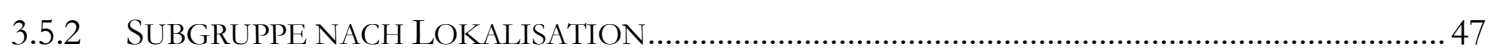

3.6 LABORPARAMETER DER BB(+) UND BB(-)-GRUPPE.........................................50

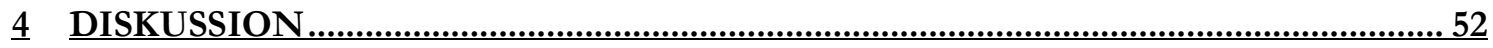

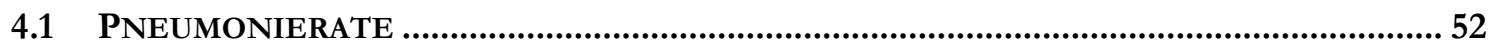

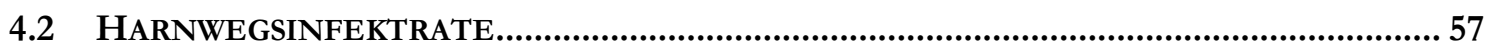

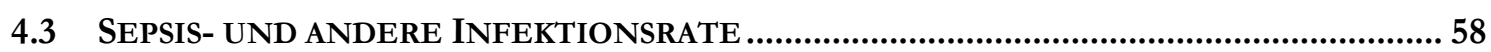

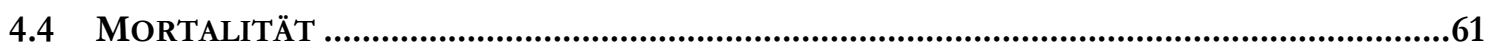

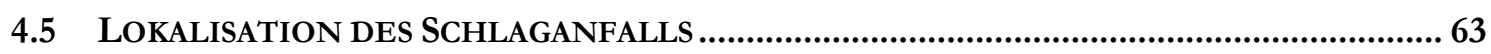

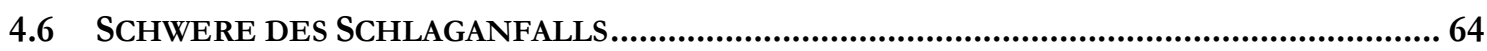

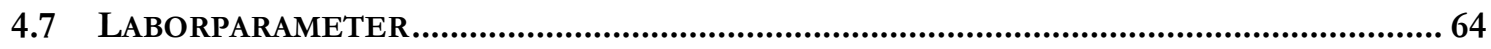

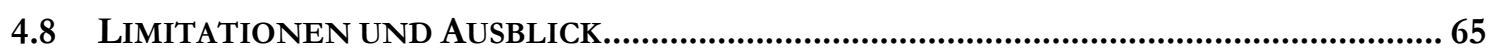

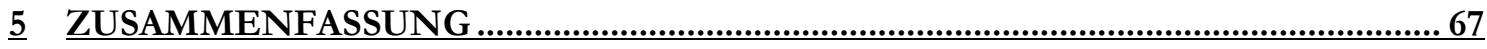

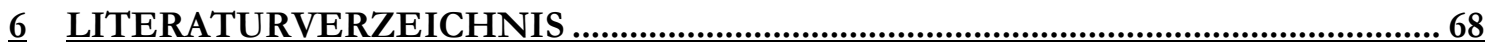




\section{Abbildungsverzeichnis}

ABBILDUNG 1: FLIEßDIAGRAMM ZUM EIN- UND AussCHLUSS DER PATIENTEN

ABBILDUNG 2: VERTEILUNG DER LOKALISATION DES THROMBUS IM GESAMTEN

PATIENTENKOLLEKTIV ( $\mathrm{N}=306)$ IN \%

ABBILDUNG 3: GEBIETE DES ASPECTS AUf HÖHE DER BASALGANGLIEN, CN=NUCLEUS

CAUDATUS, IC=CAPSULA INTERNA, LN=PUTAMEN, I=INSULÄRER KORTEX,

$\mathrm{A}=$ ANTERIORSTROMGEBIET, $\mathrm{P}=$ POSTERIORSTROMGEBIET MIT FREUNDLICHER

GENEHMIGUNG VON DR SUBASH THAPA, RADIOPAEDIA.ORG, RID: 40018 18

ABBILDUNG 4: GEBIETE DES ASPECTS AUF HÖHE DER VENTRIKEL UND OBERHALB DER

BASALGANGLIEN, A=ANTERIORSTROMGEBIET, P=POSTERIORSTROMGEBIET MIT

FREUNDLICHER GENEHMIGUNG VON DR SUBASH THAPA, RADIOPAEDIA.ORG, RID:

40018

AbBiLDUNG 5: KOMPLIKATIONSRATEN DER BB(+)- (N=158), BB(-)-GRUPPE ( $\mathrm{N}=148)$ UND DES

PATIENTENKOLLEKTIVS ( $\mathrm{N}=306$ ) IN \% (UNADJUSTIERT).

ABBILDUNG 6: VERTEILUNG MÖGLICHER EINFLUSSFAKTOREN IN DER BB(+)- (N=158) UND BB(-

)-GRUPPE ( $\mathrm{N}=148)$ IN \%.

ABBILDUNG 7: INTUBATIONSDAUER UND KRANKENHAUSAUFENTHALT IN TAGEN BEI

PNEUMONIE NACH ARZTBRIEF UND PNEUMONIE NACH LEITLINIE IM

PATIENTENKOLLEKTIV ( $\mathrm{N}=306)$

ABBILDUNG 8: INTUBATIONSDAUER UND KRANKENHAUSAUFENTHALT IN TAGEN BEI SEPSIS

NACH ARZTBRIEF UND SEPSIS NACH LEITLINIE IM PATIENTENKOLLEKTIV (N=306) ......37

ABBILDUNG 9: INTUBATIONSDAUER UND KRANKENHAUSAUFENTHALT IN TAGEN BEI ANDEREN

INFEKTIONEN IM PATIENTENKOLLEKTIV (N=306)

ABBILDUNG 10: BEHANDLUNGSECKDATEN DER VERSTORBENEN UND NICHT VERSTORBENEN

PATIENTEN $(\mathrm{N}=306)$

\section{Tabellenverzeichnis}

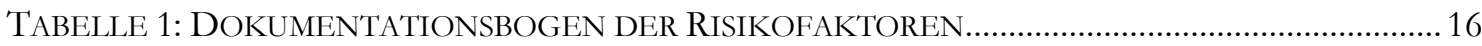

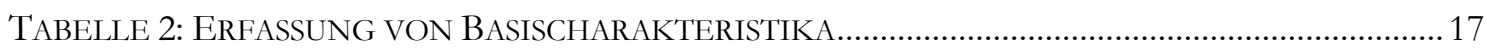

TABELLE 3: NIHSS (MODIFIZIERT NACH BERGER ET AL. 1999) ..................................................... 19

TABELLE 4: MRS (MODIFIZIERT NACH MODIFIZIERTE RANKIN-SKALA ZUR QUALIFIZIERUNG

DES NEUROLOGISCHEN DEFIZITS NACH SCHLAGANFALL; BQS INSTITUT) ........................20

TABELle 5: BASELINECHARAKTERISTIKA DER BETA-BlOCKER-POSITIVEN ( $=158)$ UND -

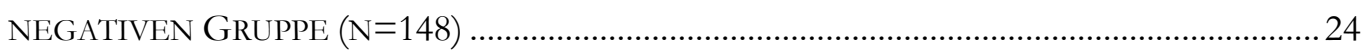

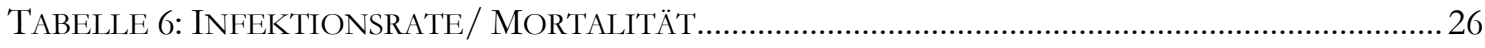

TABELLE 7: VERTEILUNG MÖGLICHER EINFLUSSFAKTOREN IN DER BB(+)- (N=158) UND BB(-)-

GRUPPE (N=148)

TABELLE 8: VERTEILUNG VON EINFLUSSFAKTOREN FÜR INFEKTIONEN BEI PNEUMONIE NACH

ARZTBRIEF IM PATIENTENKOLLEKTIV (N=306)

TABELLE 9: VERTEILUNG VON EINFLUSSFAKTOREN FÜR INFEKTIONEN BEI PNEUMONIE NACH

LEITLINIE IM PATIENTENKOLLEKTIV ( $\mathrm{N}=306)$ 
TABELLE 10: ERGEBNISSE DER UNIVARIATEN UND MULTIVARIATEN LOGISTISCHEN REGRESSION NACH DER METHODE EINSCHLUSS FÜR DEN ENDPUNKT PNEUMONIE NACH ARZTBRIEF UND LEITLINIE.

TABELLE 11: VERTEILUNG VON EINFLUSSFAKTOREN FÜR INFEKTIONEN BEI HARNWEGSINFEKT NACH ARZTBRIEF IM PATIENTENKOLLEKTIV (N=306)

TABELLE 12: VERTEILUNG VON EINFLUSSFAKTOREN FÜR INFEKTIONEN BEI HARNWEGSINFEKT NACH LEITLINIE IM PATIENTENKOLLEKTIV ( $\mathrm{N}=306)$.

TABELLE 13: ERGEBNISSE DER UNIVARIATEN UND MULTIVARIATEN LOGISTISCHEN REGRESSION NACH DER METHODE EINSCHLUSS FÜR DEN ENDPUNKT HARNWEGSINFEKT NACH ARZTBRIEF UND LEITLINIE. 34

TABELLE 14: VERTEILUNG VON EINFLUSSFAKTOREN FÜR INFEKTIONEN BEI SEPSIS NACH ARZTBRIEF IM PATIENTENKOLLEKTIV ( $=306)$ 35

TABELLE 15: VERTEILUNG VON EINFLUSSFAKTOREN FÜR INFEKTIONEN BEI SEPSIS NACH LEITLINIE IM PATIENTENKOLLEKTIV (N=306). 36

TABELLE 16: ERGEBNISSE DER UNIVARIATEN UND MULTIVARIATEN LOGISTISCHEN REGRESSION NACH DER METHODE EINSCHLUSS FÜR DEN ENDPUNKT SEPSIS NACH ARZTBRIEF UND LEITLINIE. 38

TABELLE 17: VERTEILUNG VON EINFLUSSFAKTOREN FÜR INFEKTIONEN BEI ANDEREN INFEKTIONEN IM PATIENTENKOLLEKTIV (N=306).

TABELLE 18: ERGEBNISSE DER UNIVARIATEN UND MULTIVARIATEN LOGISTISCHEN REGRESSION NACH DER METHODE EINSCHLUSS FÜR DEN ENDPUNKT ANDERE INFEKTION ..... 41

TABELlE 19: VERTEILUNG DER EINFLUSSFAKTOREN IN BEZUG AUF DIE MORTALITÄT IM PATIENTENKOLLEKTIV (N=306) IN \%

TABELLE 20: ERGEBNISSE DER UNIVARIATEN UND MULTIVARIATEN LOGISTISCHEN REGRESSION NACH DER METHODE EINSCHLUSS FÜR DEN ENDPUNKT TOD

TABELle 21: VERTEILUNG DER BETROFFENEN SEITE DER BETA-BLOCKER-POSITIVEN UND NEGATIVEN GRUPPE ( $\mathrm{N}=260)$

TABELLE 22: SEITENVERTEILUNG IN BEZUG AUF DIE INFEKTIONSRATEN UND MORTALITÄT IM PATIENTENKOLLEKTIV ( $\mathrm{N}=260)$

TABELLE 23: SEITENVERTEILUNG IN BEZUG AUF DIE INFEKTIONSRATEN UND MORTALITÄT IN DER BETA-BLOCKER-POSITIVEN GRUPPE ( $=134)$

TABELLE 24: SEITENVERTEILUNG IN BEZUG AUF DIE INFEKTIONSRATEN UND MORTALITÄT IN DER BETA-BLOCKER-NEGATIVEN GRUPPE (N=130) 46

TABELlE 25: VERTEILUNG DER INFEKTIONSRATE UND MORTALITÄT IN DER BETA-BLOCKERPOSITIVEN UND -NEGATIVEN GRUPPE IN DER SUBGRUPPE MIT EINEM ASPECTS IM CT NACH 24 STUNDEN VON $=<7$ PUNKTEN $(\mathrm{N}=141)$

TABELle 26: VERTEILUNG DER INFEKTIONSRATE UND MORTALITÄT IN DER BETA-BLOCKERPOSITIVEN UND -NEGATIVEN GRUPPE IN DER SUBGRUPPE MIT EINEM ASPECTS IM CT NACH 24 STUNDEN VON $=<5$ PUNKTEN $(\mathrm{N}=79)$.

TABELLE 27: VERTEILUNG DER INFEKTIONSRATE UND MORTALITÄT VERGLICHEN BEI PATIENTEN MIT UND OHNE SCHÄDIGUNG DES INSULÄREN KORTEX (N=213).... 48

TABELLE 28: VERTEILUNG DER INFEKTIONSRATE UND MORTALITÄT IN DER BETA-BLOCKERPOSITIVEN SOWIE -NEGATIVEN GRUPPE IN DER SUBGRUPPE MIT SCHÄDIGUNG DES INSULÄREN KORTEX (N=135) 
TABELLE 29: VERTEILUNG DER INFEKTIONSRATE UND MORTALITÄT VERGLICHEN BEI PATIENTEN MIT UND OHNE SCHÄDIGUNG DES GEBIETES DES INSULÄREN KORTEXES’ UND DER M1-REGION ( $\mathrm{N}=213)$

TABELLE 30: VERTEILUNG DER INFEKTIONSRATE UND MORTALITÄT IN DER BETA-BLOCKERPOSITIVEN SOWIE -NEGATIVEN GRUPPE IN DER SUBGRUPPE MIT SCHÄDIGUNG DES INSULÄREN KORTEXES UND M1-GEBIETES ( $=90)$.

TABELLE 31: VERTEILUNG DER INFEKTIONSRATE UND MORTALITÄT VERGLICHEN BEI PATIENTEN Mit UND OHNE SCHÄDIGUNG DES GEBIETES DES INSUlÄREN KORTEXES', DER M1- UND M4-REGION ( $=213$ ) 50

TABELLE 32: VERTEILUNG DER INFEKTIONSRATE UND MORTALITÄT IN DER BETA-BLOCKERPOSITIVEN SOWIE -NEGATIVEN GRUPPE IN DER SUBGRUPPE MIT SCHÄDIGUNG DES INSULÄREN KORTEXES, M1-UND M4-GEBIETES ( $\mathrm{N}=77$ ). 50

TABELLE 33: LABORPARAMETER DER BB(+)- UND BB(-)-GRUPPE 51 


\section{Abkürzungsverzeichnis}

$\begin{array}{ll}\text { A. } & \text { Arteria } \\ \text { AB } & \text { Arztbrief } \\ \text { ASPECTS } & \text { Alberta Stroke Program Early CT-Score } \\ \text { BB(+) } & \text { Beta-Blocker-positive Gruppe } \\ \text { BB(-) } & \text { Beta-Blocker-negative Gruppe } \\ \text { CRP } & \text { C-reaktives Protein } \\ \text { CT } & \text { Computertomographie } \\ \text { GCS } & \text { Glasgow Coma Scale } \\ \text { HWI } & \text { Harnwegsinfekt } \\ \text { ICCA } & \text { IntelliSpace Critical Care and Anaesthesia } \\ \text { IFN } \gamma & \text { Interferon gamma } \\ \text { IL-10 } & \text { Interleukin-10 } \\ \text { iNKT } & \text { invariante natürliche Killer-T } \\ \text { IQR } & \text { Interquartilsabstand } \\ \text { KbE } & \text { Kolonie-bildende Einheit } \\ \text { KHK } & \text { koronare Herzerkrankung } \\ \text { LL } & \text { Leitlinie } \\ \text { MHC } & \text { Major Histocompalibility Complex } \\ \text { mRS } & \text { modifizierte Rankin-Skala } \\ \text { MRT } & \text { Magnetresonanztomographie } \\ \text { mTICI } & \text { Modified Treatment in Cerebral Infarction } \\ \text { NIHSS } & \text { National Institutes of Health Stroke Scale } \\ \text { pAVK } & \text { periphere arterielle Verschlusskrankheit } \\ \text { PCT } & \text { Prokalzitonin } \\ \text { rt-PA } & \text { Alteplase } \\ \text { TIA } & \text { transiente ischämische Attacke } \\ \text { TNF- } \alpha & \text { Tumor-Nekrose-Faktor Alpha } \\ \text { TOAST } & \text { Trial of Org 10172 in Acute Stroke Treatment } \\ \text { UMG } & \text { Universitätsmedizin Göttingen } \\ \text { SOFA } & \text { Sequential (Sepsis-Related) Organ Failure Assessment } \\ \text { VHF } & \text { Vorhofflimmern } \\ & \end{array}$




\section{$1 \quad$ Einleitung}

Der Schlaganfall ist auch aufgrund des demographischen Wandels der Bevölkerung eine häufige Erkrankung. Die Lebenszeitprävalenz eines Schlaganfalls liegt bereits in der Altersgruppe von 40-79 Jahren bei 2,9\%. Sie steigt aber mit zunehmenden Lebensalter an, sodass sich in der älteren Bevölkerung Prävalenzen von knapp über 20\% beobachten lassen (Russo et al. 2011; Hornsten et al. 2012; Busch et al. 2013; Niklasson et al. 2014). So schätzt die American Heart Association, dass in den USA im Durchschnitt alle 40 Sekunden jemand einen Schlaganfall erleidet (Mozaffarian et al. 2015). Der Schlaganfall ist durch eine Durchblutungsstörung in bestimmten Bereichen des Gehirns gekennzeichnet. Als Ursache liegt meist ein ischämischer Schlaganfall vor, das heißt ein Verschluss einer Hirnarterie, oder seltener ein hämorrhagischer Schlaganfall, bei dem es zu einer Ruptur einer Hirnarterie kommt. Der Schlaganfall gehört weltweit zu den führenden Todesursachen (Lozano et al. 2012) und zu den führenden Ursachen für eine anhaltende Behinderung (Murray et al. 2012). Auch für das Gesundheitssystem entstehen durch die intensive Betreuung in Rehabilitationseinrichtungen und die langfristige, häusliche Pflege enorme Kosten (Kolominsky-Rabas et al. 2006). Die Einrichtung der Stroke-Units in Krankenhäusern ist durch eine frühestmögliche multimodale Behandlung ein effektiver Schritt, um den Verlust von Körperfunktionen und Eigenständigkeit des Patienten zu verhindern. Eine Versorgung auf einer Stroke-Unit reduziert im Vergleich zu einer Normalstation wirkungsvoll die Mortalität (Stroke Unit Trialists' Collaboration 2013). Des Weiteren stehen mit der intravenösen Lysetherapie und interventionellen Thrombektomie effiziente Therapien zur Verfügung, die die Prognose der Patienten signifikant verbessern (Hacke et al. 2008; Lees et al. 2008; Lees et al. 2010; Emberson et al. 2014; Berkhemer et al. 2015; Campbell et al. 2015; Goyal et al. 2015; Saver et al. 2015; Fransen et al. 2016). Trotzdem kommt es nach Schlaganfällen häufig zu Komplikationen, sodass die Optimierung der Behandlung nach einem Schlaganfall eine wichtige Position einnimmt. Besonders bedeutsam ist das Verhindern von Infektionen, wie zum Beispiel einer Pneumonie oder eines Harnwegsinfekts. Eine Pneumonie tritt in fast 30\% und ein Harnwegsinfekt in ungefähr 20\% der Patienten mit einem Schlaganfall auf (Westendorp et al. 2011). Dabei verschlechtern diese die Prognose der Patienten deutlich (Langhorne et al. 2000; Roth et al. 2001; Weimar et al. 2002; Bae et al. 2005). Eine prophylaktische Antibiotikagabe hat sich jedoch in mehreren Studien als nicht vorteilhaft herausgestellt (Harms et al. 2008; Kalra et al. 2015; Westendorp et al. 2015). Bei der Infektentwicklung könnte eine Verbindung zwischen zentralem Nervensystem und systemischer Immunabwehr eine entscheidende Rolle spielen. Das Immunsystem wird supprimiert, was dem Zweck dienen könnte, das Gehirn vor weiterem Schaden durch eine gesteigerte Inflammation im Bereich des geschädigten Gewebes zu schützen (Meisel et al. 2005; Offner et al. 2006; Dirnagl et al. 2007). Dafür scheint es entscheidend zu sein, dass der Schlaganfall die Inselregion und bzw. oder das anteromediale Stromgebiet der A cerebri media einschließt (Sander et al. 2001; Harms et al. 2011; Walter 
et al. 2013). Gleichzeitig könnte über diesen immunmodulierenden Prozess jedoch die Anfälligkeit für Infekte erhöht werden. Als entscheidender Mechanismus könnte ein gesteigerter Sympathikustonus fungieren, der über erhöhte Katecholaminkonzentrationen zur Bildung von anti-inflammatorischen Immunsubzelltypen beitragen kann und mit einer erhöhten Infektionsrate assoziiert sein könnte. Eine Unterstützung dieser These gibt es aus dem Mausmodell, hier konnte dieser Mechanismus bereits erfolgreich durch den unselektiven BetaBlocker Propranolol unterbunden werden (Prass et al. 2003). Eine retrospektive Studie konnte diesbezüglich in einer generellen Schlaganfallpopulation protektive Effekte hinsichtlich von Harnwegsinfekten, jedoch keinen Effekt hinsichtlich Pneumonien zeigen (Maier et al. 2015). In dieser retrospektiven Datenanalyse soll der protektive Effekt von Beta-Blockern in einer Population von Patienten mit schweren Schlaganfällen untersucht werden.

\subsection{Definition}

Die Bezeichnung ischämischer Schlaganfall beschreibt ein akut aufgetretenes fokal-neurologisches Defizit aufgrund der Unterversorgung eines umschriebenen Hirngebietes mit Blut und somit Sauerstoff. In dem Fall, dass sich die Symptomatik innerhalb von 24 Stunden zurückbildet, kann man die Symptomatik klinisch als eine transiente ischämische Attacke (TIA) klassifizieren (Leitlinie Schlaganfalltherapie 2012). Durch die Weiterentwicklung der radiologischen Diagnostik kann man eine solche Konstellation bei Nachweis einer stimmigen Läsion in der Magnetresonanztomographie (MRT) heutzutage als Schlaganfall diagnostizieren. Der Begriff TIA wird weiterhin für alle kurz andauernden fokal-neurologischen Defizite ohne bildmorphologisches Korrelat verwendet (Easton et al. 2009).

\subsection{Einteilung}

Der ischämische Schlaganfall kann ätiologisch nach seiner Ursache weiter unterteilt werden. Diese Einteilung wird klassischerweise nach der Trial of Org 10172 in Acute Stroke Treatment, auch kurz als TOAST-Klassifikation bezeichnet, vorgenommen und beruht dabei auf den klinischen Untersuchungsbefunden, kraniellen Magnetresonanztomographie (MRT)- und Computertomographie (CT)-Bildern, Duplexsonographie der extra- und intrakraniellen Gefäße, transthorakaler und —ösophagealer Echokardiographie, Aufzeichnung von Elektrokardiogrammen, Blutdruckmessungen und Laborwerten, die Hinweise auf Grunderkrankungen geben können (Adams et al. 1993).

Eine arteriosklerotische Grunderkrankung, meist verursacht durch eine Kombination aus kardiovaskulären Risikofaktoren wie Diabetes mellitus, einer arteriellen Hypertonie und/ oder einer Hyperlipidämie, kann bei einer signifikanten arteriellen Stenose einen Schlaganfall auslösen. Von einer makroangiopathischen Ursache spricht man, wenn der Schlaganfall durch eine Atherosklerose der großen Hirnarterien, meist Arteria (A.) carotis interna oder $A$. cerebri media, verursacht wird. Außerdem müssen die neurologischen, klinisch beobachteten 
Ausfälle mit dem Versorgungsbereich der betroffenen Arterien übereinstimmen und/oder auf den darstellenden Bildern eine mehr als 1,5 Zentimeter große Läsion zu sehen sein. Wenn dementsprechend die arteriosklerotischen Veränderungen der kleineren Hirnarterien ursächlich für die Entstehung des Schlaganfalls sind, ist der Schlaganfall mikroangiopathischen Ursprungs. Diese Infarkte haben einen eher kleinen ( $<1,5$ Zentimeter) Durchmesser (Adams et al. 1993).

Durch Einschwemmung eines Blutgerinnsels kann es zu einem embolischen Verschluss von Hirnarterien kommen. Zum einen ist hier der Mechanismus des kardial-embolischen Schlaganfalls zu nennen. Bestimmte kardiale Grunderkrankungen, vor allem Herzrhythmusstörungen und hier insbesondere das Vorhofflimmern (VHF), begünstigen die Bildung von Blutgerinnseln, die irgendwann in den Blutkreislauf ausgeschwemmt werden und konsekutiv eine Arterie verstopfen können. Zum anderen kann sich ein Thrombus von makroangiopathischen arteriellen Plaques lösen und dadurch ein kleineres, distales Gefäß okkludieren. Dies bezeichnet man als arterio-arterielle Embolie. Diese Pathomechanismen stellen die häufigsten Ursachen dar und sind für ca. mindestens 60-77\% der Schlaganfälle verantwortlich (Grau et al. 2001; Kolominsky-Rabas et al. 2001; Steiner und Brainin 2003; Palm et al. 2012).

Seltenere Ätiologien werden im Folgenden ausgewählt kurz skizziert. Hier sind hämodynamische Infarkte zu nennen. Bei einem Blutdruckabfall und gleichzeitiger Stenose vorgeschalteter Arterien kann es zu einer Minderversorgung von Hirngewebe mit Blut und Sauerstoff und folglich zu einem Schlaganfall kommen. Davon sind vor allem die Gebiete betroffen, in denen sich die Versorgungsgebiete der großen Arterien treffen und sich gewissermaßen die Endstrecke der arteriellen Versorgung befindet. Daher spricht man von Grenzzoneninfarkten. Zudem können eine arterielle Dissektion, v.a. $\operatorname{der} A$. carotis, aber auch entzündliche Veränderungen wie Vaskulitiden oder Vaskulopathien und Gerinnungsstörungen wie das AntiPhospholipid-Syndrom Hirninfarkte auslösen (Adams et al. 1993).

Darüber hinaus ist eine morphologische Unterteilung der Läsion möglich. Bei großen und proximalen Gefäßverschlüssen kommt es zu einem Territorialinfarkt, der sich in der Bildgebung keilförmig abbildet. Davon sind lakunäre Infarkte zu unterscheiden, die sich eher in punktförmigen, kleinen Defekten darstellen. Als dritte Entität sind die oben bereits erwähnten Grenzzoneninfarkte zu erwähnen, die sich an den Grenzstromgebieten der großen Hirnarterien manifestieren (Adams et al. 1993).

\subsection{Diagnostik}

Die klinisch-körperliche Untersuchung und Anamnese, besonders bezüglich des Zeitpunkts des Auftretens der Symptomatik, sind wichtige Instrumente zur Diagnostik eines Schlaganfalls. Die bildgebende Basisuntersuchung bei einem Schlaganfall ist die CT des Schädels ohne Kontrastmittel (Wintermark et al. 2013). Zum einen kann hier eine Hirnblutung als Ursache 
des fokal-neurologischen Defizits ausgeschlossen werden und zum anderen zeigen sich irreversible Schädigungen bereits als Hypodensitäten und ermöglichen eine erste zeitliche Einordnung des Geschehens (Pexman et al. 2001). Vor allem ist eine CT-Untersuchung heutzutage in den meisten Notaufnahmen schnell verfügbar und durchgeführt. Die sensitivste Untersuchung zum Nachweis einer ischämischen Läsion sind jedoch die diffusionsgewichteten Sequenzen des MRT des Neurokraniums (Schellinger et al. 2010). Aufgrund des längeren zeitlichen Aufwands kommt die MRT in der Akutdiagnostik nur bei speziellen klinischen Fragestellungen zum Einsatz. Sie wird jedoch meist im Verlauf des klinischen Aufenthalts zur Evaluation der Größe des Infarktareals durchgeführt.

Weiterführend kann bei Patienten mit dem Verdacht auf einen Gefäßverschluss eine Darstellung der Hirnarterien mittels CT- oder MRT-Angiographie erfolgen. Hinweise wären beispielsweise eine großes fokal-neurologisches Defizit. Bei Nachweis eines solchen Verschlusses und Ausschluss von Kontraindikationen ist ein interventioneller Eingriff zur endovaskulärer Revaskularisation mittlerweile die Standardtherapie (Wintermark et al. 2013; Berkhemer et al. 2015; Campbell et al. 2015; Goyal et al. 2015; Saver et al. 2015).

\subsection{Therapie}

Die Behandlung des akuten ischämischen Schlaganfalls zielt darauf ab, das betroffene Gefäß zu rekanalisieren und somit den Schaden für das Gehirn gering zu halten, indem möglichst viele Hirnnervenzellen vor dem Zelluntergang geschützt werden. Die Grundlage der Akuttherapie des Schlaganfalls ist das Prinzip der Penumbra. Bei Okklusion eines hirnarteriellen Blutgefäßes bildet sich im Zentrum der Unterversorgung ein irreversibler Infarktkern. Hier gehen die Nervenzellen vollständig zugrunde und können sich nicht mehr erholen. Das Penumbra-Modell beschreibt nun, dass um diesen Kern ein, abhängig von Lokalisation und Kollateralisierung, großes Gebiet entsteht, dessen Gewebe durch eine geeignete Therapie noch gerettet werden kann. Kann die Blutversorgung wiederhergestellt werden, können diese Zellen im Gebiet der Penumbra regenerieren und ihre Funktion wiederaufnehmen. Je länger diese Minderversorgung jedoch besteht, desto größer wird der Infarktkern und desto kleiner wird das Gebiet der Penumbra mit den Zellen, die potenziell gerettet werden können (Astrup et al. 1981). Dabei spielt der Faktor Zeit logischerweise eine übergeordnete Rolle: Je schneller der Blutfluss wiederhergestellt wird, desto besser ist die Prognose des Patienten. Es existieren aktuell zwei Methoden zur Wiedereröffnung verschlossener Hirngefäße. Zum einen gibt es die Möglichkeit des Versuches, den Thrombus medikamentös durch eine intravenöse Lyse aufzulösen. Hierzu wird dem Patienten gewichtsadaptiert $(0,9 \mathrm{mg} / \mathrm{kg}$ Körpergewicht, maximal aber $90 \mathrm{mg}$ ) Alteplase (rt-PA) zunächst als Bolus (maximal 10\% der Gesamtdosis) und dann die restliche Dosis als Infusion über eine Stunde verabreicht. Diese Therapie steht in der Regel nur in den ersten viereinhalb Stunden nach Symptombeginn zur Verfügung (NINDS rt-PA Stroke Study Group 1995; ATLANTIS,ECASS, and NINDS rt-PA Stroke

Study Group Investigators 2004; Hacke et al. 2008; Lees et al. 2010; Emberson et al. 2014). 
Das sogenannte Lysezeitfenster kann aber in selektiven Einzelfällen auf bis zu sechs Stunden ausgeweitet werden, wenn in der differenzierteren Bildgebung, zum Beispiel der MRT, ein Mismatch von Perfusion zu Diffusion dargestellt werden kann (Schellinger et al. 2007; Mishra et al. 2010). Dort wird das Gewebe abgebildet, das durch eine Thrombolyse potenziell gerettet werden kann. Da massiv in die Gerinnungsfähigkeit des Blutes eingegriffen wird und dementsprechend eine erhöhte Gefahr einer Blutung besteht, sind weitere Grundvoraussetzungen nötig, damit eine solche Therapie möglichst nebenwirkungsarm durchgeführt werden kann. Einerseits sollte der Blutdruck $<185 / 100 \mathrm{mmHg}$ nicht überschreiten und andererseits sollte der Patient kein relevantes gesteigertes Blutungsrisiko besitzen (Ahmed et al. 2009). Dazu gehören beispielsweise eine gerinnungswirksame Vormedikation oder eine größere Operation oder Blutungsquelle in den letzten drei Monaten. Für diese Therapieempfehlung gilt mittlerweile auch keine Alterseinschränkung mehr (Emberson et al. 2014; Leitlinie Schlaganfalltherapie- Ergänzung Rekanalisierende Therapie 2015).

Zum anderen hat sich in den letzten Jahren in der Behandlung des akuten ischämischen Schlaganfalls eine interventionelle Methode zur Wiedereröffnung des Gefäßes etabliert. Zur Identifizierung möglicher profitierender Patienten ist eine angiographische Darstellung mittels CT oder MRT nötig. Bei großen proximalen arteriellen Verschlüssen steht diese Behandlungsmöglichkeit zur Verfügung. Diese Therapie wird in einem deutlich erweiterten Zeitfenster von bis zu 24 Stunden zwischen Symptombeginn und Leistenpunktion bei einem passenden Infarkt im vorderen arteriellen Kreislauf, welcher die A. carotis interna, A. cerebri anterior und vor allem die $A$. cerebri media beinhaltet, empfohlen (Berkhemer et al. 2015; Campbell et al. 2015; Goyal et al. 2015; Saver et al. 2015; Fransen et al. 2016). Allerdings sind Therapien jenseits des Sechs-Stunden-Zeitfenster eine individuelle Entscheidung abhängig von bildgebungsbasierten Parametern. Ist die $A$. basilaris betroffen, gibt es kein klares, einschränkendes Zeitfenster, weil die Prognose eines solchen Infarkts ohne Behandlung häufig infaust ist. Der Vorteil der Behandlung ist, dass sie durchgeführt werden kann, wenn Kontraindikationen gegen eine intravenöse Lyse vorliegen. Im Falle fehlender Kontraindikationen für eine systemische Lysetherapie sollten gemäß den aktuellen Empfehlungen beide Therapien parallel durchgeführt werden. Die Therapiemöglichkeit der mechanischen Rekanalisation wird vorwiegend in Krankenhäusern mit intensivmedizinischer neurologischer und neuroradiologischer Expertise vorgehalten, sodass unter Umständen ein Transport von einem regionalen Schlaganfallversorger ohne diese Expertise in sogenannte überregionale Zentren notwendig ist. In der Leitlinie wird, abhängig von den geographischen und versorgungstechnischen Verhältnissen, empfohlen, den Patienten bei der Diagnose eines entsprechenden Verschlusses in ein Behandlungszentrum zu transportieren und überbrückend während des Transports eine intravenöse Lysetherapie zu verabreichen. Generell ist hier ein hohes Alter kein Ausschlusskriterium, um für eine solche Intervention in Frage zu kommen (Goyal et al. 2015; Leitlinie Schlaganfalltherapie- Ergänzung Rekanalisierende Therapie 2015). 


\subsection{Infektionen und Infektionsraten nach Schlaganfall}

Nach einem Schlaganfall muss man bei den Patienten, auch bedingt durch die körperlichen Defizite, mit einigen Komplikationen rechnen. So ist beispielsweise das Risiko für Infektionen erhöht. Ein Review stellte in der Metaanalyse von 87 Studien fest, dass sich im gesamten untersuchten Patientenpool, der knapp 140000 Patienten beinhaltete, bei 30\% der Patienten nach einem Schlaganfall eine Infektion entwickelte. Besonders häufig traten Pneumonien und Harnwegsinfekte auf, die jeweils zehn Prozent der Infekte ausmachten (Westendorp et al. 2011). Verglichen mit orthopädischen Patienten, die vor und nach einer Operation ebenso für eine gewisse Zeit immobil waren, fällt auf, dass dort wesentlich niedrige Inzidenzen von Infektionen, beispielsweise Pneumonieraten von 0,8-4,9\%, dokumentiert wurden (Parker und Pryor 1992; Smektala et al. 2008; Mnif et al. 2009; Edelstein et al. 2015; Hessels et al. 2016; Lv et al. 2016). Das bedeutet im Umkehrschluss, dass Schlaganfallpatienten anfälliger als orthopädische Patienten für Infektionen zu sein scheinen. Für Patienten, die auf einer Intensivstation behandelt werden mussten, zeigten sich höhere Infektionsraten. Bei knapp der Hälfte der Patienten (45\%) wurde im Anschluss an den Schlaganfall eine Infektion festgestellt. Vor allem erhöhten sich im Vergleich zu Normalstationpatienten die Pneumonieauf fast ein Drittel (28\%) und die Harnwegsinfektrate auf ein Fünftel der Patienten (20\%) (Westendorp et al. 2011). Weitere einzelne Analysen auf verschiedenen Intensivstationen kamen auf Pneumonieraten von etwas über 20 Prozent (Hilker et al. 2003; Walter et al. 2007). Es gibt für diese hohen Auftretenswahrscheinlichkeiten verschiedene Erklärungsmöglichkeiten. Zum einen kann der Schlaganfall zentral und peripher eine Immunsuppression hervorrufen. Dieses Thema wird in den folgenden Kapiteln 1.6 und 1.7 näher betrachtet. Zum anderen wird die Entwicklung von Infektionen durch die körperlichen Beeinträchtigungen begünstigt. Der Schluckakt, ein komplexer motorischer Ablauf, kann durch den Schlaganfall schnell gestört werden. So tritt eine Dysphagie beispielsweise in über der Hälfte aller Schlaganfälle auf und sorgt somit für ein erhöhtes Aspirationsrisiko (Martino et al. 2005). Als Folge benötigen die Betroffenen eine naso-gastrale Sonde, die wiederum auch die Gefahr birgt, eine Eintrittspforte für Bakterien darzustellen (Leibovitz et al. 2003b; Leibovitz et al. 2003a; Leibovitz et al. 2005). Weiter erhöht auch eine vorherrschende Immobilität, möglicherweise bedingt durch die Schlaganfallfolgen, das Risiko für Infektionen (Brogan et al. 2014b). Als unabhängige Risikofaktoren für die Entwicklung von Pneumonien wurden bisher einige Prädiktoren ermittelt. Die oben bereits beschriebene Dysphagie gehört ebenso wie die Schwere des Schlaganfalls dazu (Aslanyan et al. 2004; Walter et al. 2007; Westendorp et al. 2011; Brogan et al. 2014a; Ashour et al. 2016). Des Weiteren sind großvolumige Infarktareale mit einer höheren Infektionsrate, insbesondere bei Pneumonien, assoziiert (Walter et al. 2007; Minnerup et al. 2010; Ashour et al. 2016). Ein zusätzlicher Risikofaktor für die Pneumonien, der besonders bei Patienten auf der Intensivstation herausragt, ist die mechanische Ventilation, die in den Organismus des Respirationstrakts eingreift (Hilker et al. 2003; Walter et al. 2007). 
Obgleich der Harnwegsinfekt nach einem Schlaganfall ungefähr genauso häufig wie eine Pneumonie auftritt, ist er aufgrund seiner niedrigeren Malignität seltener Gegenstand von Studien. Ein höheres Alter, weibliches Geschlecht oder die Anlage eines transurethralen Katheters, als Manipulation und Eintrittspforte für Bakterien im Harnabflusssystem, wurden als Risikofaktoren für seine Entwicklung beschrieben (Aslanyan et al. 2004; Westendorp et al. 2011). Generell wirkt sich eine schwere Betroffenheit durch den Schlaganfall ebenso verstärkend auf die Entstehung eines Harnwegsinfekts aus (Aslanyan et al. 2004).

Die Diagnose einer Sepsis wird meist in eine gesammelte Kategorie aller weiteren Infektionen eingeordnet, und Daten für die Entwicklung einer Sepsis nach einem Schlaganfall werden seltener dezidiert festgehalten. Bei großen Patientenkollektiven, in denen Schlaganfälle aller Schweregrade erfasst wurden, ergaben sich niedrige Inzidenzraten von gut einem Prozent (Aslanyan et al. 2004; Colbert et al. 2016).

\subsection{Immunreaktion nach Schlaganfall}

Die Tatsache, dass Patienten nach einem Schlaganfall vermehrt Infektionen bekommen, legt den Verdacht nahe, dass der Schlaganfall das Immunsystem ungünstig beeinflusst. Einige mögliche Effekte konnten in experimentellen Studien bereits gezeigt werden.

Der grundlegende Mechanismus der Immunabwehr wird im folgenden Abschnitt zum Verständnis kurz skizziert. Zur Bekämpfung von Infektionen arbeiten das angeborene Immunsystem und das adaptive Immunsystem zusammen. Hierbei muss das adaptive Immunsystem, also die T- und B-Lymphozyten, von dem angeborenen aktiviert werden. Diese Vermittlerrolle übernehmen antigenpräsentierende Zellen, wie zum Beispiel dendritische Zellen, Monozyten oder Makrophagen. Über Rezeptoren, beispielsweise den Toll-like-Rezeptor, erkennen die Zellen körperfremde Antigene, präsentieren diese und initiieren so die Immunantwort von T- und/oder B-Zellen (Iwasaki und Medzhitov 2015). Die Immunabwehr des adaptiven Immunsystems ist viel spezifischer und effektiver gegen die Pathogene und kann so für eine Immunantwort sorgen, die die Krankheitserreger vollständig bekämpfen kann.

Eine experimentelle Studie stellte fest, dass bei Mäusen, bei denen ein Schlaganfall über einen Verschluss $\operatorname{der}$ A. cerebri media induziert wurde, die Kostimulation zwischen antigenpräsentierenden Zellen und Lymphozyten weniger effizient ist. Dies könnte eine Rolle in der geschwächten Immunabwehr nach einem Schlaganfall spielen, jedoch konnte der Effekt bisher noch nicht bei Menschen bewiesen werden (Hug et al. 2011). Die Monozyten präsentieren die Antigene auf dem sogenannten Major-Histocompatibility-Complex (MHC)-II-Protein. Dort werden sie von T-Helferzellen erkannt, die wiederum u.a. die humorale Immunantwort mit Antikörpersynthese in Gang setzen. Ein Schaden des zentralen Nervensystems setzt die Expression der MHC-II-Moleküle herab (Hug et al. 2011; Meisel et al. 2012). Zum einen geschieht dieser Prozess dadurch, dass weniger des Botenstoffs Interferon Gamma (IFN $\gamma$ ) produziert wird, welcher normalerweise die Produktion von MHC-II-Proteinen stimuliert. 
Zum anderen sorgt zusätzlich die vermehrte Ausschüttung von Stresshormonen, Interleukin-10 (IL-10) und Transforming-Growth-Factor-Beta, beides antiinflammatorische Mediatoren, für eine Hemmung der MHC-II Expression (Chamorro et al. 2006; Klehmet et al. 2009; Vogelgesang et al. 2010; Meisel et al. 2012). Der Schlaganfall könnte folglich in die Interaktion zwischen angeborenem und adaptivem Immunsystem eingreifen und zum Beispiel die spezifische Immunantwort auf bakterielle Pathogene behindern. Dieser Mechanismus würde dann zu einer erhöhten Infektionsrate nach einem ischämischen Schlaganfall beitragen.

So kommt es innerhalb des ersten Tages nach einem Schlaganfall zu einem Verlust und erniedrigten Zahlen von Lymphozyten, vor allem von T-Helfer-Zellen (Vogelgesang et al. 2008; Klehmet et al. 2009; Ruhnau et al. 2014). Dieser Verlust erholte sich normalerweise innerhalb der ersten Tage. Wenn der Patienten aber eine Infektion erleidet, verzögerte sich diese Erholungsphase (Vogelgesang et al. 2008). Außerdem ist ab dem ersten Tag bis zu drei Monate nach dem Schlaganfall die Produktion von IFN $\gamma$ und Tumor-Nekrose-Faktor Alpha (TNF- $\alpha$ ) signifikant erniedrigt (Klehmet et al. 2009; Vogelgesang et al. 2010). Diese beiden Zytokine werden hauptsächlich von den T-Helferzellen vom Typ 1 nach dem Kontakt mit antigenpräsentierenden Zellen ausgeschüttet und stimulieren die weitere Proliferation des Immunsystems. Sie regen das Immunsystem an, auf das präsentierte Antigen mit einer vermehrten Bildung von T-Killerzellen zu reagieren. Folglich ist nach einem Schlaganfall die über T-Helferzellen vom Typ 1 vermittelte Immunantwort supprimiert und könnte somit ein weiterer Mechanismus der schlaganfallinduzierten peripheren Immunsuppression sein.

Ein weiterer Faktor, der in dem Zusammenspiel zwischen zentralem Nervensystem und Immunabwehr eine Rolle innehat, ist eine Hormonausschüttung infolge des Schlaganfalls. Kurz nach dem Ereignis sind stark erhöhte Kortisol- bzw. Glukokortikoid-Spiegel festzustellen, die sich jedoch nach 24 Stunden wieder zu normalisieren scheinen (Emsley et al. 2003). Glukokortikoide können Lymphozyten beeinflussen, indem sie beispielsweise eine Apoptose einleiten, die IFN $\gamma$-Produktion erniedrigen oder über Monozyten die IL-10-Produktion steigern (Prass et al. 2003). Diese sogenannten Stresshormone, zu denen auch Kortisol gehört, haben auf diese Weise eine immunsuppressive Wirkung. Des Weiteren konnte diese „Stresshypothese" durch die Beobachtung untermauert werden, dass Patienten, die nach einem Schlaganfall einen Infekt entwickelten, höhere Metanephrin-, ein Katecholaminabbauprodukt, und Kortisol-Spiegel im Blut zeigten (Vogelgesang et al. 2010). Der Schaden im Gehirn regt das sympathische Nervensystem an, Katecholamine auszuschütten. Katecholamine besitzen unter anderem auch immunmodulatorische Fähigkeiten, da einige Immunzellen BetaZell-Rezeptoren ausbilden und auf diese Weise beeinflusst werden können (Kohm und Sanders 2001). Über diese Rezeptoren wird durch die vermehrte Produktion von IL-10 und die verminderte Produktion von TNF-Alpha hauptsächlich die Immunantwort der T-Helferzellen vom Typ-1 auf bakterielle Antigene abgeschwächt und dementsprechend gleichfalls die Anfälligkeit für Infektionen erhöht (Bergmann und Sautner 2002). Alles in allem bestehen 
mehrere Verbindungen zwischen dem zentralen Nervensystem und der systemischen Immunabwehr, die bei einem Gewebeschaden im Gehirn aktiviert werden.

\subsection{Sympathikus-Aktivierung und Immunsuppression}

In diesem Abschnitt wird noch einmal gesondert auf die Theorie eingegangen, die die Grundlage dieser Dissertation bildet. Wie bereits in Kapitel 1.6 beschrieben, sind nach einem Schlaganfall im Blut erhöhte Konzentrationen von Katecholaminen zu beobachten. Diese scheinen auf verschiedene Art und Weise das Immunsystem zu beeinflussen. So stellten Prass et al. 2003 in einer experimentellen Studie fest, dass eine Blockade des sympathischen Nervensystems das Immunsystem stärkte und die Inzidenz von Infektionen sowie die Mortalität verringerte. Dazu wurde Mäusen nach einem induzierten Schlaganfall der unselektive BetaBlocker Propranolol appliziert und im Blut wieder normale und im Vergleich zu den nichtPropranolol-behandelten Mäusen erhöhte Konzentrationen von TNF- $\alpha$ oder IFN $\gamma$ im Blut beobachtet. Weiter erniedrigte sich im Vergleich zu nicht behandelten Mäusen die bakterielle Last in Lunge und Blut. Diese Effekte zeigte sich vor allem bei einem Applikationszeitpunkt möglichst kurz nach dem Schlaganfall. Dies könnte ein Hinweis sein, dass die Unterdrückung der T-Helferzellen-Typ-1-vermittelten Immunantwort aufgehoben worden ist (Prass et al. 2003).

Zum anderen könnten invariante Natürliche Killer-T-Zellen (iNKT-Zellen) in diesem Signalweg eine wichtige Rolle spielen. Sie gehören zu der Gruppe der T-Zellen und besitzen Rezeptoren die Lipidantigene, die von antigenpräsentierenden Zellen präsentiert werden, oder Fremdlipidantigene von Bakterien, Viren etc. erkennen (Kinjo und Ueno 2011). Als Folge produzieren die iNKT- Zellen Zytokine, die die weitere Reaktion des Immunsystem auf diesen Reiz fördern. iNKT-Zellen sind zum Beispiel in der Leber oder Milz zu finden. In einer experimentellen Studie hat man das Verhalten der iNKT-Zellen in der Leber von Mäusen nach einem Schlaganfall untersucht. Dabei bleib die Anzahl der Zellen unverändert, jedoch ließ sich eine signifikante Erniedrigung der bewegenden und eine Erhöhung der stationären und damit inaktivierten iNKT-Zellen infolge des Schlaganfalls feststellen (Wong et al. 2011). Dabei schütteten die iNKT-Zellen eher Mediatoren (vor allem IL-10) aus, die eine Immunantwort über T-Helferzellen vom Typ-2, als Mediatoren (beispielsweise IFN $\gamma$ ), die eher eine Immunantwort über die T-Helferzellen vom Typ-1 anregen (Wong et al. 2011). Zusätzlich fand man in dieser Studie heraus, dass diese Veränderungen nach einem Schlaganfall vor allem auf das aktivierte sympathische Nervensystem zurückzuführen sind, da die Reaktion auch dann noch zu beobachten war, als anderweitige, entscheidende Aktivierungswege der iNKT-Zellen gezielt blockiert wurden (Wong et al. 2011). Diese These wurde dadurch unterstützt, dass in einem weiteren Schritt eine lokale Stimulation mit Noradrenalin ebenso wie ein Schlaganfall zu einem Arrest und zur Inaktivierung führte. Nach der Behandlung mit dem Beta-Blocker Propranolol konnte beobachtet werden, dass das Zytokinmilieu 
sich wieder mehr in Richtung der T-Helferzellen vom Typ-1 Reaktion verschob und vermehrt IFN $\gamma$ produzierte (Wong et al. 2011).

\subsection{Beta-Blocker}

In diesem Kapitel soll allgemein über Wirkung und Einsatzgebiet der Beta-Blocker berichtet werden. Grob können sie in drei Generationen eingeteilt werden. Die erste Generation beinhaltet die sogenannten unselektiven Beta-Blocker. Sie blockieren sowohl $\beta_{1^{-}}$als auch $\beta_{2^{-}}$ Rezeptoren. Die nächste Generation wird als selektive Beta-Blocker bezeichnet, weil sie bevorzugt $\beta_{1}$-Rezeptoren blockieren. Als weitere Kategorie können die Beta-Blocker mit zusätzlicher vasodilatativer Wirkung genannt werden. Die Vasodilatation wird dabei auf verschiedene Art und Weise ausgeübt, bei dem Wirkstoff Carvedilol beispielsweise durch eine zusätzliche $\alpha_{1}$-Rezeptorblockade. Heutzutage wird überwiegend die Gruppe der selektiven Beta-Blocker eingesetzt. Sie besitzen eine Indikation bei einer Vielzahl von kardialen Erkrankungen, da eine Blockade des $\beta_{1}$-Rezeptors vor allem am Herzen wirkt. Derart wird eine verminderte Erregbarkeit des Herzens, initial verminderte Kontraktilität des Myokards, eine verlangsamte Herzfrequenz und Leitungsgeschwindigkeit ausgelöst. Das Einsatzgebiet umfasst Herzrhythmusstörungen wie supraventrikuläre Tachykardien, Patienten mit akutem Herzinfarkt, nach überlebtem Infarkt, koronarer Herzerkrankung, Angina pectoris aber auch in der Stufentherapie der Herzinsuffizienz. Des Weiteren stehen die Beta-Blocker bei der Behandlung der arteriellen Hypertonie als Zweitlinienmedikament zur Verfügung (Herold 2014). Die $\beta_{2}$-Rezeptoren kommen dagegen eher in der Peripherie in den Bronchien, Blutgefäßen, in der Gebärmutter, aber auch in diversen Immunzellen vor (Elenkov et al. 2000; Lamers und Schubert-Zsilavecz 2011). Eine Blockade dieses Rezeptors führt zum Beispiel zu einer Bronchokonstriktion. Zusätzlich existieren $\beta_{3}$-Rezeptoren, deren Aufgabe noch nicht gänzlich geklärt ist. Sie kommen besonders im Fettgewerbe vor und wirken auf die Regulierung der Lipolyse ein. Jedoch sind sie genauso im Intestinaltrakt, in der Gallenblase und in der Blase vorhanden und steuern dort die Kontraktilität (Krief et al. 1993; Michel et al. 2010).

\subsection{Beta-Blocker und Infektionsraten}

Erstmals wurde bereits 1988 beobachtet, dass Schlaganfallpatienten im Vergleich zu einer Placebo-Therapie von einer Beta-Blocker-Therapie profitierten und sich das Outcome in Bezug auf die Sterblichkeit und Funktionalität der Patienten verbesserte (Barer et al. 1988). Seit Prass et al. 2003 in einer experimentellen Studie einen protektiven Effekt von BetaBlockern festgestellt haben (vgl. Kapitel 1.7), wurde diesem Zusammenhang weiter nachgegangen. Allerdings bieten die Studien zu dem Thema kein einheitliches Bild. In mehreren Studien zeigte sich bei Patienten, die mit einem Beta-Blocker vorbehandelt waren, eine niedrigere Inzidenz von Pneumonien nach einem Schlaganfall (Dziedzic et al. 2007; Sykora et al. 
2015). Dieser Effekt konnte aber nicht überall bestätigt werden (Maier et al. 2015). Die neueste Untersuchung zu dem Thema brachte das Ergebnis hervor, dass die Patienten, die einen Beta-Blocker in der Vormedikation besaßen, ein höheres Risiko für die Entwicklung einer Pneumonie hatten. Außerdem stellte sich dort ein Beta-Blocker sogar als Risikofaktor für Infekte dar (Westendorp et al. 2016). In gleicher Weise liegen für die Harnwegsinfektrate differierende Daten vor. Zum einen zeigte sich in einem unselektiertem Kollektiv von Patienten mit ischämischen Schlaganfall eine geringere Rate in der Beta-Blocker-Gruppe (Maier et al. 2015) und zum anderen wurde wiederum das Gegenteil festgestellt (Westendorp et al. 2016). In ähnlicher Weise verhält es sich mit den Vergleichen der Mortalitätsrate zwischen Beta-Blocker- und nicht-Beta-Blocker-Patienten. Es gibt Hinweise, dass ein Beta-Blocker die Sterblichkeit während des Krankenhausaufenthalts reduzieren könnte (Phelan et al. 2015). Die Mortalität 30 Tage nach dem Schlaganfall zeigte sich sowohl erniedrigt (Dziedzic et al. 2007) als auch zum Teil signifikant erhöht (Maier et al. 2015). Für die Mortalität nach 90 Tagen liegen bisher nur Daten vor, die eine erhöhte Mortalitätsrate der Beta-Blocker-Gruppe festgestellt haben (Sykora et al. 2015; Westendorp et al. 2016). Des Weiteren konnte ein Einfluss des Beta-Blockers auf die Schwere des Schlaganfalls nicht eindeutig bewiesen werden. Einige Studien legen die Tendenz eines protektiven Effekts nahe (Laowattana und Oppenheimer 2007; Maier et al. 2015), während andere Studien diese These nicht belegen konnten (De Raedt et al. 2012).

\subsection{Bisherige immunmodulatorische Therapieansätze}

Infektionen bestimmen maßgeblich die Prognose der Patienten mit (Katzan et al. 2003; Vermeij et al. 2009; Finlayson et al. 2011; Popović et al. 2013). Daher wird nach Wegen und Mitteln geforscht, um den Ausbruch von Infektionen zu verhindern und folglich ebenso die Prognose zu verbessern. Beim Auftreten einer Infektion wird bei den Patienten nach heutigem Standard eine entsprechende Therapie, meist in Form einer Antibiotikagabe, eingeleitet. Ein möglicher Ansatz war die Untersuchung, ob sich eine präventive Gabe von Antibiotika vorteilhaft auswirken könnte. In der Preventive Antibiotic Therapy in Ischemic Stroke-Studie, Gabe von Moxifloxacin, und der preventive antibiotics in stroke study-Studie, Gabe von Ceftriaxon, zeigten sich zwar erniedrigte Infektionsraten, jedoch hatte dies keinen Effekt auf die Mortalität oder die funktionelle Prognose (Harms et al. 2008; Westendorp et al. 2015). In der STROKE-INF-Studie, Gabe von Clarithromycin in Kombination mit Amoxicillin, ergab sich keine Erniedrigung der Infektionsraten (Kalra et al. 2015). Anhand der Studienlage zeigte sich die präventive Antibiotikagabe bisher nicht der konventionellen Therapie überlegen, die vorsieht erst dann mit einer antibiotischen Therapie zu beginnen, wenn Zeichen einer Infektion vorliegen. Die Strategie, bakterielle Infekte dann gezielt nach Antibiogramm zu behandeln, scheint auch angesichts der notwendigen Berücksichtigung der lokalen Antibiotikaresistenzlage die Methode der Wahl zu bleiben. 
Als Grund für die physiologische Immunsuppression nach einem Schlaganfall wird angenommen, dass das Gehirn vor einer überschießenden Immunreaktion und weiterem Schaden geschützt werden soll. Das körpereigene Immunsystem reagiert auf das nekrotische Gewebe im Gehirn, und Immunzellen wandern dort ein (An et al. 2014). Eine gestörte Permeabilität der Bluthirnschranke, zum Beispiel durch den ischämisch bedingten Zelluntergang, kann diese Einwanderung fördern (Khatri et al. 2012). Die Rolle der verschiedenen Abwehrzellen ist zum aktuellen Zeitpunkt nicht eindeutig geklärt. Auf der einen Seite gibt es Studien, die herausgefunden haben, dass die Immigration den Schaden im Gehirn erweitert (Hurn et al. 2007; Buck et al. 2008; Clausen et al. 2008), und auf der anderen Seite beschreiben Studien einen neuroprotektiven Effekt (Liesz et al. 2011; Gliem et al. 2012). Auf der Grundlage der Theorie der schädigenden Einwanderung beruhen Untersuchungen, die sich mit der Möglichkeit der Immunmodulation nach einem Schlaganfall beschäftigen. Hier sind vor allem die Multiple Sklerose-Medikamente Natalizumab und Fingolimod Gegenstand der Forschung. Natalizumab ist ein monoklonaler Antikörper, der Strukturen blockiert, die für die Lymphozyteninfiltration ins Gehirn zuständig sind (Baron et al. 1993). In experimentellen Studien ließen sich bislang unterschiedliche Ergebnisse gewinnen (Langhauser et al. 2014). Unter bestimmten Bedingungen wies die Behandlung einen positiven Effekt (Liesz et al. 2011; Llovera et al. 2015). Währenddessen limitiert Fingolimod über einen Rezeptor die Migration von Lymphozyten aus den Lymphknoten und ins zentrale Nervensystem (Schwab et al. 2005). Bislang zeigten sich hier überwiegend vorteilhafte Effekte. In experimentellen Studien hatten Mäuse nach der Behandlung mit Fingolimod kleinere Infarkte und geringere neurologische Defizite, (Wei et al. 2011; Campos et al. 2013). Zusätzlich zeigte sich in experimentellen und präklinischen Studien, wenn Fingolimod außerhalb des Lysezeitfensters appliziert wurde, ein benefizieller Effekt. Die neurologische Prognose und Rehabilitation der Patienten verbesserte sich durch diese Maßnahme (Campos et al. 2013; Fu et al. 2014; Zhu et al. 2015).

\subsection{Einfluss der Lokalisation des Schlaganfalls}

Die einzelnen Hirnregionen besitzen bekanntermaßen unterschiedliche Funktionen und erfüllen differenzierte motorische, sensorische, endokrine und autonome Funktionen. Störungen, die beispielsweise durch eine Ischämie verursacht werden, können eine Fehlsteuerung dieser Areale verursachen und so zum Ausfall oder Dysregulation motorischer und sensorischer, aber auch endokriner und autonomer, also die Steuerung des autonomen Nervensystems mit Sympathikus und Parasympathikus, führen.

Harms et al. beobachteten in der Analyse der Daten aus der Preventive Antibiotic Therapy in Ischemic Stroke-Studie, dass ein Infarkt im Versorgungsgebiet des anterioren Mediastromgebiets, das sogenannte M1-Gebiet nach der Alberta Stroke Program Early CT Score-Einteilung, eine signifikante Assoziation mit der Entwicklung von Infekten zeigte. Weiterhin waren erhöhte Norepinephrin-Werte im Urin ein Indikator für das Risiko des Erleidens eines Infekts (,Stressantwort“ nach ischämischem Schlaganfall, siehe Kapitel 1.6). 
In der Analyse eines größeren Patientenkollektiv zeigte sich ein Zusammenhang zwischen dem Schlaganfallvolumen und erhöhter Sympathikusaktivierung. Größere Infarkte $(>33 \%)$ $\operatorname{der}$ A. cerebri media wiesen höhere Werte von Norepinephrin im Urin als kleinere Infarkte auf. Jedoch stellte man fest, dass Patienten mit einem kleineren Infarkt $(<33 \%)$, der aber die Inselregion betraf, ebenso eine erhöhte Aktivität des Sympathikus in Form von erhöhten Norepinephrinwerten in Urin oder Blut zeigten (Sander et al. 2001; Walter et al. 2013). Patienten, deren Infarkt die Inselregion einschließt, scheinen also ein erhöhtes Risiko für einen Infekt nach einem Schlaganfall zu besitzen (Steinhagen et al. 2009; Walter et al. 2013).

\subsection{Fragestellung}

Wie die Einleitung gezeigt hat, gibt es Hinweise, dass Schlaganfälle eine periphere Immunsuppression bewirken können. Diese Immunmodulation könnte über den Sympathikus gesteuert werden und bei Schlaganfällen auftreten, die das Stromgebiet $\operatorname{der}$ A. cerebri media oder die Inselregion betreffen. Die Sympathikusaktivität könnte das periphere Immunsystem beeinflussen und unterdrücken, sodass sich die Infektanfälligkeit der Patienten erhöht. Mittels eines Beta-Blockers konnte in experimentellen Studien die Immunsuppression rückgängig gemacht werden. Die bisherigen Studien zu dem Thema, ob der Effekt auch im menschlichen Körper zu beobachten sei, zeigen kein einheitliches Bild und wurden oft retrospektiv an einem Kollektiv vollzogen, an dem ursprünglich eine andere Analyse durchgeführt wurde. Aus diesem Grund war das Kollektiv oft sehr heterogen und enthielt sowohl leichte als auch schwere Schlaganfälle, sodass es unsicher erscheint, dass das für die Steuerung zuständige Hirnareal bei allen eingeschlossenen Patienten mitbetroffen ist.

Daher soll hier nun an einem ausgewählten, homogenen Patientenkollektiv analysiert werden, ob eine bestehende Beta-Blocker-Medikation bei Schlaganfallpatienten vor der Entwicklung von Infektionen schützt, indem sie die Immunmodulation verhindert. Das Kollektiv beinhaltet dabei ausschließlich Patienten, bei denen ein proximaler Gefäßverschluss vorlag, die also einen schweren Schlaganfall erlitten haben und bei denen mit hoher Wahrscheinlichkeit das entsprechende Hirngebiet betroffen ist. Dadurch besteht ein hohes Risiko, dass der Mechanismus der peripheren Immunsuppression stattfindet. Es handelt sich um ein Kollektiv, dass ebenso durch die schwere Beeinträchtigung und die damit verbundenen Maßnahmen, beispielsweise Intubation und Behandlung auf der Intensivstation, ein großes Infektionsrisiko besitzt. 


\section{$2 \quad$ Material und Methoden}

In dieser Analyse wurden Daten einer prospektiv geführten Datenbank von Patienten mit einem großen Hirngefäßverschluss und anschließender interventioneller Thrombektomie genutzt. In einem Zeitraum vom 24.01.2006 bis zum 25.02.2017 wurden dort 522 Patienten aufgenommen, die in der Universitätsmedizin Göttingen (UMG) behandelt wurden.

Ergänzend wurden retrospektiv mithilfe des IntelliSpace Critical Care and Anaesthesia (ICCA)Systems von Phillips und des Systems der ixserv (ixmid Software Technologie GmbH)-Plattform der UMG Befunde und Arztbriefe erhoben.

\subsection{Ein- und Ausschluss von Patienten}

Ursprünglich standen in der Datenbank 522 Patienten zur Verfügung. In die Datenbank wurden alle Patienten eingepflegt, die an der UMG mit einer interventionellen Thrombektomie aufgrund eines Verschlusses einer großen Hirnarterie behandelt wurden. Aufgrund der Fragestellung dieser Arbeit, ob es einen Einfluss von Beta-Blockern auf Infektionsraten nach einem Schlaganfall gibt, wurden alle Patienten mit unbekannter Vormedikation aus der Analyse ausgeschlossen. Die ausgeschlossene Gruppe umfasste 216 Patienten, sodass das untersuchte Patientenkollektiv letztendlich eine Anzahl von 306 Patienten aufwies. Diese wurden in einem Zeitraum von 12.04.2011 bis zum 25.02.2017 medizinisch in der UMG versorgt. Die Patienten wurden anhand ihrer Vormedikation in zwei Gruppen eingeteilt. Die erste Gruppe erhielt vor dem Schlaganfall und während der Behandlung einen Beta-Blocker. Dabei spielten der Wirkstoff, die Dosis und Selektivität des Beta-Blockers keine Rolle. In die zweite Gruppe wurden alle Patienten einsortiert, die keinen Beta-Blocker in der bestehenden Medikation aufwiesen (siehe Abbildung 1).

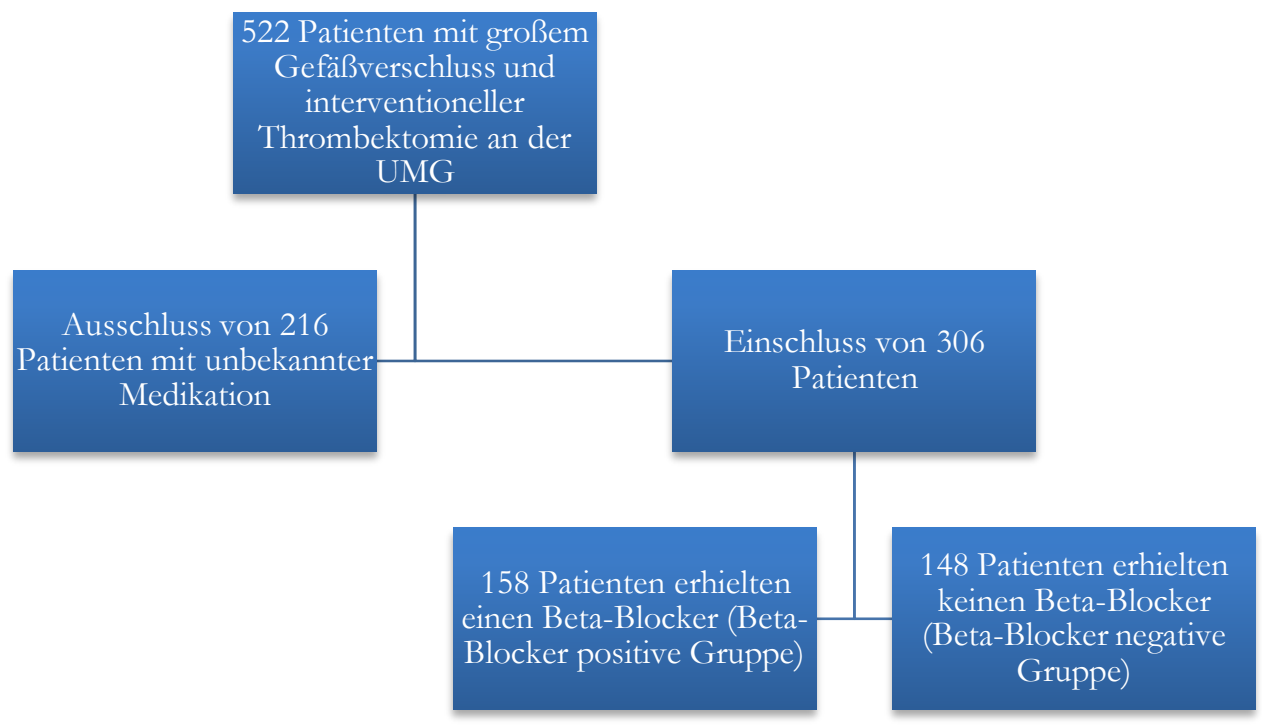

Abbildung 1: Fließdiagramm zum Ein- und Ausschluss der Patienten 
Von den 306 eingeschlossenen Patienten erlitten 49 Patienten (15,9\% des Kollektivs) einen Schlaganfall, der sich nicht auf das Stromgebiet $\operatorname{der} A$. cerebri media erstreckte. Hierbei war bei 43 Patienten (14\%) die A. basilaris, 5 Patienten (1,6\%) die A. cerebri posterior und einem Patienten $(0,3 \%)$ die $A$. cerebri anterior betroffen. Diese Patienten wurden von der Subgruppenanalyse ausgeschlossenen, während die übrigen Schlaganfälle sich bei 156 Patienten (51\%) auf den M1-Bereich, bei 26 Patienten (8\%) auf den M2-Bereich, bei 65 Patienten (21\%) auf das Karotis T-Bereich, bei 13 Patienten (4\%) auf die proximale $A$. carotis interna (siehe Abbildung 2) verteilen und in diese Analyse eingeschlossen wurden (siehe Kapitel 3.5.2).

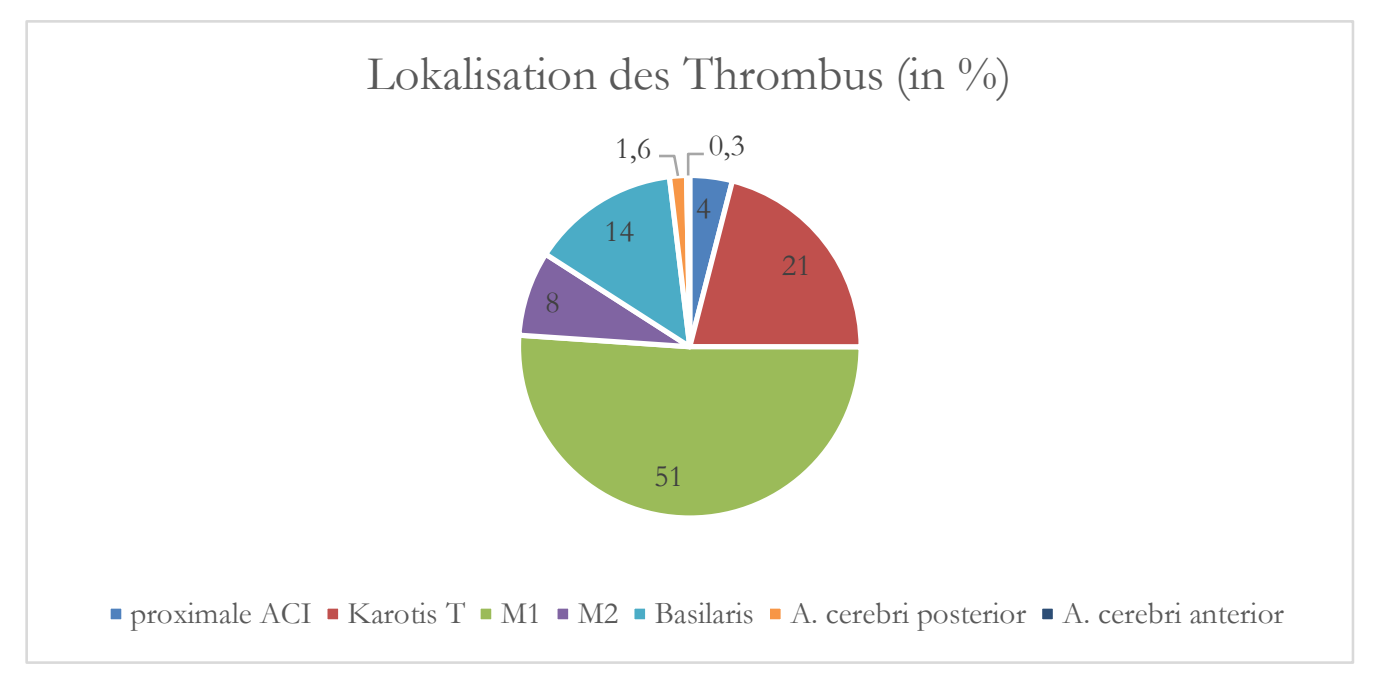

Abbildung 2: Verteilung der Lokalisation des Thrombus im gesamten Patientenkollektiv $(\mathrm{n}=306)$ in $\%$

\subsection{Diagnosekriterien von Infektionen}

Die Art der Infektionen wurde in vier verschiedene Subtypen unterteilt: Pneumonie, Harnwegsinfekt, Sepsis und als vierte Kategorie alle anderen Infektionen. Bei den Pneumonien, Harnwegsinfekten und der Sepsis wurde noch einmal genauer zwischen der klinischen (Verdachts-)Diagnose und einer leitlinienkonformen Diagnose differenziert, die klare Vorgaben zur Erfüllung der Diagnose macht. Ein im Arztbrief beschriebener Infekt wurde in eine der vier Kategorien eingeordnet. Weiter wurde mithilfe der zur Verfügung stehenden Materialien im ICCA- und ixserv-System geprüft und erhoben, ob der diagnostizierte Infekt einer leitliniengerechten Diagnose entspricht. Hierfür wurde jeweils die aktuellste Leitlinie verwendet. Bei der Diagnose der Pneumonie musste im Röntgenthorax in zwei Ebenen ein neu aufgetretenes Infiltrat oder zumindest der Verdacht auf ein Infiltrat bei mindestens zwei bestehenden klinischen Zeichen wie Husten, Fieber $\left(>38,0{ }^{\circ} \mathrm{C}\right)$, Leukozytose oder -penie $(>10.000$ oder $<4.000 / \mu \mathrm{l})$ oder der Nachweis eines Pneumonie-typischen Erregers im Sputum, Bronchialsekret oder Blutkultur zu finden sein (Leitlinie Pneumonie 2016). Die Diagnose eines Harnwegsinfekts wurde sowohl bei einem klinisch symptomatischen Harnwegsinfekt als auch bei einer asymptomatischen Bakteriurie gestellt. Als Symptomatik galten 
relevante Schmerzen oder Beschwerden wie häufige Miktion oder imperativer Harndrang. Ein nitrit-positiver Urinteststreifen, Bakterien im Mittelstrahlurin $\left(10^{3}\right.$ Kolonie-bildendeEinheit (KbE)/ ml bei Symptomen oder $10^{5} \mathrm{KbE} / \mathrm{ml}$ ohne Symptome) oder eine positive Urinkultur mit harnwegsinfekttypischen Bakterien wurden als Bakteriurie gewertet (Leitlinie Harnwegsinfekt 2017). Die Definition der Sepsis wurde im Jahr 2016 erneuert. Diese stellt die lebensgefährliche Organdysfunktion in den Vordergrund. Zwei Punkte auf dem Sequential (Sepsis-Related) Organ Failure Assessment (SOFA)-Score, der die Faktoren Atmung, Koagulation, Leber, Herz-Kreislauf- und Nierenfunktion sowie die Glasgow Coma-Scale (GCS) in verschiedener Gewichtung berücksichtigt, erlaubten die Sepsis-Diagnose (Singer et al. 2016). Bei der leitliniengerechten Sepsisdiagnose im Patientenkollektiv wurde dieser Empfehlung entsprochen. In die Kategorie der anderen Infektionen wurden alle Infektionen, die nicht einer der ersten drei Kategorien zugehörig waren, eingeordnet. Die Gruppe ist folglich sehr heterogen und enthält Krankheiten wie Bindehautentzündung oder Divertikulitis.

\subsection{Erfassung von möglichen Infektionseinflussfaktoren}

In dem in Tabelle 1 abgebildeten Dokumentationsbogen sind wesentliche Risiko- und Einflussfaktoren für die Entwicklung von Infektionen, die erhoben wurden, abgebildet.

Die Dysphagie lag dann vor, wenn der ärztlichen und logopädischen Untersuchung zufolge eine orale Kostaufnahme nicht, nur bedingt über eine naso-gastrale Sonde oder als Dysphagiekost möglich waren. Eine weitere Differenzierung bezüglich der Schweregrade fand nicht statt. Bei der Bewertung wurde auf die logopädische Dokumentation im ICCA zurückgegriffen.

Die Intubationsdauer wurde in Tagen gemessen. War ein Patient für den Zeitraum der Thrombektomie (wenige Stunden) intubiert, wurde dies als ein Tag gewertet. Dadurch wurde nicht unterschieden, ob der Patient für die kurze Dauer oder noch darüber hinaus (bis zu 24 Stunden) intubiert war. Die Kategorien der naso-gastralen Sonde oder des transurethralen Katheters wurden unabhängig von der Dauer bei der erstmaligen Anlage als positiv gewertet. Unter der Kategorie „,andere OP“ wurden alle Eingriffe gewertet, die über die Standardbehandlung des Schlaganfalls hinausgingen, beispielsweise eine Koloskopie.

Tabelle 1: Dokumentationsbogen der Risikofaktoren

\begin{tabular}{|l|l|}
\hline Merkmal & Auswahlmöglichkeit \\
\hline $\begin{array}{l}\text { Immunmodulatorische Vormedikation (Kortison (oder dement- } \\
\text { sprechende äquivalente Wirkstoffe), Methothrexat etc.) }\end{array}$ & $\mathrm{Ja} /$ nein \\
\hline naso-gastrale Sonde & $\mathrm{Ja} /$ nein \\
\hline Dysphagie & $\mathrm{Ja} /$ nein \\
\hline transurethraler Katheter & $\mathrm{Ja} /$ nein \\
\hline
\end{tabular}




\begin{tabular}{|l|l|}
\hline Intubation & $\mathrm{Ja} /$ nein \\
\hline Intubationsdauer & Dauer in Tagen \\
\hline Tracheotomie & $\mathrm{Ja} /$ nein \\
\hline Zeitraum von Schlaganfall bis Tracheotomie & Dauer in Tagen \\
\hline Hemikraniektomie & $\mathrm{Ja} /$ nein \\
\hline andere/ weitere OP & $\mathrm{Ja} /$ nein \\
\hline
\end{tabular}

\subsection{Erfassung der Basischarakteristika}

Weiter wurden mithilfe des Dokumentationsbogens (vgl. Tabelle 2) die Grunderkrankungen des Patientenkollektivs erfasst. Die Informationen wurden aus älteren Arztbriefen, Vormedikationen, aktuellen Befunden und Anamnese des Patienten gewonnen.

Die Kategorie Adipositas wurde ab einem Body-Mass-Index $\left(\mathrm{kg} / \mathrm{m}^{2}\right)$ von 30 als positiv gewertet. Als Raucher/in galten alle Patienten, die in der Vergangenheit über einen längeren Zeitraum (mehrere Monate) oder zum Zeitpunkt regelmäßig geraucht haben.

Tabelle 2: Erfassung von Basischarakteristika

\begin{tabular}{|l|l|}
\hline Charakteristikum & $\begin{array}{l}\text { Auswahlmöglich- } \\
\text { keit }\end{array}$ \\
\hline Arterielle Hypertonie & $\mathrm{Ja} /$ nein \\
\hline Hyperlipidämie & $\mathrm{Ja} /$ nein \\
\hline Diabetes mellitus & $\mathrm{Ja} /$ nein \\
\hline Arrythmia absoluta & $\mathrm{Ja} /$ nein \\
\hline Periphere arterielle Verschlusskrankheit & $\mathrm{Ja} /$ nein \\
\hline Adipositas & $\mathrm{Ja} /$ nein \\
\hline Raucher/in & $\mathrm{Ja} /$ nein \\
\hline Koronare Herzkrankheit & $\mathrm{Ja} /$ nein \\
\hline Chronische Herzinsuffizienz & $\mathrm{Ja} /$ nein \\
\hline Geschlecht & $\mathrm{Männlich} \mathrm{/} \mathrm{weiblich}$ \\
\hline
\end{tabular}

\subsection{Alberta Stroke Program Early CT-Score (ASPECTS)}

Der Alberta Stroke Program Early CT-Score (ASPECTS) wird anhand einer CT-Bildgebung bei Schlaganfällen $\operatorname{der} A$. cerebri media des Schädels erhoben und bewertet, wie groß das Gebiet des Gehirns ist, das von dem Schlaganfall betroffen ist. Anhand des Scores kann die Prog- 
nose des Patienten abgeschätzt werden. Eine Gehirnhälfte wird dabei in zehn Bereiche eingeteilt. Nucleus caudatus, Putamen, Capsula interna, insulärer Kortex sowie sechs Teilgebiete des A. cerebri media-Stromgebietes: M1 bezeichnet den anterioren Kortexanteil, M2 das Gebiet lateral der Insel, M3 den posterioren Kortexanteil, M4 den anterioren Anteil oberhalb von M1, M5 den lateralen Anteil oberhalb von M2 und M6 den posterioren Anteil oberhalb von M3 (vgl. Abbildung 3 und Abbildung 4, Barber et al. 2000). Zeigt das Mediastromgebiet im CT-Bild bei einem Schlaganfall keine ischämischen Läsionen auf, dann ergibt sich ein ASPECTS von 10. Für jedes betroffene Gebiet wird nun von diesem Wert 10 ein Punkt abgezogen. Das bedeutet, dass je niedriger der ASPECTS liegt, desto größer ist der Schlaganfall und desto schlechter ist das funktionelle Outcome der Patienten (Barber et al. 2000).

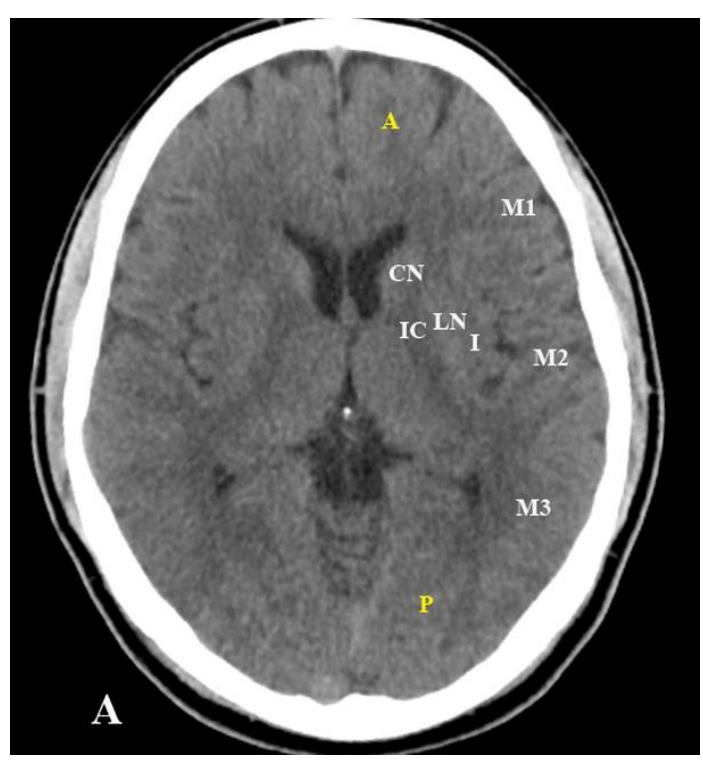

Abbildung 3: Gebiete des ASPECTS auf Höhe der Basalganglien, $\mathrm{CN}=$ Nucleus caudatus, $\mathrm{IC}=$ Capsula interna, $\mathrm{LN}=$ Putamen, $\mathrm{I}=$ insulärer Kortex, $\mathrm{A}=$ Anteriorstromgebiet, $\mathrm{P}=$ Posteriorstromgebiet mit freundlicher Genehmigung von Dr Subash Thapa, Radiopaedia.org, rID: 40018 


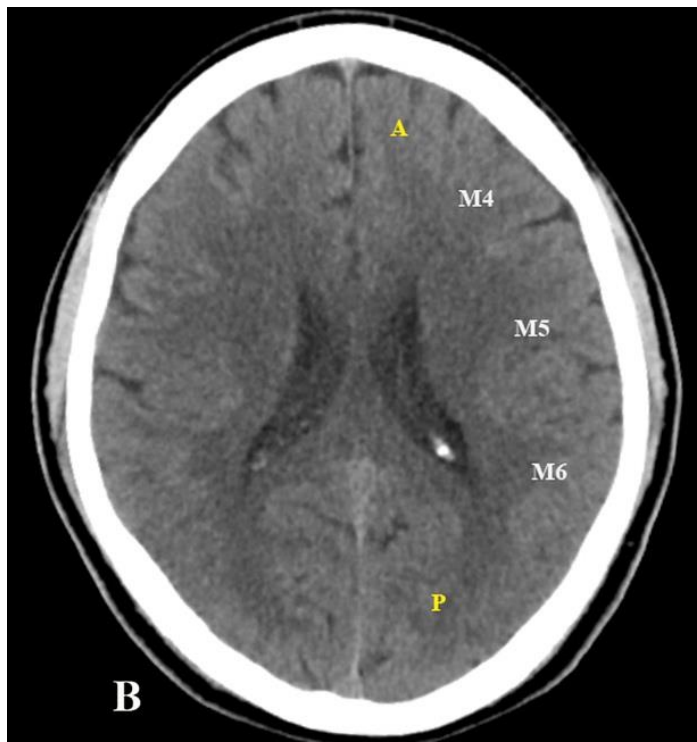

Abbildung 4: Gebiete des ASPECTS auf Höhe der Ventrikel und oberhalb der Basalganglien, $\mathrm{A}=$ Anteriorstromgebiet, $\mathrm{P}=$ Posteriorstromgebiet mit freundlicher Genehmigung von Dr Subash Thapa, Radiopaedia.org, rID: 40018

\subsection{National Institutes of Health Stroke Scale (NIHSS)}

Die National Institutes of Health Stroke Scale (NIHSS) ist ein Scoring-System, das in der akuten Befunderhebung und zur Verlaufsbeobachtung eines Schlaganfalls genutzt wird (Brott et al. 1989). Er kann Werte von null bis maximal 42 annehmen. Bei Werten von unter fünf gelten die Patienten als leicht, bei Werten von fünf bis 14 als leicht bis schwer und bei Werten über 14 als schwerst betroffen (Rundek et al. 2000; Schlegel et al. 2003). Die berücksichtigten Items sind in Tabelle 3 dargestellt.

Die NIHSS-Werte wurden aus dem ICCA-System und den Arztbriefen übernommen, wo sie initial von dem ärztlichen Personal dokumentiert wurden.

Tabelle 3: NIHSS (modifiziert nach Berger et al. 1999)

\begin{tabular}{|l|l|l|}
\hline Merkmal & Befund & Punkte \\
\hline Vigilanz & Wach - somnolent - soporös - komatös & 0 bis 3 \\
\hline Orientierung & Alter und aktueller Monat & 0 bis 2 \\
\hline $\begin{array}{l}\text { Befolgen von Aufforderun- } \\
\text { gen }\end{array}$ & $\begin{array}{l}\text { Augenschluss und -öffnen, Faustschluss und - } \\
\text { öffnen }\end{array}$ & 0 bis 2 \\
\hline Okulomotorik & $\begin{array}{l}\text { Normalbefund - partielle Blickparese - forcierte } \\
\text { Blickdeviation/ totale Blickparese }\end{array}$ & 0 bis 2 \\
\hline Gesichtsfeld & $\begin{array}{l}\text { Keine Einschränkung - partielle Hemianopsie - } \\
\text { komplette Hemianopsie - bilaterale Hemianop- } \\
\text { sie }\end{array}$ & 0 bis 3 \\
\hline
\end{tabular}




\begin{tabular}{|c|c|c|}
\hline Faszialisparese & Normalbefund - gering - partiell - vollständig & 0 bis 3 \\
\hline $\begin{array}{l}\text { Armmotorik (rechts und } \\
\text { links) }\end{array}$ & $\begin{array}{l}\text { Kein Absinken innerhalb von } 10 \text { sek - absinken } \\
\text { - Anheben gegen die Schwerkraft möglich - } \\
\text { kein Anheben gegen die Schwerkraft möglich - } \\
\text { keine Bewegung }\end{array}$ & 0 bis 4 \\
\hline $\begin{array}{l}\text { Beinmotorik (rechts und } \\
\text { links) }\end{array}$ & $\begin{array}{l}\text { Kein Absinken innerhalb von } 5 \text { sek - absinken - } \\
\text { Anheben gegen die Schwerkraft möglich - kein } \\
\text { Anheben gegen die Schwerkraft möglich - keine } \\
\text { Bewegung }\end{array}$ & 0 bis 4 \\
\hline Ataxie & $\begin{array}{l}\text { Nicht vorhanden - in einer Extremität vorhan- } \\
\text { den - in zwei Extremitäten vorhanden }\end{array}$ & 0 bis 2 \\
\hline Sensibilität & $\begin{array}{l}\text { Normale Sensibilität - leichter bis mittlerer Sen- } \\
\text { sibilitätsverlust - schwerer Sensibilitätsverlust }\end{array}$ & 0 bis 3 \\
\hline Sprache & $\begin{array}{l}\text { Normale Sprache - leichte bis mittlere Aphasie } \\
\text { - schwere Aphasie - stumm, globale Aphasie }\end{array}$ & 0 bis 3 \\
\hline Dysarthrie & Normal - leicht bis mittel - schwer - & 0 bis 2 \\
\hline Neglect & $\begin{array}{l}\text { Kein Neglect - visueller, taktiler, auditiver oder } \\
\text { personenbezogener Neglect - Neglect in min- } \\
\text { destens zwei Qualitäten }\end{array}$ & 0 bis 2 \\
\hline
\end{tabular}

\section{7 modifizierte Rankin-Skala (mRS)}

Die modifizierte Rankin-Skala (vgl. Tabelle 4) bewertet die Eigenständig- und Unabhängigkeit des vom Schlaganfall betroffenen Patienten. Sie kann Werte von null bis sechs einnehmen, wobei hohe Werte eine schwere Betroffenheit darstellen (Rankin 1957; Swieten et al. 1988). Die mRS-Werte wurden von dem ärztlichen Personal und angeleiteten Hilfspersonal dokumentiert und aus dem ICCA-System oder Arztbrief übernommen.

Tabelle 4: mRS (modifiziert nach Modifizierte Rankin-Skala zur Qualifizierung des neurologischen Defizits nach Schlaganfall; BQS Institut)

\begin{tabular}{|l|l|}
\hline Schweregrad & Neurologisches Defizit \\
\hline Rankin 0 & kein neurologisches Defizit \\
\hline Rankin 1 & $\begin{array}{l}\text { funktionell irrelevantes Defizit: alle alltäglichen } \\
\text { Tätigkeiten können wieder ausgeführt werden }\end{array}$ \\
\hline Rankin 2 & $\begin{array}{l}\text { funktionell geringgradiges Defizit: leichte Ein- } \\
\text { schränkungen im alltäglichen Leben }\end{array}$ \\
\hline
\end{tabular}




\begin{tabular}{|l|l|}
\hline Rankin 3 & $\begin{array}{l}\text { funktionell deutliches Defizit: deutliche Ein- } \\
\text { schränkung im alltäglichen Leben bei erhaltener } \\
\text { Gehfähigkeit (mit/ ohne Hilfsmittel) }\end{array}$ \\
\hline Rankin 4 & $\begin{array}{l}\text { funktionell deutliches Defizit: deutliche Ein- } \\
\text { schränkung im alltäglichen Leben und Gehen } \\
\text { nur mit assistierter Hilfe möglich }\end{array}$ \\
\hline Rankin 5 & $\begin{array}{l}\text { Funktionell deutliches Defizit: deutliche Ein- } \\
\text { schränkung im alltäglichen Leben und Bettläge- } \\
\text { rigkeit }\end{array}$ \\
\hline Rankin 6 & tödlicher Ausgang \\
\hline
\end{tabular}

\subsection{Erfassung der Mortalität}

Die Mortalität im Patientenkollektiv wurde mithilfe des bei Krankenhausentlassung erhobenen Werts der modifizierten Rankin-Skala (=6) bestimmt.

\subsection{Daten zur endovaskulären Therapie}

Der Erfolg der endovaskulären Therapie wurde mithilfe der Modified Treatment in Cerebral Infarction (=mTICI)-Score bewertet. Ein Score von 0 besagt dort, dass trotz des Eingriffes keine Reperfusion erreicht wurde. Bei einem Wert von 1 wird das Blutgefäß wieder über den Verschluss durchblutet, aber weiter distal bricht die Versorgung dann ab. Grad 2 wird nochmal in a und b unterteilt. Stadium 2a bedeutet, dass weniger als 50\% des Stromgebietes der betroffenen Arterie wieder perfundiert werden, während es bei Stadium 2b mehr als 50\% des Stromgebietes sind. Grad 3 drückt aus, dass die verschlossene Arterie komplett ohne weitere Okklusion durchblutet wird (Zaidat et al. 2013). Ein Score von mTICI größer oder gleich 2b wurde in dieser Analyse als erfolgreiche Rekanalisation gewertet.

\subsection{Erfassung der Laborparameter}

Bei der Erfassung der Serumwerte von Leukozyten, C-reaktives Protein (CRP) und Prokalzitonin (PCT) wurde auf die Daten im ixserv-System der UMG zurückgegriffen, die während des Krankenhausaufenthaltes der Patienten erhoben wurden. Unter dem Maximalwert wurde der höchste und unter dem Minimalwert der niedrigste Stand des jeweiligen Parameters im Zeitraum der stationären Behandlung dokumentiert. Das Delta-Leukozyten beschreibt die Differenz des Maximums und Minimums. 


\subsection{Statistik}

Die in der Datenbank erfassten Daten wurden mit im Rahmen dieser Untersuchung neu erhobenen Daten verknüpft und in SPSS Statistics (Version 23.0) der Firma IBM als Datenbank zusammengefasst. Die statistisch deskriptive Analyse erfolgte mit SPSS Statistics (Version 23.0) in Zusammenarbeit mit dem Institut für Medizinische Statistik der Universitätsmedizin Göttingen (Direktor: Prof. Dr. Tim Friede).

Kategoriale Variable wurden als absolute Häufigkeiten und Prozente angegeben und mittels Pearson-Chi-Square-Test auf statistisch signifikante Unterschiede zwischen den verglichenen Gruppen untersucht. Ein p-Wert von $<0,05$ wurde in diesem Zusammenhang als statistisch signifikanter Unterschied gewertet.

Bei kontinuierlichen Variablen wurde der Mittelwert bestimmt und der Bereich einer Standardabweichung angegeben. Mittels T-Test bei unabhängigen Stichproben wurden die verschiedenen Gruppen auf signifikante Unterschiede untersucht. Hier wurde ebenso ein pWert von $<0,05$ als statistisch signifikant gewertet.

Weiterhin wurde eine univariate, zur Beurteilung der Rolle des Beta-Blockers, und multivariate logistische Regression zur Prädiktion möglicher Einflussfaktoren für die Endpunkte Pneumonie (Arztbrief, Leitlinie), Harnwegsinfekt (Arztbrief, Leitlinie), Sepsis (Arztbrief, Leitlinie), andere Infektion und Tod durchgeführt. Hierzu wurden die relevanten Konfounder ( $p<0,2$ und zusätzlich klinische Relevanz) eines univariaten Vortests des jeweiligen Endpunktes in die Analyse eingespeist. Diese logistische Regression wurde als Einschluss-Verfahren durchgeführt. Die Ergebnisse der logistischen Regression wurden als Odds-Ratios dargestellt. Ein p-Wert von $<0,05$ wurde als statistisch signifikant gewertet. 


\section{Ergebnisse}

\subsection{Eingeschlossene Patienten}

Im Zeitraum vom 24.01.2006 bis zum 25.02.2017 wurden in der Universitätsmedizin Göttingen 522 Patienten mit einem ischämischen Hirninfarkt einer Thrombektomie und in die vorliegende Datenbank zugeführt. Bei 216 Patienten war die Vormedikation unbekannt und sie wurden von dieser Studie ausgeschlossen, sodass letztendlich ein Patientenkollektiv von 306 Patienten im Rahmen der Dissertation analysiert wurde.

158 Patienten (51,6\%) bekamen in der Vormedikation einen Beta-Blocker und wurden in die Beta-Blocker-positive $(\mathrm{BB}(+))$ Gruppe eingeordnet. Dementsprechend bestand die BetaBlocker-negative (BB(-)) Gruppe aus 148 Patienten (48,4\%).

\subsection{Beta-Blocker-positive und -negative Gruppe}

\subsubsection{Basischarakteristika der $\mathrm{BB}(+)$ - und BB(-)-Gruppe}

In Tabelle 5 sind die unterschiedlichen Inzidenzen von Risikofaktoren für ischämische Schlaganfälle in der Beta-Blocker-positiven sowie -negativen Gruppe dargestellt. Dabei zeigten sich signifikanten Unterschiede in den Parametern Alter $(\mathrm{p}<0,001)$, arterieller Hypertonie $(\mathrm{p}<0,001)$, Arrhythmia absoluta $(\mathrm{p}<0,001)$ Adipositas $(\mathrm{p}=0,012)$, koronare Herzerkrankung $($ KHK, $\mathrm{p}<0,001)$ und chronische Niereninsuffizienz $(\mathrm{p}=0,006)$ zuungunsten der Beta-Blocker-Population. In den Faktoren Hyperlipidämie, Diabetes mellitus, peripherer arterieller Verschlusskrankheit (pAVK) und Dauer des Krankenhausaufenthaltes ergaben sich keine signifikanten Unterschiede. Der Vergleich der erfolgreichen Rekanalisationsraten der beiden Gruppen offenbarte ebenso keinen signifikanten Unterschied ( $\mathrm{p}=0,521)$. Die Beta-Blockernegativen Gruppe wies signifikant häufiger eine positive Raucheranamnese auf $(p=0,014)$. Bezüglich der Schwere des Schlaganfalls zeigte sich, dass die BB(+)-Gruppe bei Aufnahme einen höheren NIHSS- (16,29 vs. 14,97 Punkte, $\mathrm{p}=0,095)$ und mRS-Wert (4,46 vs. 4,18 Punkte, $\mathrm{p}=0,08)$ als die BB(-)-Gruppe besaß. Posttherapeutisch tat sich ein signifikanter Unterschied hinsichtlich des NIHSS-Wertes auf $(\mathrm{BB}(+)$ 16,55 und $\mathrm{BB}(-)$ 13,88, $\mathrm{p}=0,016)$. Bezüglich des Geschlechts zeigte sich in der Beta-Blocker-Gruppe der Anteil der Frauen signifikant höher im Vergleich zu den männlichen Probanden $(\mathrm{p}<0,001)$. 
Tabelle 5: Baselinecharakteristika der Beta-Blocker-positiven $(n=158)$ und -negativen Gruppe ( $\mathrm{n}=148)$

\begin{tabular}{|c|c|c|c|}
\hline & $\mathrm{BB}(+)$ & $\mathrm{BB}(-)$ & p-Wert \\
\hline Alter in Jahren (Mittelwert) & 75,9 & 67,1 & $<0,001$ \\
\hline arterielle Hypertonie (\%) & 96,8 & 61,9 & $<0,001$ \\
\hline Hyperlipidämie (\%) & 48 & 41,8 & 0,296 \\
\hline Diabetes mellitus (\%) & 34 & 25,9 & 0,134 \\
\hline Arrhythmia absoluta (\%) & 57,4 & 24,7 & $<0,001$ \\
\hline pAVK (\%) & 8,4 & 4,1 & 0,157 \\
\hline Adipositas (\%) & 41,1 & 26,6 & 0,012 \\
\hline Raucher/in (\%) & 11,1 & 22,9 & 0,014 \\
\hline KHK (\%) & 36,5 & 11,6 & $<0,001$ \\
\hline chron. Niereninsuffizienz (\%) & 25 & 12,1 & 0,006 \\
\hline $\begin{array}{l}\text { NIHSS bei Aufnahme (Punkte, } \\
\text { IQR) }\end{array}$ & $16,29(10)$ & $14,97(9)$ & 0,095 \\
\hline $\begin{array}{l}\text { NIHSS posttherapeutisch } \\
\text { (Punkte, IQR) }\end{array}$ & $16,55(15)$ & $13,88(17)$ & 0,016 \\
\hline $\begin{array}{l}\text { NIHSS bei Entlassung (Punkte, } \\
\text { IQR) }\end{array}$ & $8,85(11,75)$ & $7,48(12)$ & 0,142 \\
\hline $\begin{array}{l}\text { mRS bei Aufnahme (Punkte, } \\
\text { IQR) }\end{array}$ & $4,46(1)$ & $4,18(1)$ & 0,08 \\
\hline erfolgreiche Rekanalisation (\%) & 74,5 & 70,9 & 0,521 \\
\hline Tage im Krankenhaus & 12,5 & 13,1 & 0,577 \\
\hline Männlich (\%) & 36,1 & 61,5 & $<0,001$ \\
\hline Weiblich (\%) & 63,9 & 38,5 & $<0,001$ \\
\hline
\end{tabular}

\subsubsection{Infektionsraten in der $\mathrm{BB}(+)-$ und $\mathrm{BB}(-)-G r u p p e$}

Im Weiteren wurde generell die Entwicklung von Infektionen nach einem Schlaganfall zwischen der $\mathrm{BB}(+)$ - und $\mathrm{BB}(-)-G r u p p e$ verglichen (siehe Abbildung 5 und Tabelle 6). In der $\mathrm{BB}(+)-$ Gruppe entwickelten 50\% der Patienten ( $\mathrm{n}=79$ ) eine Pneumonie nach Arztbrief $(\mathrm{AB})$, wohingegen die Rate in der BB(-)-Gruppe bei 39,9\% ( $n=59)$ lag. Dieses Ungleichgewicht 
war mit $\mathrm{p}=0,085$ tendenziell. Bei der Pneumoniediagnose nach Leitlinie (LL) war der Unterschied zwischen den beiden Gruppen geringer (27,8 vs. 27\%, p=0,898). Auch bei den Harnwegsinfektdiagnosen nach $\mathrm{AB}$ und nach LL zeigten sich in der $\mathrm{BB}(+)$-Gruppe mit 20,3\% $(\mathrm{n}=32)$ bzw. 31,6\% $(\mathrm{n}=50)$ höhere Infektionsraten als in der $\mathrm{BB}(-)$-Gruppe, wo sich ein Harnwegsinfekt (HWI) nach AB bei 14,2\% $(n=21)$ und nach LL bei 20,3\% $(n=30)$ der Patienten zeigte. Hierbei war der Unterschied zwischen den beiden Gruppen bei den Harnwegsinfekten nach LL statistisch signifikant $(\mathrm{p}=0,027)$. In den Punkten der Sepsis nach AB und nach LL zeigten sich nur geringe Unterschiede zuungunsten der $\mathrm{BB}(+)-G r u p p e$. Infektionen der Kategorie der anderen Infektionen traten in der BB(-)-Gruppe in 9,5\% der Fälle ( $n=14)$ öfter als in der $\mathrm{BB}(+)$-Gruppe $(7 \%, \mathrm{n}=11)$ auf $(\mathrm{p}=0,532)$. Bei dem Vergleich der Mortalitätsrate bei Entlassung aus dem Krankenhaus verstarb die Beta-Blocker-Population häufiger, aber gab es zwischen den beiden Gruppen keinen signifikanten Unterschied ( $p=0,206)$.

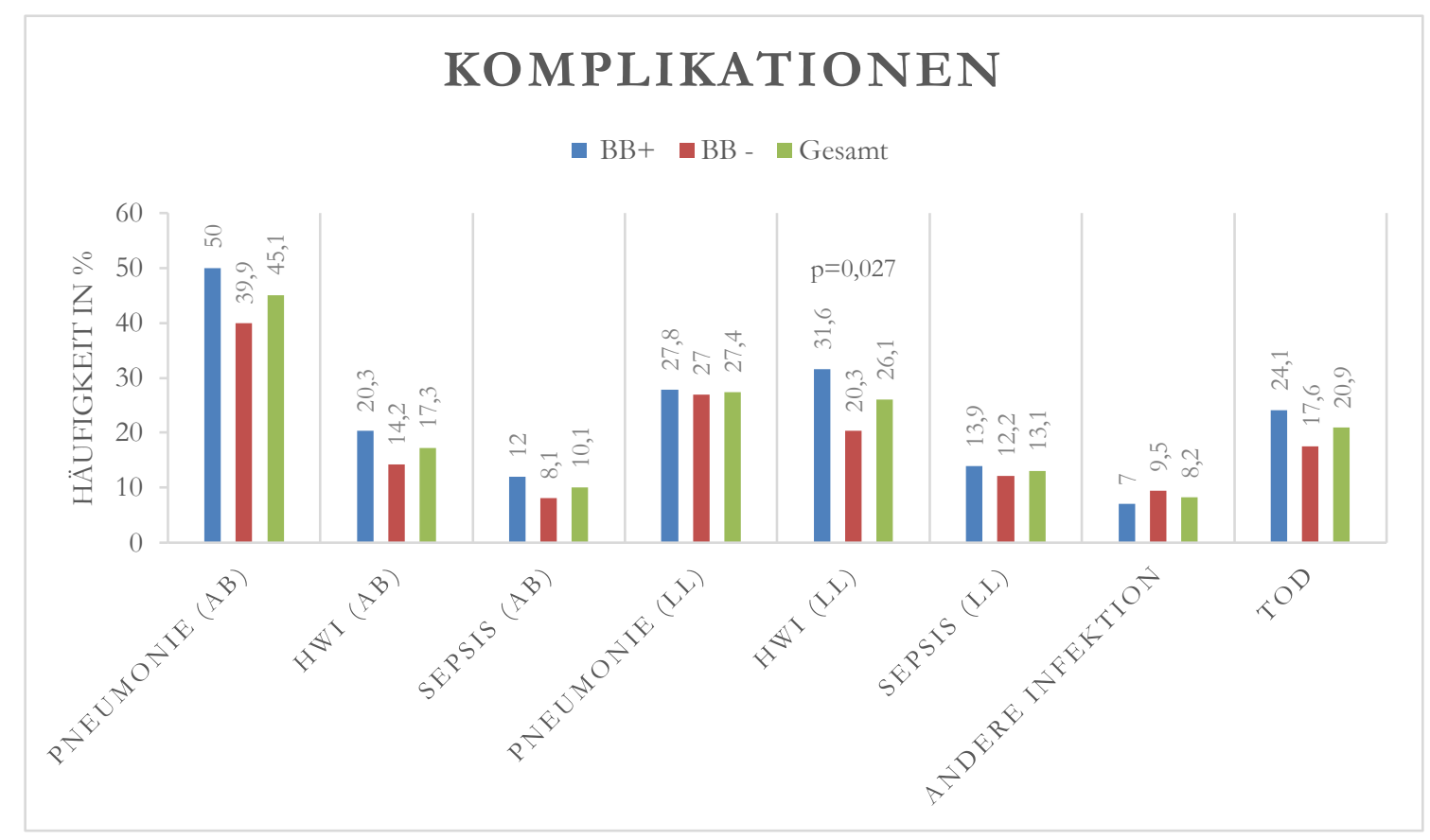

Abbildung 5: Komplikationsraten der BB(+)- $(\mathrm{n}=158)$, BB(-)-Gruppe ( $\mathrm{n}=148)$ und des Patientenkollektivs ( $\mathrm{n}=306)$ in \% (unadjustiert) 
Tabelle 6: Infektionsrate/ Mortalität

\begin{tabular}{|l|c|c|c|c|} 
& $\begin{array}{c}\text { Beta-Blocker } \\
\mathbf{n}=\mathbf{1 5 8}\end{array}$ & $\begin{array}{c}\text { Beta-Blocker - } \\
\mathbf{n = 1 4 8}\end{array}$ & $\begin{array}{c}\text { Gesamt } \\
\mathbf{n}=\mathbf{3 0 6}\end{array}$ & $\mathbf{p}$ - Wert \\
\hline $\begin{array}{l}\text { Pneumonie } \\
\text { (Arztbrief) }\end{array}$ & $79(50 \%)$ & $59(39,9 \%)$ & $138(45,1 \%)$ & $\mathbf{0 , 0 8 5}$ \\
\hline $\begin{array}{l}\text { Harnwegsinfekt } \\
\text { (Arztbrief) }\end{array}$ & $32(20,3 \%)$ & $21(14,2 \%)$ & $53(17,3 \%)$ & 0,176 \\
\hline Sepsis (Arztbrief) & $19(12 \%)$ & $12(8,1 \%)$ & $31(10,1 \%)$ & 0,343 \\
\hline $\begin{array}{l}\text { Pneumonie } \\
\text { (Leitlinie) }\end{array}$ & $44(27,8 \%)$ & $40(27 \%)$ & $84(27,4 \%)$ & 0,898 \\
\hline $\begin{array}{l}\text { Harnwegsinfekt } \\
\text { (Leitlinie) }\end{array}$ & $50(31,6 \%)$ & $30(20,3 \%)$ & $80(26,1 \%)$ & $\mathbf{0 , 0 2 7}$ \\
\hline Sepsis (Leitlinie) & $22(13,9 \%)$ & $18(12,2 \%)$ & $40(13,1 \%)$ & 0,735 \\
\hline andere Infektion & $11(7 \%)$ & $14(9,5 \%)$ & $25(8,2 \%)$ & 0,532 \\
\hline Tod & $38(24,1 \%)$ & $26(17,6 \%)$ & $64(20,9 \%)$ & 0,206 \\
\hline
\end{tabular}

\subsubsection{Verteilung von Einfussfaktoren in der BB(+)- und BB(-)-Gruppe}

Im nächsten Schritt wurden die möglichen Einflussfaktoren auf die Entwicklung einer Infektion analysiert (vgl. Abbildung 6 und Tabelle 7). Bei der BB(+)-Gruppe litten 127 Patienten $(80,4 \%)$ nach dem Schlaganfall unter einer Dysphagie, während der Anteil in der BB(-)Gruppe bei 99 Patienten (66,9\%) lag. Dieser Unterschied war statistisch signifikant $(p=0,006)$. Nahezu alle Patienten der Beta-Blocker-positiven Gruppe ( $n=149,94,3 \%)$ bedurften eines transurethralen Katheters und damit tendenziell häufiger $(p=0,099)$ als in der Beta-Blocker-negativen Gruppe ( $\mathrm{n}=131,88,5 \%)$. Des Weiteren benötigten die Patienten mit Beta-Blocker in der Vormedikation häufiger eine naso-gastrale Sonde ohne, dass sich eine statistische Signifikanz ausbildete $(\mathrm{p}=0,493)$. Die Patienten der BB(-)-Gruppe mussten sich hingegen signifikant öfter einem weiteren Eingriff $(p=0,036)$ und einer dekompressiven Hemikraniektomie $(p=0,022)$ unterziehen. Der Unterschied wies statistische Signifikanz auf $(p=0,036)$. Ebenso nahmen Patienten der BB $(-)-$ Gruppe tendenziell häufiger $(p=0,059)$ eine immunmodulierende Vormedikation $(\mathrm{n}=17,11,5 \%)$ ein, da dies nur 8 Patienten $(5,1 \%)$ der $\mathrm{BB}(+)$-Gruppe taten. Während Patienten in der BB(-)-Gruppe häufiger intubiert waren, allerdings ohne statistische Signifikanz $(\mathrm{p}=0,124)$, zeigte sich in der Länge der Intubation nur ein geringer Unterschied $(\mathrm{p}=0,507)$. In dem Kollektiv der Patienten ohne Beta-Blocker in der Vormedikation erfolgte häufiger eine Tracheotomie $(p=0,413)$. 


\section{EINFLUSSFAKTOREN}

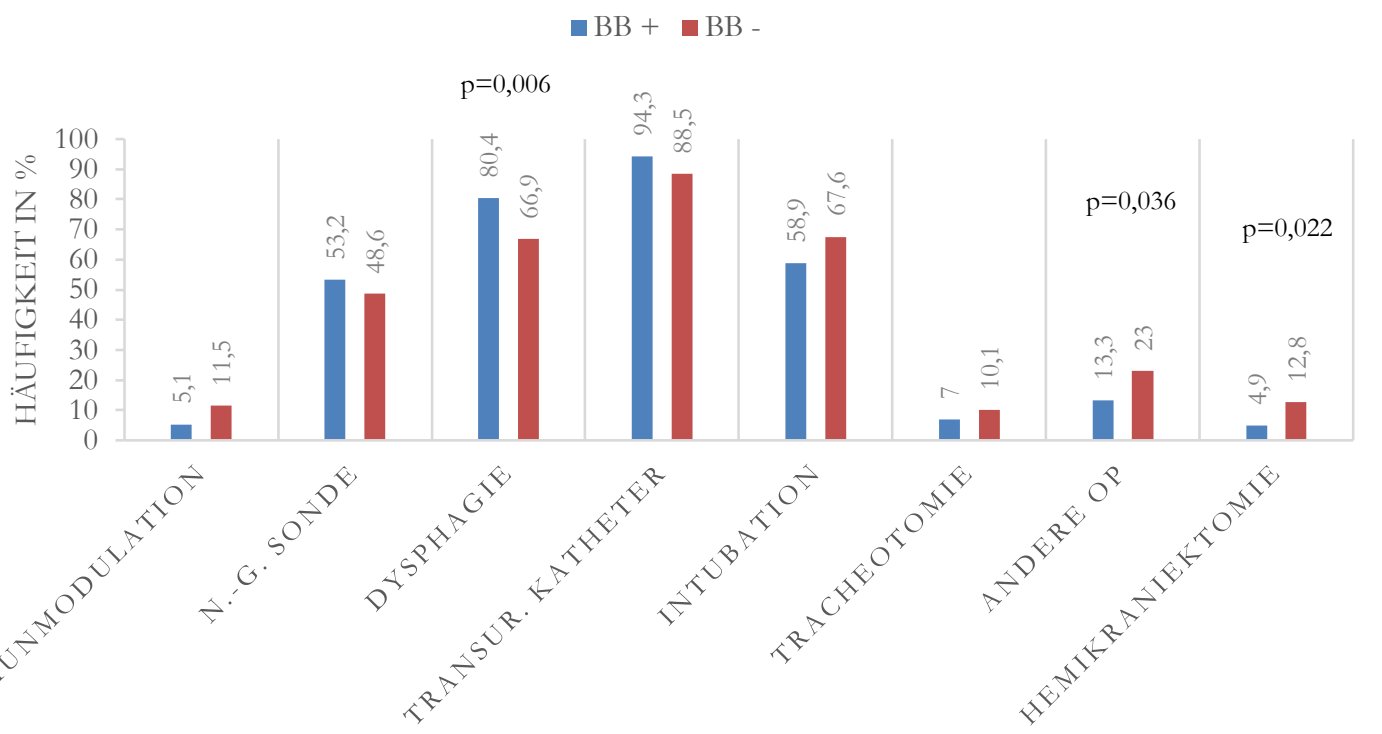

Abbildung 6: Verteilung möglicher Einflussfaktoren in der $\mathrm{BB}(+)-(\mathrm{n}=158)$ und $\mathrm{BB}(-)-$ Gruppe $(\mathrm{n}=148)$ in \%

Tabelle 7: Verteilung möglicher Einflussfaktoren in der BB(+)- $(\mathrm{n}=158)$ und BB(-)-Gruppe $(\mathrm{n}=148)$

\begin{tabular}{|c|c|c|c|}
\hline & $\begin{array}{c}\text { Beta-Blocker }+ \\
n=158\end{array}$ & $\begin{array}{l}\text { Beta-Blocker - } \\
\text { n=148 }\end{array}$ & p-Wert \\
\hline Immunmodulation (\%) & 5,1 & 11,5 & 0,059 \\
\hline naso-gastrale Sonde ( $\%)$ & 53,2 & 48,6 & 0,493 \\
\hline Dysphagie (\%) & 80,4 & 66,9 & 0,006 \\
\hline $\begin{array}{l}\text { transurethraler Katheter } \\
(\%)\end{array}$ & 94,3 & 88,5 & 0,099 \\
\hline Intubation (\%) & 58,9 & 67,6 & 0,124 \\
\hline Intubationsdauer (Tage) & 3,78 & 4,28 & 0,507 \\
\hline Tracheotomie (\%) & 7,0 & 10,1 & 0,413 \\
\hline $\begin{array}{l}\text { Dauer Stroke bis Tracheo- } \\
\text { tomie (Tage) }\end{array}$ & 13,27 & 13,93 & 0,76 \\
\hline andere $\mathrm{OP}(\%)$ & 13,3 & 23 & 0,036 \\
\hline Hemikraniektomie $(\%)$ & $\begin{array}{c}4,9 \\
\mathrm{n} / \mathrm{a}: 16\end{array}$ & $\begin{array}{l}12,8 \\
\text { n/a: } 7\end{array}$ & 0,022 \\
\hline
\end{tabular}




\subsection{Analyse der Infektions- und Mortalitätsgruppen}

\subsubsection{Einfluss auf die Entwicklung einer Pneumonie}

Im gesamten Patientenkollektiv ( $\mathrm{n}=306)$ entwickelte sich in 138 Fällen $(45,1 \%)$ eine Pneumonie, die im Arztbrief beschrieben wurde, und in 84 Fällen (27,4\%) eine Pneumonie, die einer leitliniengerechten Diagnose entsprach. Im Weiteren wurde nun untersucht, ob und welche Risikofaktoren besonders häufig bei den Pneumonien auftraten und so an der Entwicklung hätten beteiligt sein können (vgl. Tabelle 8 und Tabelle 9).

Hierbei stellte sich heraus, dass bei der Diagnose nach Arztbrief und nach Leitlinie fast die gleichen Risikofaktoren statistisch signifikant häufiger auftraten. So litten fast alle Patienten mit Pneumonie an einer Dysphagie und damit statistisch hochsignifikant häufiger als Patienten ohne Pneumonie $(p<0,001)$. Patienten mit Pneumonie hatten statistisch signifikant öfter eine naso-gastrale Sonde oder in nahezu allen Fällen einen transurethralen Katheter (jeweils $\mathrm{p}<0,001)$. Auch waren die Patienten statistisch hochsignifikant mehr intubiert $(\mathrm{p}<0,001)$ und mussten wesentlich häufiger tracheotomiert werden $(p<0,001)$ als die Patienten, die keine Pneumonie erlitten. In den Pneumonie-positiven Gruppen wurden signifikant häufiger weitere Eingriffe oder Operationen durchgeführt $(p<0,001)$. Des Weiteren waren die Patienten, die von einer Pneumonie betroffen waren, statistisch signifikant älter (Pneumonie AB $\mathrm{p}=0,025$, Pneumonie LL $\mathrm{p}=0,173$ ) und wiesen bei Aufnahme einen zum Teil signifikant höheren NIHSS- (Pneumonie AB $p=0,001$, Pneumonie LL $p=0,053$ ) und mRS-Wert (Pneumonie $\mathrm{AB} p<0,001$, Pneumonie LL $\mathrm{p}=0,027)$ auf.

Eine erfolgreiche Rekanalisation hatte einen protektiven Einfluss bezüglich der Entwicklung einer Pneumonie und war in der Patientengruppe, die eine Pneumonie entwickelte, statistisch signifikant seltener erfolgreich $(p=0,003$ bei Pneumonie nach AB, $p=0,002$ bei Pneumonie nach LL).

Tabelle 8: Verteilung von Einflussfaktoren für Infektionen bei Pneumonie nach Arztbrief im Patientenkollektiv ( $\mathrm{n}=306)$

\begin{tabular}{|l|c|c|c|}
\hline & $\begin{array}{c}\text { Pneumonie + (Arztbrief) } \\
\mathbf{n = 1 3 8}\end{array}$ & $\begin{array}{c}\text { Pneumonie - (Arztbrief) } \\
\mathbf{n = 1 6 8}\end{array}$ & p-Wert \\
\hline $\begin{array}{l}\text { Beta-Blocker in Vormedika- } \\
\text { tion (n, \%) }\end{array}$ & $79(57,2)$ & $79(47,0)$ & 0,085 \\
\hline Immunmodulation (n, \%) & $9(6,5)$ & $16(9,5)$ & 0,405 \\
\hline naso-gastrale Sonde (n, \%) & $100(72,5)$ & $56(33,3)$ & $<\mathbf{0 , 0 0 1}$ \\
\hline Dysphagie (n, \%) & $131(94,9)$ & $95(56,5)$ & $<\mathbf{0 , 0 0 1}$ \\
\hline
\end{tabular}




\begin{tabular}{|l|c|c|c|}
\hline transurethraler Katheter (n, \%) & $136(98,6)$ & $144(85,7)$ & $<\mathbf{0 , 0 0 1}$ \\
\hline Intubation (n, \%) & $109(79)$ & $84(50)$ & $<\mathbf{0 , 0 0 1}$ \\
\hline Tracheotomie (n, \%) & $23(16,7)$ & $3(1,8)$ & $<\mathbf{0 , 0 0 1}$ \\
\hline andere OP (n, \%) & $39(28,3)$ & $16(9,5)$ & $<\mathbf{0 , 0 0 1}$ \\
\hline Hemikraniektomie (n, \%) & $20(15,7)$ & $5(3,2)$ & $\mathbf{2 0 , 0 0 1}$ \\
\hline erfolgreiche Rekanalisation (n, \\
\%)
\end{tabular}

Tabelle 9: Verteilung von Einflussfaktoren für Infektionen bei Pneumonie nach Leitlinie im Patientenkollektiv ( $\mathrm{n}=306)$

\begin{tabular}{|c|c|c|c|}
\hline & $\begin{array}{c}\text { Pneumonie }+ \text { (Leitlinie) } \\
\mathrm{n}=84\end{array}$ & $\begin{array}{c}\text { Pneumonie - (Leitlinie) } \\
n=220\end{array}$ & p-Wert \\
\hline $\begin{array}{l}\text { Beta-Blocker in Vormedika- } \\
\text { tion }(n, \%)\end{array}$ & $44(52,4)$ & $113(51,4)$ & 0,898 \\
\hline Immunmodulation (n, \%) & $4(4,8)$ & $21(9,5)$ & 0,243 \\
\hline naso-gastrale Sonde (n, \%) & $61(73,5)$ & $94(42,7)$ & $<0,001$ \\
\hline Dysphagie (n, \%) & $81(96,4)$ & $145(65,9)$ & $<0,001$ \\
\hline transurethraler Katheter (n, \%) & $84(100)$ & $194(88,2)$ & $<0,001$ \\
\hline Intubation $(\mathrm{n}, \%)$ & $70(83,3)$ & $122(55,5)$ & $<0,001$ \\
\hline Tracheotomie (n, \%) & $19(22,6)$ & $7(3,2)$ & $<0,001$ \\
\hline andere $\mathrm{OP}(\mathrm{n}, \%)$ & $32(38,1)$ & $23(10,5)$ & $<0,001$ \\
\hline Hemikraniektomie (n, \%) & $\begin{array}{c}16(21,1) \\
\text { n/a: } 8\end{array}$ & $\begin{array}{l}9(4,4) \\
\text { n/a: } 15\end{array}$ & $<0,001$ \\
\hline
\end{tabular}




\begin{tabular}{|l|c|c|c|}
\hline $\begin{array}{l}\text { erfolgreiche Rekanalisation (n, } \\
\mathbf{0})\end{array}$ & $\begin{array}{l}49(59) \\
\text { n/a: } 1\end{array}$ & $171(77,7)$ & $\mathbf{0 , 0 0 2}$ \\
\hline $\begin{array}{l}\text { NIHSS bei Aufnahme } \\
\text { (Punkte) }\end{array}$ & 16,9 & 15,2 & 0,053 \\
\hline mRS bei Aufnahme (Punkte) & 4,51 & 4,26 & $\mathbf{0 , 0 2 7}$ \\
\hline Alter (Jahre) & 73,2 & 71 & 0,173 \\
\hline $\begin{array}{l}\text { Geschlecht (männlich (n, \%), } \\
\text { weiblich (n, \%)) }\end{array}$ & $46(54,8)$ & $101(45,9)$ & 0,199 \\
\hline
\end{tabular}

Weiterhin wiesen Patienten mit einer Pneumonie sowohl nach Arztbrief als auch nach Leitlinie eine signifikant längere Intubationsdauer als Patienten ohne Pneumonie auf $(p<0,001)$. Ebenso waren die Patienten mit Pneumonie mehr als sieben Tage länger im Krankenhaus als Patienten ohne Pneumonie. Dieser Unterschied war bei einem $\mathrm{p}<0,001$ statistisch signifikant (vgl. Abbildung 7).

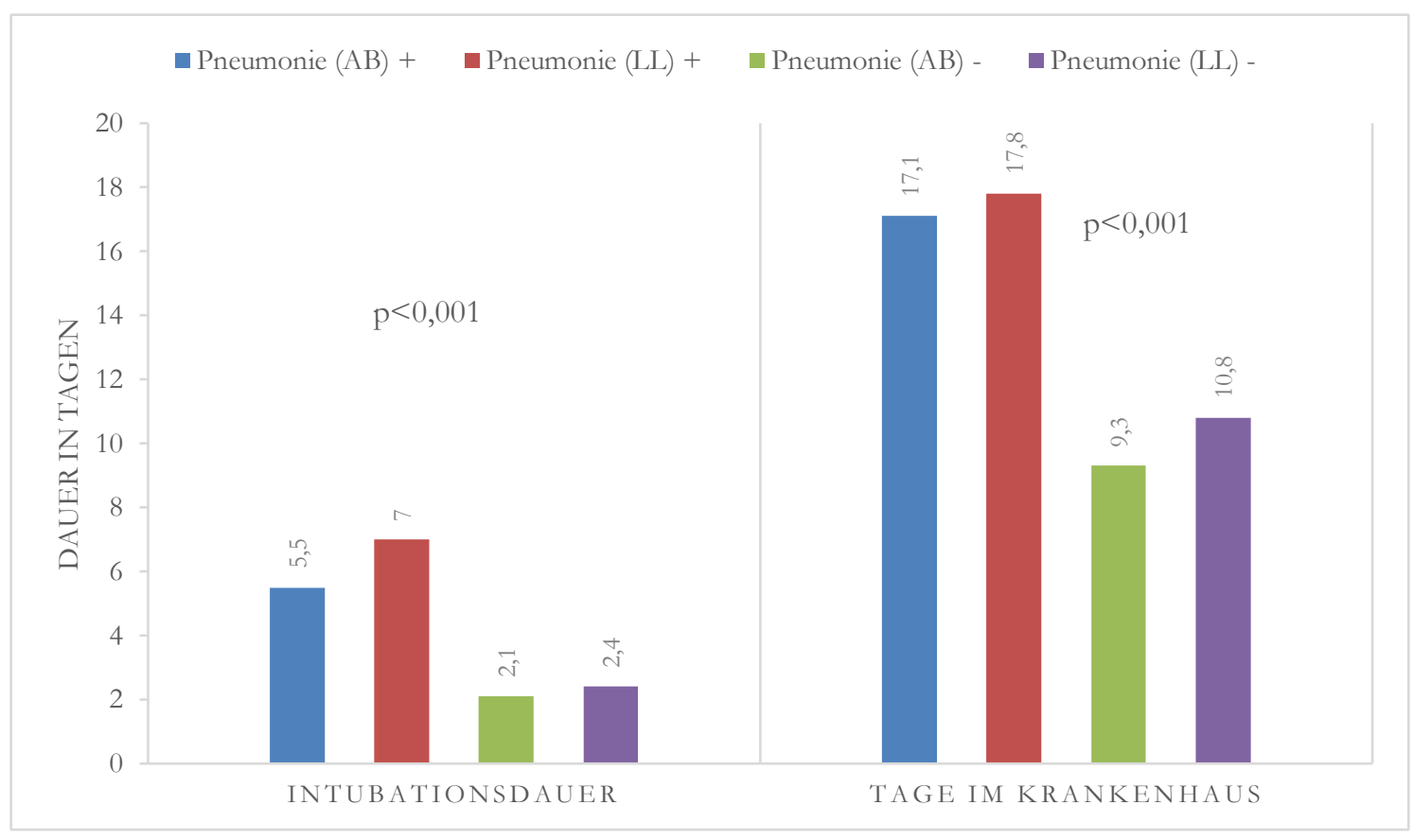

Abbildung 7: Intubationsdauer und Krankenhausaufenthalt in Tagen bei Pneumonie nach Arztbrief und Pneumonie nach Leitlinie im Patientenkollektiv ( $\mathrm{n}=306)$

In der weiteren Datenanalyse wurde eine univariate und multivariate logistische Regression zur Determinierung von unabhängigen Risikofaktoren, die zur Entstehung einer Pneumonie beitragen, durchgeführt (vgl. Tabelle 10). Dazu wurden alle relevanten Konfounder ( $p<0,2$ und klinische Relevanz) des univariaten Vortests in die Analyse einbezogen. Eine Beta-Blocker-Medikation wurde aufgrund der Relevanz hinsichtlich des Themas dieser Dissertation 
automatisch miteinbezogen. Der transurethraler Katheter sowie die Dauer des Krankenhausaufenthalts unterschieden sich in den beiden Gruppen signifikant, wurden aber aus der logistischen Regression aus fehlender klinischer Relevanz ausgeschlossen. Aufgrund des Polaritätsprinzips wurde nur der NIHSS-Wert bei Aufnahme verwendet und dem mRS-Wert bei Aufnahme vorgezogen. Es zeigte sich, dass eine kürzere Intubationsdauer mit einem geringeren Risiko für das Erleiden einer Pneumonie behaftet war (Pneumonie AB p=0,005, OR 0,62; Pneumonie LL p=0,004, OR 0,76). Weiterhin waren bei der Pneumonie nach Arztbrief eine naso-gastrale Sonde $(p=0,001$, OR 3,93) und ein rechtshirniger Infarkt $(p=0,031$, OR $2,18)$ unabhängige Prädiktoren. Bei der Pneumonie nach Leitlinie wiesen sich eine Dysphagie $(p=0,031$, OR 10,92) und eine andere OP $(p=0,038$, OR 3,52) als statistisch signifikante Risikofaktoren auf (vgl. Tabelle 10).

Tabelle 10: Ergebnisse der univariaten und multivariaten logistischen Regression nach der Methode Einschluss für den Endpunkt Pneumonie nach Arztbrief und Leitlinie

\begin{tabular}{|c|c|c|c|}
\hline & & OR $(95 \% \mathrm{KI})$ & p-Wert \\
\hline \multicolumn{4}{|l|}{$\begin{array}{l}\text { Pneumonie (Arzt- } \\
\text { brief) }\end{array}$} \\
\hline Univariate Analyse & $\begin{array}{l}\text { Beta-Blocker-Vormedi- } \\
\text { kation }\end{array}$ & $1,51(0,96-2,37)$ & 0,076 \\
\hline \multirow[t]{13}{*}{ Multivariate Analyse } & $\begin{array}{l}\text { Beta-Blocker-Vormedi- } \\
\text { kation }\end{array}$ & $1,39(0,67-2,89)$ & 0,374 \\
\hline & Dysphagie & $3,25(0,96-10,99)$ & 0,058 \\
\hline & Intubationsdauer & $0,62(0,44-0,86)$ & 0,005 \\
\hline & $\begin{array}{l}\text { erfolgreiche Rekanalisa- } \\
\text { tion }\end{array}$ & $0,83(0,38-1,84)$ & 0,645 \\
\hline & Intubation & $0,98(0,41-2,3)$ & 0,955 \\
\hline & andere OP & $1,19(0,32-4,34)$ & 0,797 \\
\hline & naso-gastrale Sonde & $3,93(1,73-8,89)$ & 0,001 \\
\hline & Tracheotomie & $0,23(0,01-9,84)$ & 0,441 \\
\hline & Hemikraniektomie & $0,38(0,03-4,99)$ & 0,46 \\
\hline & Seite des Schlaganfalls & $2,18(1,07-4,43)$ & 0,031 \\
\hline & NIHSS bei Aufnahme & $0,95(0,89-1)$ & 0,08 \\
\hline & Alter & $0,98(0,95-1,01)$ & 0,183 \\
\hline & Geschlecht & $1,62(0,81-3,24)$ & 0,175 \\
\hline \multicolumn{4}{|l|}{ Pneumonie (Leitlinie) } \\
\hline Univariate Analyse & $\begin{array}{l}\text { Beta-Blocker-Vormedi- } \\
\text { kation }\end{array}$ & $1,04(0,63-1,72)$ & 0,874 \\
\hline
\end{tabular}




\begin{tabular}{|l|l|c|c|}
\hline Multivariate Analyse & $\begin{array}{l}\text { Beta-Blocker-Vormedi- } \\
\text { kation }\end{array}$ & $0,89(0,4-1,98)$ & 0,774 \\
\hline & naso-gastrale Sonde & $1,82(0,77-4,28)$ & 0,17 \\
\hline & Dysphagie & $10,92(1,25-95,31)$ & $\mathbf{0 , 0 3 1}$ \\
\hline & Intubationsdauer & $0,76(0,63-0,91)$ & $\mathbf{0 , 0 0 4}$ \\
\hline & Tracheotomie & $0,45(0,03-5,86)$ & 0,54 \\
\hline & andere OP & $3,52(1,07-11,57)$ & $\mathbf{0 , 0 3 8}$ \\
\hline & Intubation & $0,82(0,33-2,04)$ & 0,667 \\
\hline & $\begin{array}{l}\text { erfolgreiche Rekanalisa- } \\
\text { tion }\end{array}$ & $0,84(0,37-1,89)$ & 0,67 \\
\hline & Hemikraniektomie & $0,34(0,04-2,86)$ & 0,324 \\
\hline & Seite des Schlaganfalls & $1,88(0,88-3,99)$ & 0,101 \\
\hline & NIHSS bei Aufnahme & $0,97(0,91-1,03)$ & 0,336 \\
\hline & Alter & $0,97(0,93-1,01)$ & 0,106 \\
\hline & Geschlecht & $2,01(0,95-4,27)$ & 0,068 \\
\hline
\end{tabular}

\subsubsection{Einfluss auf die Entwicklung eines Harnwegsinfekts}

Der einzige Faktor, der in der Patientengruppe mit Harnwegsinfekt-nur bei der leitlinienkonformen Harnwegsinfektdiagnose- statistisch signifikant häufiger als in der Patientengruppe ohne Harnwegsinfekt vorkam, war wie bereits in Kapitel 3.2.2 beschrieben eine Beta-Blocker-Vormedikation ( $p=0,027$ ). Bei den Harnwegsinfekten nach Leitlinie zeigte sich, dass diese Patienten signifikant öfter weiblich waren $(p=0,006)$, tendenziell häufiger an einer Dysphagie litten $(p=0,053)$ und länger im Krankenhaus blieben $(p=0,075)$. In den übrigen Faktoren ergaben sich keine signifikanten Unterschiede. (vgl. Tabelle 11 und Tabelle 12).

Tabelle 11: Verteilung von Einflussfaktoren für Infektionen bei Harnwegsinfekt nach Arztbrief im Patientenkollektiv ( $\mathrm{n}=306)$

\begin{tabular}{|l|c|c|c|}
\hline & $\begin{array}{c}\text { Harnwegsinfekt + (Arzt- } \\
\text { brief) } \\
\mathbf{n = 5 3}\end{array}$ & $\begin{array}{c}\text { Harnwegsinfekt - (Arzt- } \\
\text { brief) } \\
\mathbf{n}=\mathbf{2 5 3}\end{array}$ & p-Wert \\
\hline $\begin{array}{l}\text { Beta-Blocker in Vormedi- } \\
\text { kation (n, \%) }\end{array}$ & $32(60,4)$ & $126(49,8)$ & 0,176 \\
\hline Immunmodulation (n, \%) & $5(9,4)$ & $20(7,9)$ & 0,782 \\
\hline naso-gastrale Sonde (n, \%) & $31(58,5)$ & $125(49,4)$ & 0,29 \\
\hline Dysphagie (n, \%) & $44(83)$ & $182(71,9)$ & 0,121 \\
\hline
\end{tabular}




\begin{tabular}{|c|c|c|c|}
\hline $\begin{array}{l}\text { transurethraler Katheter (n, } \\
\% \text { ) }\end{array}$ & $49(92,5)$ & $231(91,3)$ & 1,0 \\
\hline Intubation $(\mathrm{n}, \%)$ & $36(67,9)$ & $157(62,1)$ & 0,44 \\
\hline Intubationsdauer (Tage) & 4,6 & 3,9 & 0,448 \\
\hline Tracheotomie (n, \%) & $7(13,2)$ & $19(7,5)$ & 0,18 \\
\hline andere $\mathrm{OP}(\mathrm{n}, \%)$ & $10(18,9)$ & $45(17,8)$ & 0,845 \\
\hline Hemikraniektomie (n, \%) & $\begin{array}{l}\mathrm{p} \\
\mathrm{n} / \mathrm{a}: 3\end{array}$ & $\begin{array}{l}20(8,6) \\
\text { n/a: } 20\end{array}$ & 0,784 \\
\hline $\begin{array}{l}\text { erfolgreiche Rekanalisation } \\
(\mathrm{n}, \%)\end{array}$ & $34(64,2)$ & $\begin{array}{c}188(74,6) \\
\text { n/a: } 1\end{array}$ & 0,129 \\
\hline Tage im Krankenhaus & 13,9 & 12,5 & 0,334 \\
\hline $\begin{array}{l}\text { NIHSS bei Aufnahme } \\
\text { (Punkte) }\end{array}$ & 16,26 & 15,53 & 0,477 \\
\hline $\begin{array}{l}\text { mRS bei Aufnahme } \\
\text { (Punkte) }\end{array}$ & 4,26 & 4,34 & 0,592 \\
\hline Alter (Jahre) & 72,7 & 71,2 & 0,5 \\
\hline $\begin{array}{l}\text { Geschlecht (männlich (n, } \\
\%) \text {, weiblich }(n, \%))\end{array}$ & $\begin{array}{l}21(39,6) \\
32(60,4)\end{array}$ & $\begin{array}{l}127(50,2) \\
126(49,8)\end{array}$ & 0,176 \\
\hline
\end{tabular}

Tabelle 12: Verteilung von Einflussfaktoren für Infektionen bei Harnwegsinfekt nach Leitlinie im Patientenkollektiv ( $\mathrm{n}=306)$

\begin{tabular}{|l|c|c|c|}
\hline & $\begin{array}{c}\text { Harnwegsinfekt }+ \text { (Leitli- } \\
\text { nie) } \\
\end{array}$ & $\begin{array}{c}\text { Harnwegsinfekt - (Leitli- } \\
\text { nie) }\end{array}$ & p-Wert \\
\hline $\begin{array}{l}\text { Beta-Blocker in Vormedika- } \\
\text { tion (n, \%) }\end{array}$ & $50(62,5)$ & $108(47,8)$ & $\mathbf{0 , 0 2 7}$ \\
\hline Immunmodulation (n, \%) & $7(8,8)$ & $18(8)$ & 0,815 \\
\hline naso-gastrale Sonde (n, \%) & $47(58,8)$ & $109(48,2)$ & 0,120 \\
\hline $\begin{array}{l}\text { Dysphagie (n, \%) } \\
\text { transurethraler Katheter (n, } \\
\text { \%) }\end{array}$ & $66(82,5)$ & $160(70,8)$ & 0,053 \\
\hline Intubation (n, \%) & $76(95)$ & $204(90,3)$ & 0,247 \\
\hline
\end{tabular}




\begin{tabular}{|l|c|c|c|}
\hline Intubationsdauer (Tage) & 4,7 & 3,8 & 0,28 \\
\hline Tracheotomie (n, \%) & $9(11,3)$ & $17(7,5)$ & 0,351 \\
\hline andere OP (n, \%) & $16(20)$ & $39(17,3)$ & 0,612 \\
\hline Hemikraniektomie (n, \%) & $9(11,7)$ & $16(7,8)$ & 0,347 \\
\hline $\begin{array}{l}\text { erfolgreiche Rekanalisation } \\
\text { (n, \%) }\end{array}$ & n/a: 3 & n/a: 20 & 0,381 \\
\hline Tage im Krankenhaus & $55(68,8)$ & $167(74,2)$ & n/a: \\
\hline $\begin{array}{l}\text { NIHSS bei Aufnahme } \\
\text { (Punkte) }\end{array}$ & 14,4 & 12,2 & 0,075 \\
\hline mRS bei Aufnahme (Punkte) & 16,55 & 15,33 & 0,173 \\
\hline $\begin{array}{l}\text { Alter (Jahre) } \\
\text { Geschlecht (männlich (n, } \\
\text { \%), weiblich (n, \%)) }\end{array}$ & $28(35)$ & $106(46,9)$ & 0,561 \\
\hline
\end{tabular}

In der multivariaten logistischen Regression nach der Methode Einschluss wurden bei dem Harnwegsinfekt nach Arztbrief die Faktoren Tracheotomie und Dysphagie und bei dem Harnwegsinfekt nach Leitlinie die Faktoren Intubation, Tage im Krankenhaus, naso-gastrale Sonde und Dysphagie aufgrund fehlender klinischer Relevanz bei der Harnwegsinfektentwicklung ausgeschlossen. Das Kriterium der Beta-Blocker-Vormedikation wurde dahingegen hinsichtlich der Fragestellung dieser Arbeit den weiteren vorselektierten Einflussfaktoren $(p<0,2)$ hinzugefügt. Bei der Harnwegsinfekt Diagnose nach Leitlinie zeigte sich ein männliches Geschlecht als protektiv ( $\mathrm{p}=0,02$, OR 0,52, vgl. Tabelle 13).

Tabelle 13: Ergebnisse der univariaten und multivariaten logistischen Regression nach der Methode Einschluss für den Endpunkt Harnwegsinfekt nach Arztbrief und Leitlinie

\begin{tabular}{|c|c|c|c|}
\hline $\begin{array}{c}\text { Harnwegsinfekt } \\
\text { (Arztbrief) }\end{array}$ & OR (95\% KI) & p-Wert \\
\hline Univariate Analyse & $\begin{array}{c}\text { Beta-Blocker-Vormedi- } \\
\text { kation }\end{array}$ & $1,54(0,84-2,81)$ & 0,163 \\
\hline Multivariate Analyse & $\begin{array}{c}\text { Beta-Blocker-Vormedi- } \\
\text { kation }\end{array}$ & $1,45(0,77-2,71)$ & 0,247 \\
\hline & $\begin{array}{l}\text { erfolgreiche Rekanalisa- } \\
\text { tion }\end{array}$ & $0,59(0,31-1,11)$ & 0,099 \\
\hline & Geschlecht & $0,69(0,37-1,29)$ & 0,247 \\
\hline
\end{tabular}




\begin{tabular}{|c|l|c|c|}
\hline $\begin{array}{c}\text { Harnwegsinfekt } \\
\text { (Leitlinie) }\end{array}$ & & $1,82(1,08-3,07)$ & $\mathbf{0 , 0 2 5}$ \\
\hline Univariate Analyse & $\begin{array}{l}\text { Beta-Blocker-Vormedi- } \\
\text { kation }\end{array}$ & $1,5(0,87-2,58)$ & 0,144 \\
\hline Multivariate Analyse & $\begin{array}{l}\text { Beta-Blocker-Vormedi- } \\
\text { kation }\end{array}$ & $0,98(0,94-1,01)$ & 0,188 \\
\hline & NIHSS bei Aufnahme & $0,52(0,3-0,9)$ & $\mathbf{0 , 0 2}$ \\
\hline & Geschlecht & \\
\hline
\end{tabular}

\subsubsection{Einfluss auf die Entwicklung einer Sepsis}

Bei der Analyse des Vorhandenseins von Risikofaktoren bei Patienten mit Sepsis (vgl. Tabelle 14 und

Tabelle 15) fiel auf, dass bei allen Patienten eine Dysphagie beschrieben wurde. Dieser Unterschied war zu der Patientengruppe ohne Sepsis statistisch signifikant $(\mathrm{p}<0,001)$. Alle Patienten mit Sepsis besaßen einen transurethralen Katheter, wobei hier zwischen der Sepsis nach Leitlinie-Gruppe und ohne Sepsis-Gruppe ein statistisch signifikanter Unterschied $(\mathrm{p}=0,033)$ bestand. Für die Patientengruppe mit Sepsis nach Arztbrief war dieser Unterschied tendenziell $(p=0,09)$. Ein sehr hoher Anteil von Patienten mit Sepsis ( $n=28,90,3 \%$ nach Arztbrief und $n=37,92,5 \%$ nach Leitlinie) war während des Krankenhausaufenthalts intubiert und damit statistisch hochsignifikant häufiger $(p<0,001)$. Ungefähr ein Drittel der Patienten mit Sepsis ( $n=10,32,3 \%$ nach Arztbrief und $n=14,35 \%$ nach Leitlinie) mussten tracheotomiert werden, wohingegen der Anteil bei Patienten ohne Sepsis wesentlich geringer war. Dieser Unterschied war ebenso statistisch hochsignifikant $(p<0,001)$. Zusätzlich mussten sich die Patienten mit Sepsis statistisch signifikant häufiger $(\mathrm{p}=0,013$ nach Arztbrief sowie $\mathrm{p}=0,001$ nach Leitlinie) einem weiteren Eingriff als Patienten ohne Sepsis und benötigten öfter eine dekompressive Hemikraniektomie (Sepsis AB p =0,065, Sepsis LL p=0,006). Des Weiteren zeigte sich, dass die Patienten, die eine Sepsis erlitten, statistisch signifikant seltener erfolgreich rekanalisiert werden konnten (Sepsis AB p $=0,002$, Sepsis LL $p=0,034$ ).

Tabelle 14: Verteilung von Einflussfaktoren für Infektionen bei Sepsis nach Arztbrief im Patientenkollektiv $(\mathrm{n}=306)$

\begin{tabular}{|l|c|c|c|}
\hline & $\begin{array}{c}\text { Sepsis + (Arztbrief) } \\
\mathbf{n = 3 1}\end{array}$ & $\begin{array}{c}\text { Sepsis - (Arztbrief) } \\
\mathbf{n = 2 7 5}\end{array}$ & p-Wert \\
\hline $\begin{array}{l}\text { Beta-Blocker in Vormedikation } \\
\text { (n, \%) }\end{array}$ & $19(61,3)$ & $139(50,5)$ & 0,343 \\
\hline Immunmodulation (n, \%) & $5(16,1)$ & $20(7,3)$ & 0,155 \\
\hline
\end{tabular}




\begin{tabular}{|c|c|c|c|}
\hline naso-gastrale Sonde (n, \%) & $18(58,1)$ & $138(50,2)$ & 0,453 \\
\hline Dysphagie (n, \%) & $31(100)$ & $195(70,9)$ & $<0,001$ \\
\hline transurethraler Katheter (n, \%) & $31(100)$ & $249(90,5)$ & 0,09 \\
\hline Intubation $(\mathrm{n}, \%)$ & $28(90,3)$ & $165(60)$ & 0,001 \\
\hline Tracheotomie (n, \%) & $10(32,3)$ & $16(5,8)$ & $<0,001$ \\
\hline andere $\mathrm{OP}(\mathrm{n}, \%)$ & $11(35,5)$ & $44(16)$ & 0,013 \\
\hline Hemikraniektomie (n, \%) & $\begin{array}{l}5(19,2) \\
\mathrm{n} / \mathrm{a}: 5\end{array}$ & $\begin{array}{l}20(7,8) \\
\mathrm{n} / \mathrm{a}: 18\end{array}$ & 0,065 \\
\hline $\begin{array}{l}\text { erfolgreiche Rekanalisation ( } \mathrm{n} \text {, } \\
\% \text { ) }\end{array}$ & $15(48,4)$ & $\begin{array}{c}207(75,3) \\
\text { n/a: } 1\end{array}$ & 0,002 \\
\hline NIHSS bei Aufnahme (Punkte) & 16,48 & 15,56 & 0,478 \\
\hline mRS bei Aufnahme (Punkte) & 4,48 & 4,31 & 0,3 \\
\hline Alter (Jahre) & 72,2 & 71,5 & 0,785 \\
\hline $\begin{array}{l}\text { Geschlecht (männlich (n, \%), } \\
\text { weiblich }(n, \%))\end{array}$ & $\begin{array}{l}18(58,1) \\
13(41,9)\end{array}$ & $\begin{array}{l}130(47,3) \\
145(52,7)\end{array}$ & 0,263 \\
\hline
\end{tabular}

Tabelle 15: Verteilung von Einflussfaktoren für Infektionen bei Sepsis nach Leitlinie im Patientenkollektiv ( $\mathrm{n}=306)$

\begin{tabular}{|l|c|c|c|}
\hline & Sepsis + (Leitlinie) & Sepsis - (Leitlinie) & n=266-Wert \\
\hline $\begin{array}{l}\text { Beta-Blocker in Vormedikation } \\
\text { (n, \%) }\end{array}$ & $22(55)$ & $136(51,1)$ & 0,735 \\
\hline Immunmodulation (n, \%) & $5(12,5)$ & $20(7,5)$ & 0,347 \\
\hline naso-gastrale Sonde (n, \%) & $25(62,5)$ & $131(49,4)$ & 0,131 \\
\hline Dysphagie (n, \%) & $39(100)$ & $187(70,3)$ & $<\mathbf{0 , 0 0 1}$ \\
\hline transurethraler Katheter (n, \%) & $40(100)$ & $240(90,2)$ & $\mathbf{0 , 0 3 3}$ \\
\hline Intubation (n, \%) & $37(92,5)$ & $156(58,6)$ & $<\mathbf{0 0 0 1}$ \\
\hline Tracheotomie (n, \%) & $14(35)$ & $12(4,5)$ & $<\mathbf{0 , 0 0 1}$ \\
\hline andere OP (n, \%) & $16(40)$ & $39(14,7)$ & $\mathbf{0 , 0 0 1}$ \\
\hline
\end{tabular}




\begin{tabular}{|l|c|c|c|}
\hline Hemikraniektomie (n, \%) & $8(22,9)$ & $17(6,9)$ & $\mathbf{0 , 0 0 6}$ \\
\hline $\begin{array}{l}\text { erfolgreiche Rekanalisation (n, } \\
\text { \%) }\end{array}$ & n/a: 5 & n/a: 18 & $199(75,1)$ \\
\hline NIHSS bei Aufnahme (Punkte) & $23(57,5)$ & n/a: 1 & 0,034 \\
\hline mRS bei Aufnahme (Punkte) & 16,43 & 15,54 & 0,132 \\
\hline Alter (Jahre) & 4,53 & 4,29 & 0,795 \\
\hline Geschlecht (männlich (n, \%), & 71,1 & 71,7 & 0,238 \\
\hline weiblich (n, \%))
\end{tabular}

Beim Vergleich der Intubationsdauer von (vgl. Abbildung 8) Sepsis-Patienten versus NichtSepsis-Patienten fiel auf, dass die betroffenen Patienten wesentlich länger intubiert waren. Dieser Unterschied war statistisch hochsignifikant $(\mathrm{p}<0,001)$. Zusätzlich verweilten diese Patienten signifikant länger im Krankenhaus (Sepsis AB p=0,01; Sepsis LL p=0,003).

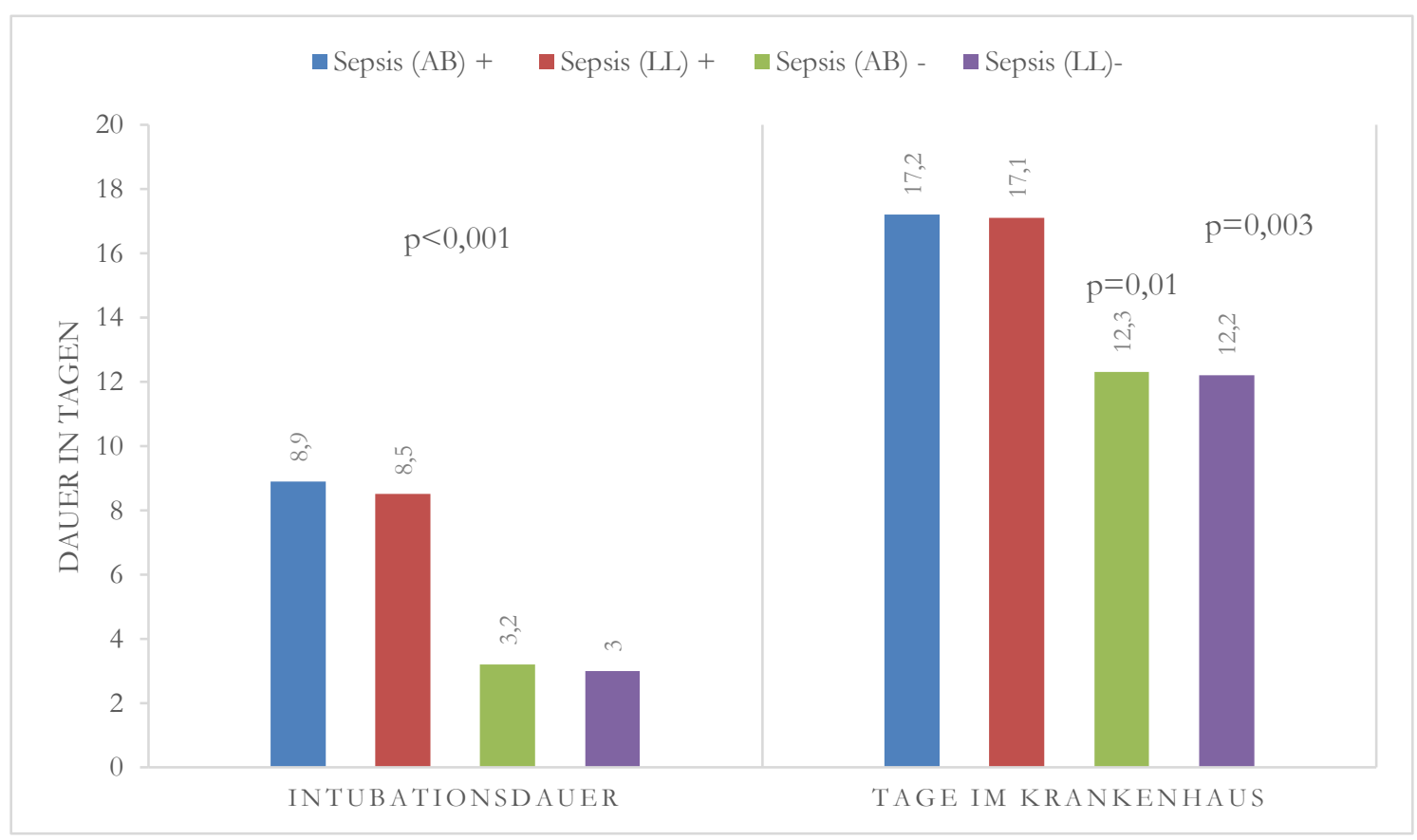

Abbildung 8: Intubationsdauer und Krankenhausaufenthalt in Tagen bei Sepsis nach Arztbrief und Sepsis nach Leitlinie im Patientenkollektiv ( $\mathrm{n}=306)$

In Tabelle 16 sind die Ergebnisse der univariaten und multivariaten logistischen Regression nach der Methode Einschluss dargestellt. Hierbei wurde der Faktor des Krankenhausaufenthalts wegen fehlender Relevanz aus- und eine Beta-Blocker-Vormedikation aufgrund der Fragestellung eingeschlossen. Hier zeigte sich, dass eine ausbleibende oder kurze Intubationsdauer ein schützender Faktor gegenüber der Entwicklung einer Sepsis war (Sepsis nach 
$\mathrm{AB} p=0,001$, OR 0,8; Sepsis nach LL $\mathrm{p}=0,001, \mathrm{OR}$ 0,8). Außerdem zeigte sich eine immunmodulierende Vormedikation als unabhängiger Risikofaktor für die Entwicklung einer Sepsis nach Arztbrief ( $\mathrm{p}=0,027$, OR 4,92).

Tabelle 16: Ergebnisse der univariaten und multivariaten logistischen Regression nach der Methode Einschluss für den Endpunkt Sepsis nach Arztbrief und Leitlinie

\begin{tabular}{|c|c|c|c|}
\hline & & OR (95\% KI) & p-Wert \\
\hline \multicolumn{4}{|l|}{ Sepsis (Arztbrief) } \\
\hline Univariate Analyse & $\begin{array}{c}\text { Beta-Blocker-Vormedi- } \\
\text { kation }\end{array}$ & $1,55(0,72-3,31)$ & 0,259 \\
\hline \multirow[t]{10}{*}{ Multivariate Analyse } & $\begin{array}{c}\text { Beta-Blocker-Vormedi- } \\
\text { kation }\end{array}$ & $1,43(0,52-3,91)$ & 0,492 \\
\hline & Intubationsdauer & $0,8(0,69-0,91)$ & 0,001 \\
\hline & $\begin{array}{l}\text { Immunmodulierende } \\
\text { Vormedikation }\end{array}$ & $4,92(1,2-20,21)$ & 0,027 \\
\hline & Intubation & $1,64(0,38-7,03)$ & 0,504 \\
\hline & andere OP & $0,81(0,18-3,57)$ & 0,775 \\
\hline & Tracheotomie & $1,15(0,19-7,11)$ & 0,88 \\
\hline & Dysphagie & & 0,997 \\
\hline & transurethraler Katheter & & 0,998 \\
\hline & $\begin{array}{l}\text { erfolgreiche Rekanalisa- } \\
\text { tion }\end{array}$ & $0,61(0,22-1,67)$ & 0,339 \\
\hline & Hemikraniektomie & $0,22(0,03-1,45)$ & 0,114 \\
\hline \multicolumn{4}{|l|}{ Sepsis (Leitlinie) } \\
\hline Univariate Analyse & $\begin{array}{l}\text { Beta-Blocker-Vormedi- } \\
\text { kation }\end{array}$ & $1,17(0,6-2,28)$ & 0,648 \\
\hline \multirow[t]{8}{*}{ Multivariate Analyse } & $\begin{array}{l}\text { Beta-Blocker-Vormedi- } \\
\text { kation }\end{array}$ & $0,9(0,37-2,21)$ & 0,818 \\
\hline & Intubationsdauer & $0,8(0,7-0,92)$ & 0,001 \\
\hline & Intubation & $2,08(0,54-8,08)$ & 0,289 \\
\hline & andere $\mathrm{OP}$ & $1(0,28-3,58)$ & 0,995 \\
\hline & naso-gastrale Sonde & $0,74(0,3-1,79)$ & 0,497 \\
\hline & Tracheotomie & $0,78(0,14-4,5)$ & 0,783 \\
\hline & Dysphagie & & 0,997 \\
\hline & transurethraler Katheter & & 0,998 \\
\hline
\end{tabular}




\begin{tabular}{|l|l|c|c|}
\hline & $\begin{array}{l}\text { erfolgreiche Rekanalisa- } \\
\text { tion }\end{array}$ & $1,28(0,51-3,22)$ & 0,603 \\
\hline & Hemikraniektomie & $0,39(0,08-1,94)$ & 0,252 \\
\hline & mRS bei Aufnahme & $1,02(0,63-1,63)$ & 0,948 \\
\hline
\end{tabular}

\subsubsection{Einfluss auf die Entwicklung anderer Infektionen}

In der Betrachtung der Anwesenheit von Risikofaktoren (vgl. Tabelle 17) bei den Patienten, die eine andere Infektion erlitten, konnte beobachtet werden, dass alle dieser Patienten einen transurethralen Katheter hatten $(\mathrm{p}=0,147)$. Eine Dysphagie trat in der betroffenen Patientengruppe ebenso $(p=0,032)$ wie auch eine naso-gastrale Sonde $(p=0,011)$ statistisch signifikant häufiger auf. Patienten mit einer anderen Infektion wurden tendenziell häufiger intubiert $(p=0,084)$. Ein weiterer, nicht zur Standardbehandlung gehörender Eingriff musste auch tendenziell häufiger $(p=0,097)$ durchgeführt werden. Auch die Maßnahmen der Tracheotomie $(\mathrm{p}=0,249)$ oder Hemikraniektomie wurden in dieser Patientengruppe öfter durchgeführt. Für die Hemikraniektomie bestand dabei statistische Signifikanz $(p=0,04)$.

Tabelle 17: Verteilung von Einflussfaktoren für Infektionen bei anderen Infektionen im Patientenkollektiv $(\mathrm{n}=306)$

\begin{tabular}{|c|c|c|c|}
\hline & $\begin{array}{l}\text { Andere Infektion }+ \\
\qquad \mathrm{n}=25\end{array}$ & $\begin{array}{l}\text { Andere Infektion - } \\
\qquad \mathbf{n}=281\end{array}$ & p-Wert \\
\hline $\begin{array}{l}\text { Beta-Blocker in Vormedikation } \\
(\mathrm{n}, \%)\end{array}$ & $11(44)$ & $147(52,3)$ & 0,532 \\
\hline Immunmodulation (n, \%) & $2(8)$ & $23(8,2)$ & 1 \\
\hline naso-gastrale Sonde (n, \%) & $19(76)$ & $137(48,8)$ & 0,011 \\
\hline Dysphagie (n, \%) & $23(92)$ & $203(72,2)$ & 0,032 \\
\hline transurethraler Katheter (n, \%) & $25(100)$ & $255(90,7)$ & 0,147 \\
\hline Intubation (n, \%) & $20(80)$ & $173(61,6)$ & 0,084 \\
\hline Tracheotomie (n, \%) & $4(16)$ & $22(7,8)$ & 0,249 \\
\hline andere $\mathrm{OP}(\mathrm{n}, \%)$ & $8(32)$ & $47(16,7)$ & 0,097 \\
\hline Hemikraniektomie (n, \%) & $\begin{array}{l}5(21,7) \\
\mathrm{n} / \mathrm{a}: 2\end{array}$ & $\begin{array}{l}20(7,7) \\
\text { n/a: } 21\end{array}$ & 0,04 \\
\hline $\begin{array}{l}\text { erfolgreiche Rekanalisation (n, } \\
\% \text { ) }\end{array}$ & $15(60)$ & $\begin{array}{c}207(73,9) \\
\mathrm{n} / \mathrm{a}: 1\end{array}$ & 0,159 \\
\hline
\end{tabular}




\begin{tabular}{|c|c|c|c|}
\hline NIHSS bei Aufnahme (Punkte) & 15,52 & 15,67 & 0,918 \\
\hline mRS bei Aufnahme (Punkte) & 4,4 & 4,32 & 0,663 \\
\hline Alter (Jahre) & 70,1 & 71,7 & 0,55 \\
\hline $\begin{array}{l}\text { Geschlecht (männlich (n, \%), } \\
\text { weiblich }(n, \%) \text { ) }\end{array}$ & $\begin{array}{l}12(48) \\
13(52)\end{array}$ & $\begin{array}{l}136(48,4) \\
145(51,6)\end{array}$ & 1 \\
\hline
\end{tabular}

Es stellte sich heraus, dass Patienten, die eine andere Infektion erlitten, eine statistisch signifikant längere Intubationsdauer $(p=0,011)$ und Verweildauer im Krankenhaus $(p=0,005)$ besaßen (vgl. Abbildung 9).

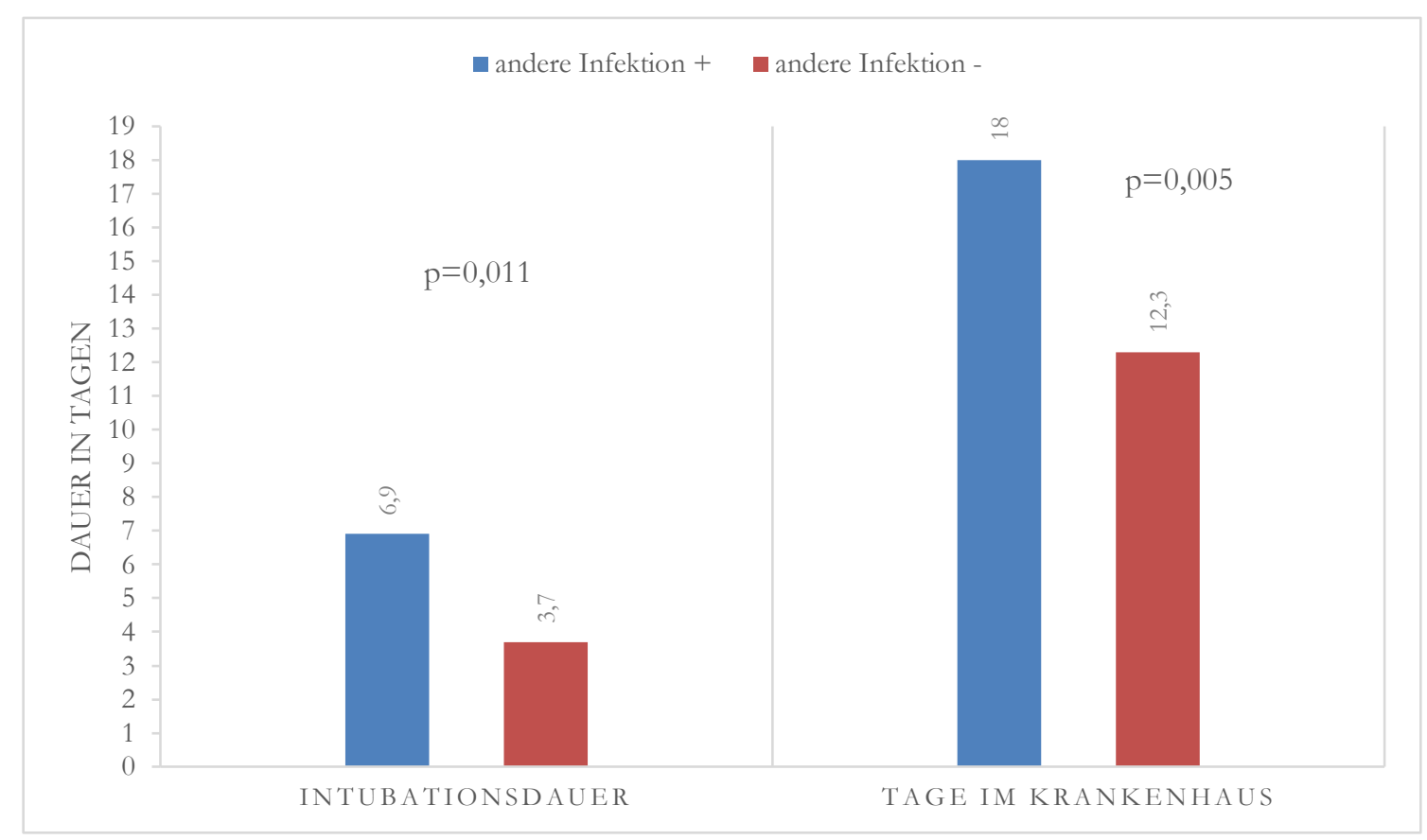

Abbildung 9: Intubationsdauer und Krankenhausaufenthalt in Tagen bei anderen Infektionen im Patientenkollektiv $(\mathrm{n}=306)$

In der univariaten und multivariaten logistische Regression für den Endpunkt andere Infektion wurde zusätzlich zu den relevanten Konfoundern ( $p<0,2$ im Vortest) hinsichtlich der Fragestellung eine Beta-Blocker-Vormedikation miteinbezogen und die Krankenhausaufenthaltsdauer aus der Analyse ausgeschlossen. Dort wies sich ein rechtshirniger Schlaganfall als signifikanter Risikofaktor auf ( $\mathrm{p}=0,01$, OR 3,89, vgl. Tabelle 18). 
Tabelle 18: Ergebnisse der univariaten und multivariaten logistischen Regression nach der Methode Einschluss für den Endpunkt andere Infektion

\begin{tabular}{|c|c|c|c|}
\hline & & OR $(95 \% \mathrm{KI})$ & p-Wert \\
\hline \multicolumn{4}{|l|}{ Andere Infektion } \\
\hline Univariate Analyse & $\begin{array}{c}\text { Beta-Blocker Vormedi- } \\
\text { kation }\end{array}$ & $0,72(0,31-1,63)$ & 0,427 \\
\hline \multirow[t]{10}{*}{ Multivariate Analyse } & $\begin{array}{c}\text { Beta-Blocker Vormedi- } \\
\text { kation }\end{array}$ & $0,7(0,25-1,93)$ & 0,488 \\
\hline & Dysphagie & $3,84(0,39-37,98)$ & 0,25 \\
\hline & andere OP & $1,24(0,25-6,14)$ & 0,795 \\
\hline & Hemikraniektomie & $1,45(0,26-8,01)$ & 0,668 \\
\hline & naso-gastrale Sonde & $1,78(0,54-5,81)$ & 0,342 \\
\hline & Intubation & $0,96(0,28-3,27)$ & 0,952 \\
\hline & Intubationsdauer & $0,97(0,88-1,07)$ & 0,569 \\
\hline & transurethraler Katheter & & 0,998 \\
\hline & Seite des Schlaganfalls & $3,89(1,39-10,88)$ & 0,01 \\
\hline & $\begin{array}{l}\text { erfolgreiche Rekanalisa- } \\
\text { tion }\end{array}$ & $0,9(0,31-2,57)$ & 0,84 \\
\hline
\end{tabular}

\subsubsection{Einfluss auf die Mortalität}

Bei der Untersuchung des Vorkommens der Risikofaktoren in der verstorbenen und nicht verstorbenen Patientengruppe ergaben sich signifikante Unterschiede (vgl. Tabelle 19). Patienten, die zum Entlassungszeitpunkt verstorben waren, wiesen signifikant häufiger eine Dysphagie $(p<0,001)$, einen transurethralen Katheter $(p=0,022)$ und eine Intubation $(p=0,002)$ auf. Außerdem war diese Population stärker von dem Schlaganfall beeinträchtigt, wie die signifikanten bzw. tendenziellen Unterschiede bei dem NIHSS-Wert bei Aufnahme $(p=0,002)$ oder posttherapeutisch $(p<0,001)$ und mRS-Wert bei Aufnahme $(p=0,067)$ belegen (vgl. Abbildung 10). Zudem zeigte sich die Patientengruppe signifikant älter $(p=0,003)$. Dahingegen bekamen die überlebenden Patienten statistisch signifikant häufiger eine nasogastrale Sonde $(p=0,024)$, wurden häufiger erfolgreich rekanalisiert $(p<0,001)$ und blieben länger im Krankenhaus ( $\mathrm{p}<0,001)$. 
Tabelle 19: Verteilung der Einflussfaktoren in Bezug auf die Mortalität im Patientenkollektiv $(\mathrm{n}=306)$ in $\%$

\begin{tabular}{|c|c|c|c|}
\hline & $\begin{array}{l}\text { Tod }+ \\
n=64\end{array}$ & $\begin{array}{l}\text { Tod - } \\
\mathrm{n}=242\end{array}$ & p-Wert \\
\hline $\begin{array}{l}\text { Beta-Blocker in Vormedikation } \\
(\mathrm{n}, \%)\end{array}$ & $38(59,4)$ & $120(49,6)$ & 0,206 \\
\hline Immunmodulation ( $\mathrm{n}, \%)$ & $8(12,5)$ & $17(7)$ & 0,197 \\
\hline naso-gastrale Sonde (n, \%) & $24(38,1)$ & $131(54,1)$ & 0,024 \\
\hline Dysphagie (n, \%) & $62(96,9)$ & $163(67,4)$ & $<0,001$ \\
\hline transurethraler Katheter (n, \%) & $63(98,4)$ & $216(89,3)$ & 0,022 \\
\hline Intubation $(\mathrm{n}, \%)$ & $51(79,7)$ & $141(58,3)$ & 0,002 \\
\hline Intubationsdauer (Tage) & 3,2 & 2,4 & 0,174 \\
\hline Tracheotomie (n, \%) & $2(3,1)$ & $23(9,5)$ & 0,124 \\
\hline andere $\mathrm{OP}(\mathrm{n}, \%)$ & $11(17,2)$ & $43(17,8)$ & 1 \\
\hline Hemikraniektomie (n, \%) & $\begin{array}{l}6(11,1) \\
\mathrm{n} / \mathrm{a}: 10\end{array}$ & $\begin{array}{l}18(7,9) \\
\text { n/a: } 14\end{array}$ & 0,424 \\
\hline $\begin{array}{l}\text { erfolgreiche Rekanalisation (n, } \\
\% \text { ) }\end{array}$ & $34(53,1)$ & $188(77,7)$ & $<0,001$ \\
\hline Tage im Krankenhaus & 6,5 & 14,3 & $<0,001$ \\
\hline NIHSS bei Aufnahme (Punkte) & 18,1 & 15,05 & 0,002 \\
\hline $\begin{array}{l}\text { NIHSS posttherapeutisch } \\
\text { (Punkte) }\end{array}$ & 23,03 & 13,2 & $<0,001$ \\
\hline mRS bei Aufnahme (Punkte) & 4,51 & 4,27 & 0,067 \\
\hline Alter (Jahre) & 75,9 & 70,5 & 0,003 \\
\hline $\begin{array}{l}\text { Geschlecht (männlich (n, \%), } \\
\text { weiblich }(n, \%) \text { ) }\end{array}$ & $\begin{array}{l}28(43,8) \\
36(56,2)\end{array}$ & $\begin{array}{l}120(49,6) \\
122(50,4)\end{array}$ & 0,482 \\
\hline
\end{tabular}




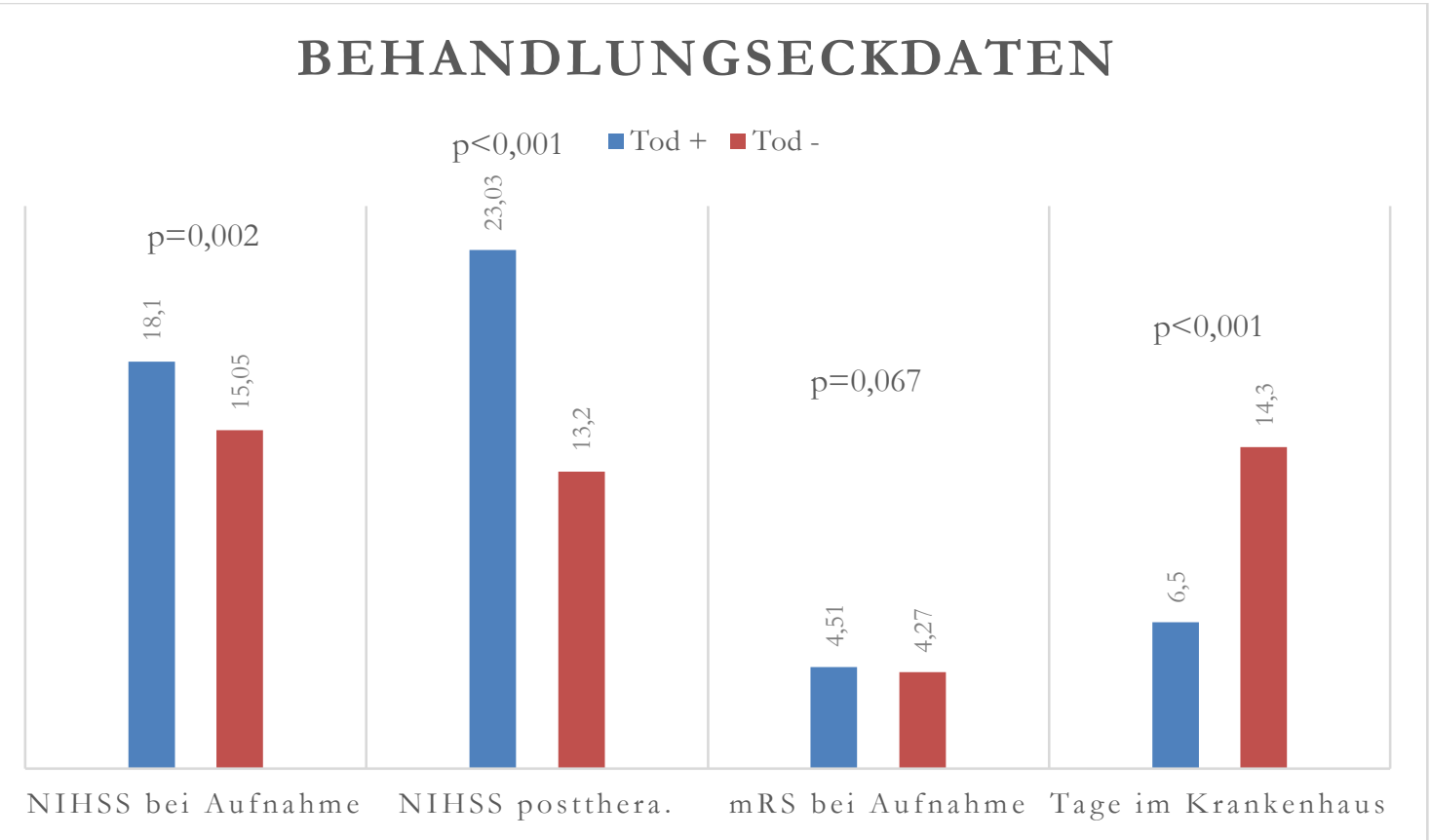

Abbildung 10: Behandlungseckdaten der verstorbenen und nicht verstorbenen Patienten $(\mathrm{n}=306)$

In der univariaten und multivariaten logistischen Regression nach der Methode „Einschluss“ wurde eine Beta-Blocker-Vormedikation erneut automatisch einbezogen, wohingegen die Krankenhausaufenthaltsdauer ausgeschlossen wurde. Des Weiteren wurde aufgrund des Polaritätsprinzips nur der NIHSS-Wert bei Aufnahme berücksichtigt und dem mRS-Wert bei Aufnahme vorgezogen. Ansonsten wurden alle relevanten Konfounder $(p<0,2)$ des Vortests eingeschlossen. In der Regression fiel eine Dysphagie ( $p=0,009$, OR 13,52) und Intubation $(p=0,015$, OR 3,08) als unabhängige Prädiktoren für ein Versterben während des Krankenhausaufenthaltes auf. Ein jüngeres Alter ( $\mathrm{p}=0,04$, OR 0,96), eine erfolgreiche Rekanalisation $(\mathrm{p}=0,018$, OR 0,38$)$ und eine naso-gastrale Sonde $(\mathrm{p}<0,001$, OR 0,24$)$ zeigten sich als protektive Faktoren (vgl. Tabelle 20).

Tabelle 20: Ergebnisse der univariaten und multivariaten logistischen Regression nach der Methode Einschluss für den Endpunkt Tod

\begin{tabular}{|c|c|c|c|}
\hline \multicolumn{1}{|c|}{ Tod } & OR (95\% KI) & p-Wert \\
\hline Univariate Analyse & $\begin{array}{r}\text { Beta-Blocker-Vormedika- } \\
\text { tion }\end{array}$ & $1,47(0,84-2,58)$ & 0,174 \\
\hline Multivariate Analyse & $\begin{array}{r}\text { Beta-Blocker-Vormedika- } \\
\text { tion }\end{array}$ & $1,69(0,75-3,81)$ & 0,203 \\
\hline & erfolgreiche Rekanalisation & $0,38(0,17-0,84)$ & $\mathbf{0 , 0 1 8}$ \\
\hline & NIHSS bei Aufnahme & $0,99(0,93-1,05)$ & 0,739 \\
\hline
\end{tabular}




\begin{tabular}{|l|l|c|c|}
\hline & Alter & $0,96(0,93-1)$ & $\mathbf{0 , 0 4}$ \\
\hline & Dysphagie & $13,52(1,9-96,34)$ & $\mathbf{0 , 0 0 9}$ \\
\hline Seite des Schlaganfalls & $0,54(0,25-1,18)$ & 0,124 \\
\hline & Immunmodulation & $1,85(0,48-7,09)$ & 0,373 \\
\hline & naso-gastrale Sonde & $0,24(0,11-0,53)$ & $<\mathbf{0 , 0 0 1}$ \\
\hline & transurethraler Katheter & $0,47(0,03-6,77)$ & 0,576 \\
\hline & Intubation & $3,08(1,24-7,62)$ & $\mathbf{0 , 0 1 5}$ \\
\hline & Intubationsdauer & $1(0,9-1,1)$ & 0,936 \\
\hline Tracheotomie & $0,32(0,04-2,73)$ & 0,299 \\
\hline
\end{tabular}

\subsection{Einfluss der Seite des Schlaganfalls}

Bei insgesamt 264 Patienten lagen Daten zur Seite des Gefäßverschlusses vor, die im Folgenden analysiert wurde. Bei 113 Patienten (42,8\%) war die rechte und bei 151 Patienten $(57,2 \%)$ die linke Gehirnhälfte von dem Schlaganfall betroffen. Zwischen der Beta-Blockerpositiven und -negativen Gruppe gab es hinsichtlich der Lateralisierung keine signifikanten Unterschiede (vgl. Tabelle 21, $\mathrm{p}=0$,214).

Tabelle 21: Verteilung der betroffenen Seite der Beta-Blocker-positiven und -negativen Gruppe $(n=260)$

\begin{tabular}{|l|l|l|}
\hline & Rechts & Links \\
$\mathbf{n = 1 1 3}$ & $\mathbf{n = 1 5 1}$ \\
\hline $\begin{array}{l}\text { BB (+) (n, } \\
\mathbf{\%})\end{array}$ & $52(46)$ & $82(54,3)$ \\
\hline $\begin{array}{l}\text { BB (-) (n, } \\
\mathbf{0})\end{array}$ & $61(54,3)$ & $69(45,7)$ \\
\hline
\end{tabular}

Wie Tabelle $22 \mathrm{zu}$ entnehmen ist, erlitten Patienten mit rechtshirnigem Infarkt signifikant häufger eine andere Infektion ( $p=0,014)$ und tendenziell häufiger eine Pneumonie nach Arztbrief $(p=0,082)$. Auch eine Pneumonie nach Leitlinie trat bei rechtshirnigen Infarkten häufiger auf $(p=0,121)$. Zum Zeitpunkt der Entlassung waren Patienten mit Schlaganfällen, deren Gefäßverschluss auf der linken Gehirnhälfte lokalisiert war, tendenziell häufiger verstorben als Patienten mit Verschlüssen der rechten Gehirnhälfte $(p=0,061)$. Bei den übrigen Endpunkten Harnwegsinfekt nach Arztbrief oder Leitlinie und Sepsis nach Arztbrief oder Leitlinie fanden sich keine wesentlichen Unterschiede. 
Tabelle 22: Seitenverteilung in Bezug auf die Infektionsraten und Mortalität im Patientenkollektiv $(n=260)$

\begin{tabular}{|l|c|c|c|}
\hline & Rechts & Links & p-Wert \\
\hline Pneumonie (AB) (n, \%) & $\mathbf{n = 1 1 3}$ & $\mathbf{n}=151$ & 0,082 \\
\hline Harnwegsinfekt (AB) (n, \%) & $58(51,3)$ & $61(40,4)$ & 0,51 \\
\hline Sepsis (AB) (n, \%) & $17(15)$ & $28(18,5)$ & 1 \\
\hline Pneumonie (LL) (n, \%) & $11(9,7)$ & $14(9,3)$ & 0,121 \\
\hline Harnwegsinfekt (LL) (n, \%) & $36(31,9)$ & $34(22,7)$ & 1 \\
\hline Sepsis (LL) (n, \%) & $29(25,7)$ & $39(25,8)$ & 1 \\
\hline Andere Infektion (n, \%) & $14(12,4)$ & $19(12,6)$ & $\mathbf{0 , 0 1 4}$ \\
\hline Mortalität bei Entlassung (n, \%) & $16(13,3)$ & $7(4,6)$ & 0,061 \\
\hline
\end{tabular}

Als weiterer Schritt wurde untersucht, ob in der Beta-Blocker-positiven oder -negativen Gruppe eine bestimmte Seite des Gefäßverschlusses häufiger von Infektion betroffen war (vgl. Tabelle 23 und

Tabelle 24). In der Beta-Blocker einnehmenden Population zeigte sich, dass bei den rechtshirnigen Infarkten statistisch signifikant häufiger eine Pneumonie nach Arztbrief $(p=0,013)$ auftrat. In der Patientengruppe, die keinen Beta-Blocker einnahm, entwickelte sich signifikant öfter eine andere Infektion $(p=0,001)$. Für die weiteren Endpunkte ergaben sich keine signifikanten Auffälligkeiten.

Tabelle 23: Seitenverteilung in Bezug auf die Infektionsraten und Mortalität in der Beta-Blocker-positiven Gruppe ( $\mathrm{n}=134)$

\begin{tabular}{|l|c|c|c|}
\hline & rechts & links & p-Wert \\
\hline Pneumonie (AB) (n, \%) & $32(61,5)$ & $32(39)$ & $\mathbf{0 , 0 1 3}$ \\
\hline Harnwegsinfekt (AB) (n, \%) & $10(19,2)$ & $15(18,3)$ & 1 \\
\hline Sepsis (AB) (n, \%) & $4(7,7)$ & $9(11)$ & 0,766 \\
\hline Pneumonie (LL) (n, \%) & $17(32,7)$ & $17(21)$ & 0,156 \\
\hline Harnwegsinfekt (LL) (n, \%) & $17(32,7)$ & $23(28)$ & 0,568 \\
\hline Sepsis (LL) (n, \%) & $5(9,6)$ & $11(13,4)$ & 0,593 \\
\hline Andere Infektion (n, \%) & $3(5,8)$ & $6(7,3)$ & 1 \\
\hline Mortalität bei Entlassung & $10(19,2)$ & $22(26,8)$ & 0,407 \\
\hline
\end{tabular}


Tabelle 24: Seitenverteilung in Bezug auf die Infektionsraten und Mortalität in der Beta-Blocker-negativen Gruppe ( $\mathrm{n}=130$ )

\begin{tabular}{|l|c|c|c|}
\hline & rechts & links & p-Wert \\
\hline Pneumonie (AB) (n, \%) & $26(42,6)$ & $29(42)$ & 1 \\
\hline Harnwegsinfekt (AB) (n, \%) & $7(11,5)$ & $13(18,8)$ & 0,331 \\
\hline Sepsis (AB) (n, \%) & $7(11,5)$ & $5(7,2)$ & 0,546 \\
\hline Pneumonie (LL) (n, \%) & $19(31,1)$ & $17(24,6)$ & 0,438 \\
\hline Harnwegsinfekt (LL) (n, \%) & $12(19,7)$ & $16(23,2)$ & 0,674 \\
\hline Sepsis (LL) (n, \%) & $9(14,8)$ & $8(11,6)$ & 0,613 \\
\hline Andere Infektion (n, \%) & $12(19,7)$ & $1(1,4)$ & $\mathbf{0 , 0 0 1}$ \\
\hline Mortalität bei Entlassung & $6(10)$ & $14(20,3)$ & 0,144 \\
\hline
\end{tabular}

\subsection{Analyse von Subgruppen}

\subsubsection{Subgruppen nach ASPECTS}

Im nächsten Abschnitt wurden die Infektionsraten und Mortalität der Beta-Blocker-positiven sowie -negativen Gruppe in Subpopulationen, die nach ASPECTS Punkten im CT des Schädels nach 24 Stunden erstellt wurden, verglichen. Insgesamt lagen bei 213 Patienten des Kollektivs Daten zu dem ASPECTS vor. In der ersten Subgruppe mit einem ASPECTS $=<7$ fanden sich $141(66,2 \%)$ und in der zweiten Subgruppe mit einem ASPECTS $=<579$ Patienten $(37,1 \%)$ wieder.

Hinsichtlich der Infektionsraten und der Mortalität ergaben sich zwischen der Beta-Blockerpositiven und -negativen Gruppe in der Subpopulation mit einem ASPECTS $=<7$ nach 24 Stunden keine signifikanten Unterschiede (vgl. Tabelle 25). In der Subpopulation mit einem ASPECTS $=<5$ nach 24 Stunden zeigten sich ebenso keine signifikanten Unterschiede hinsichtlich der Verteilung der Infektionen und Mortalität (vgl. Tabelle 26).

Tabelle 25: Verteilung der Infektionsrate und Mortalität in der Beta-Blocker-positiven und negativen Gruppe in der Subgruppe mit einem ASPECTS im CT nach 24 Stunden von $=<7$ Punkten $(\mathrm{n}=141)$

\begin{tabular}{|l|c|c|c|}
\hline & BB (+) & BB (-) & p-Wert \\
$\mathbf{n}=\mathbf{7 8}$ & $49(62,8)$ & $36(57,1)$ & 0,604 \\
\hline Pneumonie (AB) (n, \%) & $17(21,8)$ & $12(19)$ & 0,834 \\
\hline Harnwegsinfekt (AB) (n, \%) & $12(15,4)$ & $9(14,3)$ & 1 \\
\hline Sepsis (AB) (n, \%) & $28(35,9)$ & $27(42,9)$ & 0,488 \\
\hline Pneumonie (LL) (n, \%) & & \\
\hline
\end{tabular}




\begin{tabular}{|l|c|c|c|}
\hline Harnwegsinfekt (LL) (n, \%) & $28(35,9)$ & $17(27)$ & 0,281 \\
\hline Sepsis (LL) (n, \%) & $15(19,2)$ & $12(19)$ & 1 \\
\hline Andere Infektion (n, \%) & $7(9)$ & $8(12,7)$ & 0,586 \\
\hline Mortalität bei Entlassung (n, \%) & $23(29,5)$ & $14(22,2)$ & 0,344 \\
\hline
\end{tabular}

Tabelle 26: Verteilung der Infektionsrate und Mortalität in der Beta-Blocker-positiven und negativen Gruppe in der Subgruppe mit einem ASPECTS im CT nach 24 Stunden von $=<5$ Punkten $(\mathrm{n}=79)$

\begin{tabular}{|l|c|c|c|}
\hline & $\begin{array}{c}\text { BB (+) } \\
\mathbf{n = 4 2}\end{array}$ & $\begin{array}{c}\text { BB (-) } \\
\mathbf{n = 3 7}\end{array}$ & p-Wert \\
\hline Pneumonie (AB) (n, \%) & $27(64,3)$ & $26(70,3)$ & 0,636 \\
\hline Harnwegsinfekt (AB) (n, \%) & $8(19)$ & $5(13,5)$ & 0,558 \\
\hline Sepsis (AB) (n, \%) & $7(16,7)$ & $6(16,2)$ & 1 \\
\hline Pneumonie (LL) (n, \%) & $17(40,5)$ & $19(51,4)$ & 0,372 \\
\hline Harnwegsinfekt (LL) (n, \%) & $16(38,1)$ & $8(21,6)$ & 0,144 \\
\hline Sepsis (LL) (n, \%) & $10(23,8)$ & $8(21,6)$ & 1 \\
\hline Andere Infektion (n, \%) & $3(7,1)$ & $3(8,1)$ & 1 \\
\hline Mortalität bei Entlassung (n, \%) & $13(31)$ & $10(27)$ & 0,806 \\
\hline
\end{tabular}

\subsubsection{Subgruppe nach Lokalisation}

Im Weiteren wurde anhand der CT-Bilder nach dem Schlaganfall nach dem ASPECTS (vgl. Kapitel 2.5) eingeordnet, ob das Gebiet des insulären Kortex, das M1 - und M4-Gebiet der A. cerebri media betroffen war. Diese Gruppen wurden dann hinsichtlich der Endpunkte verglichen. Von den 213 Patienten wiesen 135 (63,4\%) eine Schädigung der Insel, 98 (46\%) eine Schädigung der M1- und 84 Patienten (39,4\%) eine Schädigung der M4-Region auf.

Die Patienten mit Schädigung der Insel entwickelten signifikant öfter eine Pneumonie $(\mathrm{p}<0,001)$ und eine Sepsis (Sepsis AB p =0,031, Sepsis LL p =0,006, vgl. Tabelle 27). Im Vergleich der Beta-Blocker-positiven sowie -negativen Gruppe innerhalb der Population mit Schädigung des Inselkortexes' ergaben sich bezüglich der Infektionsrate und Mortalität keine signifikanten Unterschiede (vgl. Tabelle 28). 
Tabelle 27: Verteilung der Infektionsrate und Mortalität verglichen bei Patienten mit und ohne Schädigung des insulären Kortex $(\mathrm{n}=213)$

\begin{tabular}{|l|c|c|c|}
\hline & Insel + & Insel - & p-Wert \\
\hline Pneumonie (AB) (n, \%) & $\mathbf{n = 1 3 5}$ & $\mathbf{n = 7 8}$ & $<\mathbf{0 , 0 0 1}$ \\
\hline Harnwegsinfekt (AB) (n, \%) & $76(56,3)$ & $23(29,5)$ & 0,857 \\
\hline Sepsis (AB) (n, \%) & $27(20)$ & $14(17,9)$ & $\mathbf{0 , 0 3 1}$ \\
\hline Pneumonie (LL) (n, \%) & $18(13,3)$ & $3(3,8)$ & $<\mathbf{0 , 0 0 1}$ \\
\hline Harnwegsinfekt (LL) (n, \%) & $49(36,3)$ & $11(14,1)$ & 1 \\
\hline Sepsis (LL) (n, \%) & $41(30,4)$ & $23(29,5)$ & $\mathbf{0 , 0 0 6}$ \\
\hline Andere Infektion (n, \%) & $25(18,5)$ & $4(5,1)$ & 1 \\
\hline Mortalität bei Entlassung (n, \%) & $12(8,9)$ & $7(9)$ & $<0,001$ \\
\hline
\end{tabular}

Tabelle 28: Verteilung der Infektionsrate und Mortalität in der Beta-Blocker-positiven sowie -negativen Gruppe in der Subgruppe mit Schädigung des insulären Kortex $(n=135)$

\begin{tabular}{|l|c|c|c|}
\hline & BB (+) & BB (-) & p-Wert \\
\hline Pneumonie (AB) (n, \%) & $\mathbf{n = 7 3}$ & 0,862 \\
\hline Harnwegsinfekt (AB) (n, \%) & $42(57,5)$ & $34(54,8)$ & 0,667 \\
\hline Sepsis (AB) (n, \%) & $16(21,9)$ & $11(17,7)$ & 1 \\
\hline Pneumonie (LL) (n, \%) & $10(13,7)$ & $8(12,9)$ & 0,216 \\
\hline Harnwegsinfekt (LL) (n, \%) & $23(31,5)$ & $26(41,9)$ & 0,349 \\
\hline Sepsis (LL) (n, \%) & $25(34,2)$ & $16(25,8)$ & 0,828 \\
\hline Andere Infektion (n, \%) & $13(17,8)$ & $12(19,4)$ & 0,384 \\
\hline Mortalität bei Entlassung (n, \%) & $21(28,8)$ & $7(11,3)$ & 0,438 \\
\hline
\end{tabular}

Bei Patienten, deren ischämischer Schlaganfall die Region der Insel und das M1-Gebiet betraf $(\mathrm{n}=90)$, zeigte sich eine signifikant höhere Rate an Pneumonien $(\mathrm{p}<0,001)$ und Sepsis (Sepsis AB p=0,005, Sepsis LL 0,002, vgl. Tabelle 29). Hinsichtlich der Verteilung der Infektionen bei diesen Patienten ergaben sich zwischen der Beta-Blocker-positiven und -negativen Gruppe keine signifikanten Unterschiede. Die Beta-Blocker-positive Population erlitt lediglich tendenziell häufiger einen Harnwegsinfekt nach Leitlinie ( $p=0,069$, vgl. Tabelle 30). 
Tabelle 29: Verteilung der Infektionsrate und Mortalität verglichen bei Patienten mit und ohne Schädigung des Gebietes des insulären Kortexes’ und der M1-Region ( $\mathrm{n}=213$ )

\begin{tabular}{|l|c|c|c|}
\hline & Insel und M1 & Insel und M1 - & p-Wert \\
\hline Pneumonie (AB) (n, \%) & $\mathbf{n = 9 0}$ & $<\mathbf{0 3}$ \\
\hline Harnwegsinfekt (AB) (n, \%) & $63(70)$ & $36(29,3)$ & 0,726 \\
\hline Sepsis (AB) (n, \%) & $16(17,8)$ & $25(20,3)$ & $\mathbf{0 , 0 0 5}$ \\
\hline Pneumonie (LL) (n, \%) & $15(16,7)$ & $6(4,9)$ & $<\mathbf{0 , 0 0 1}$ \\
\hline Harnwegsinfekt (LL) (n, \%) & $42(46,7)$ & $36(29,3)$ & 0,88 \\
\hline Sepsis (LL) (n, \%) & $28(31,1)$ & $9(7,3)$ & $\mathbf{0 , 0 0 2}$ \\
\hline Andere Infektion (n, \%) & $20(22,2)$ & $11(8,9)$ & 1 \\
\hline Mortalität bei Entlassung (n, \%) & $8(8,9)$ & $6(4,9)$ & $<\mathbf{0 , 0 0 1}$ \\
\hline
\end{tabular}

Tabelle 30: Verteilung der Infektionsrate und Mortalität in der Beta-Blocker-positiven sowie -negativen Gruppe in der Subgruppe mit Schädigung des insulären Kortexes und M1-Gebietes $(\mathrm{n}=90)$

\begin{tabular}{|l|c|c|c|}
\hline & BB (+) & BB (-) & p-Wert \\
\hline Pneumonie (AB) (n, \%) & $\mathbf{n}=\mathbf{3 9}$ & 1 \\
\hline Harnwegsinfekt (AB) (n, \%) & $36(70,6)$ & $27(69,2)$ & 0,163 \\
\hline Sepsis (AB) (n, \%) & $12(23,5)$ & $4(10,3)$ & 0,783 \\
\hline Pneumonie (LL) (n, \%) & $8(15,7)$ & $7(17,9)$ & 0,288 \\
\hline Harnwegsinfekt (LL) (n, \%) & $21(41,2)$ & $21(53,8)$ & 0,069 \\
\hline Sepsis (LL) (n, \%) & $20(39,2)$ & $8(20,5)$ & 1 \\
\hline Andere Infektion (n, \%) & $11(21,6)$ & $9(23,1)$ & 1 \\
\hline Mortalität bei Entlassung (n, \%) & $19(37,3)$ & $3(7,7)$ & 1 \\
\hline
\end{tabular}

Das identische Ergebnis zeigte sich bei der Analyse der Subgruppe, die eine Schädigung der Insel sowie des M1 - und M4-Region erlitten hatten. Die Patienten wiesen höhere Raten an Pneumonien $(p<0,001)$ und Sepsis (Sepsis AB p =0,003, Sepsis LL p=0,001) auf (vgl. Tabelle 31). Beim Vergleich dieser Subpopulation hinsichtlich der Infektionsraten bei Beta-Blockerpositiven und -negativen Patienten zeigten sich keine Signifikanzen. Die Beta-Blocker einnehmende Gruppe wies eine lediglich tendenziell höhere Rate an Harnwegsinfekten auf $(p=0,079$, vgl. Tabelle 32). 
Tabelle 31: Verteilung der Infektionsrate und Mortalität verglichen bei Patienten mit und ohne Schädigung des Gebietes des insulären Kortexes', der M1 - und M4-Region ( $\mathrm{n}=213$ )

\begin{tabular}{|l|c|c|c|}
\hline & $\begin{array}{r}\text { Insel, M1 und M4 + } \\
\mathbf{n = 7 7}\end{array}$ & $\begin{array}{c}\text { Insel, M1 und M4 - } \\
\mathbf{n = 1 3 6}\end{array}$ & p-Wert \\
\hline Pneumonie (AB) (n, \%) & $53(68,8)$ & $46(33,8)$ & 0,001 \\
\hline Harnwegsinfekt (AB) (n, \%) & $13(16,9)$ & $28(20,6)$ & 0,589 \\
\hline Sepsis (AB) (n, \%) & $14(18,2)$ & $7(5,1)$ & $\mathbf{0 , 0 0 3}$ \\
\hline Pneumonie (LL) (n, \%) & $37(48,1)$ & $23(16,9)$ & $<\mathbf{0 , 0 0 1}$ \\
\hline Harnwegsinfekt (LL) (n, \%) & $24(31,2)$ & $40(29,4)$ & 0,877 \\
\hline Sepsis (LL) (n, \%) & $19(24,7)$ & $10(7,4)$ & $\mathbf{0 , 0 0 1}$ \\
\hline Andere Infektion (n, \%) & $7(9,1)$ & $12(8,8)$ & 1 \\
\hline Mortalität bei Entlassung (n, \%) & $32(41,6)$ & $7(5,1)$ & $<\mathbf{0 , 0 0 1}$ \\
\hline
\end{tabular}

Tabelle 32: Verteilung der Infektionsrate und Mortalität in der Beta-Blocker-positiven sowie -negativen Gruppe in der Subgruppe mit Schädigung des insulären Kortexes, M1-und M4Gebietes ( $\mathrm{n}=77$ )

\begin{tabular}{|l|c|c|c|}
\hline & BB (+) & BB (-) & p-Wert \\
\hline Pneumonie (AB) (n, \%) & n=45 & 1 \\
\hline Harnwegsinfekt (AB) (n, \%) & $31(68,9)$ & $22(68,8)$ & 0,217 \\
\hline Sepsis (AB) (n, \%) & $10(22,2)$ & $3(9,4)$ & 1 \\
\hline Pneumonie (LL) (n, \%) & $8(17,8)$ & $6(18,8)$ & 0,254 \\
\hline Harnwegsinfekt (LL) (n, \%) & $19(42,2)$ & $18(56,3)$ & 0,079 \\
\hline Sepsis (LL) (n, \%) & $18(40)$ & $6(18,8)$ & 1 \\
\hline Andere Infektion (n, \%) & $11(24,4)$ & $8(25)$ & 1 \\
\hline Mortalität bei Entlassung (n, \%) & $4(8,9)$ & $3(9,4)$ & 0,816 \\
\hline
\end{tabular}

\subsection{Laborparameter der BB(+) und BB(-)-Gruppe}

Beim Vergleich der Entzündungswerte im Blut von Patienten der Beta-Blocker-positiven und -negativen Gruppe stellten sich keine wesentlichen Unterschiede heraus (vgl. Tabelle 33). 
Tabelle 33: Laborparameter der BB(+)- und BB(-)-Gruppe

\begin{tabular}{|c|c|c|c|}
\hline & $\begin{array}{c}\text { Beta-Blocker }+ \\
n=158\end{array}$ & $\begin{array}{l}\text { Beta-Blocker - } \\
\qquad n=147\end{array}$ & p-Wert \\
\hline $\begin{array}{l}\text { Leukozyten-Maximum } \\
(\text { Anzahl/*10^3 } \mu 1, \mathrm{SD})\end{array}$ & $13510(+-5221)$ & $13460(+-5688)$ & 0,936 \\
\hline $\begin{array}{l}\text { Leukozyten-Minimum (An- } \\
\text { zahl/ } \mu 1, \mathrm{SD})\end{array}$ & $7184(+-2545)$ & $7230(+-2607)$ & 0,878 \\
\hline Delta-Leukozyten & 6,33 & 6,23 & \\
\hline $\begin{array}{l}\text { CRP-Maximum } \quad(\mathrm{mg} / \mathrm{dl} \text {, } \\
\text { SD) }\end{array}$ & $\begin{array}{c}53,32(+-61,65) \\
\text { n/a: } 9\end{array}$ & $\begin{array}{c}55,71(+-72,54) \\
\mathrm{n} / \mathrm{a}: 16\end{array}$ & 0,766 \\
\hline $\begin{array}{l}\text { CRP-Minimum } \quad(\mathrm{mg} / \mathrm{dl} \text {, } \\
\mathrm{SD})\end{array}$ & $\begin{array}{c}14,64(+-29,47) \\
\text { n/a: } 9\end{array}$ & $\begin{array}{c}13,79(+-25,76) \\
\text { n/a: } 16\end{array}$ & 0,798 \\
\hline PCT-Maximum $(\mu \mathrm{g} / 1, \mathrm{SD})$ & $\begin{array}{c}1,19(+-3,47) \\
\text { n/a: } 42\end{array}$ & $\begin{array}{c}1,11(+-3,71) \\
\text { n/a: } 44\end{array}$ & 0,875 \\
\hline PCT-Minimum $(\mu \mathrm{g} / 1, \mathrm{SD})$ & $\begin{array}{c}0,19(0,21) \\
\text { n/a: } 42\end{array}$ & $\begin{array}{l}0,16(0,2) \\
\text { n/a: } 44\end{array}$ & 0,32 \\
\hline
\end{tabular}




\section{Diskussion}

Der Schlaganfall ist für sich genommen und mit seinen Folgen eine häufige und vor allem lebensverändernde Erkrankung. Die durchschnittliche Lebenserwartung steigt in den Industrieländern aufgrund der vielfältigen medizinischen Behandlungsmöglichkeiten weiter an. Doch mit steigendem Alter, zunehmenden Komorbiditäten und arteriosklerotischen Veränderungen erhöht sich unter anderem auch das Risiko für eine zerebro-vaskuläre Erkrankung (Asplund et al. 2009). Der Schlaganfall zählt weiter zu den führenden Todesursachen, auch wenn seine Mortalität in den letzten Jahren aus verschiedenen Gründen abgenommen hat (Lozano et al. 2012; Lackland et al. 2014). Obgleich der Schlaganfall seltener zum Tode führt, sind seine gesundheitlichen Folgen und Einschränkungen massiv. Er gehört zu den häufigsten Ursachen für Behinderungen und Pflegebedürftigkeit (Kolominsky-Rabas et al. 2006; Murray et al. 2012). In der Frühphase nach einem Schlaganfall tragen insbesondere Infektionen zu der Prognose und Rehabilitation der Patienten bei. Sie treten dabei als eine häufige Komplikation auf und bedürfen folglich größtmöglicher Prävention. Als zukünftige Präventivmaßnahme ist die Möglichkeit, in die schlaganfallinduzierte Immunmodulation einzugreifen, Gegenstand aktueller Untersuchungen. In experimentellen Versuchen wirkte sich die Verabreichung von Beta-Blockern nach einem Schlaganfall protektiv gegenüber der Entwicklung von Infektionen oder der Sterblichkeit aus (Prass et al. 2003). In den folgenden Abschnitten sollen die Ergebnisse der Analyse des untersuchten Patientenkollektivs erklärt, interpretiert und mit anderen, schon bestehenden Studien verglichen werden.

\subsection{Pneumonierate}

Bei der Analyse der Pneumonieraten stach besonders hervor, dass in den Arztbriefen bei $50 \%$ aller Beta-Blocker-Patienten eine Pneumonie dokumentiert war und sich der Unterschied zu der Gruppe ohne Beta-Blocker-Vormedikation (39,9\%) tendenziell $(p=0,085)$ zeigte. Die Quote nach der Leitliniendiagnose erniedrigte sich auf 27,8\% mit einer nur kleinen Differenz zu der Beta-Blocker-negativen Gruppe (27\%). Zunächst einmal fiel die Diskrepanz zwischen der Diagnose im Arztbrief und nach Leitlinie auf. Laut Diagnose im Arztbrief erlitten fast doppelt so viele Patienten eine Pneumonie wie nach leitliniengerechter Diagnose. Hier spielen mutmaßlich vor allem zwei Faktoren eine entscheidende Rolle. Zum einen haben bildgebend radiologisch festgestellte, neu aufgetretene Infiltrate eine herausragende Stellung bei der Diagnose einer Pneumonie (Leitlinie Pneumonie 2016). Sie müssen fast obligat vorliegen. Die Standarduntersuchung ist an dieser Stelle das Röntgen-Thorax, das jedoch nur eine eingeschränkte Spezifität und Sensitivität besitzt. Das große Problem ist hierbei, dass sich nicht bei allen Pneumonien Infiltrate darstellen. Vorliegende Untersuchungen legen nahe, dass bei ungefähr einem Fünftel aller Pneumonien kein Infiltrat beobachtet werden kann (Basi et al. 2004; Hagaman et al. 2009). Zusätzlich ist die radiologische Befundung stark vom jeweiligen Untersucher abhängig (Young und Marrie 1994). Die klinische Beurteilung des Patienten ist demnach für die Diagnose einer Lungenentzündung essentiell, 
damit eine entsprechende Therapie möglichst schnell eingeleitet werden kann. Sie kam in dem Endpunkt Pneumonie nach Leitlinie daher nicht ausreichend zur Geltung, was die niedrigere Inzidenz miterklären kann. Zum anderen fiel bei der Datenerhebung auf, dass bei Anzeichen eines Infekts, wie zum Beispiel steigende Infektwerte (wie Leukozyten oder CRP) im Blut oder steigende Körpertemperatur, bei dem aber kein eindeutiger Fokus festgestellt werden konnte, in vielen Fällen der Verdacht einer Aspirationspneumonie gestellt wurde, obgleich die Kriterien für eine Pneumonie nicht erfüllt waren. Die Pneumonien könnten folglich in den Arztbriefen überdiagnostiziert worden sein, da die Diagnose verhältnismäßig rasch gestellt wurde. Die tatsächliche Inzidenzrate in diesem Patientenkollektiv könnte demnach in dem Bereich zwischen den zwei verschiedenen Diagnosen liegen und folglich ungefähr 27 bis $45 \%$ betragen. Bei dem Vergleich mit bisherigen Studien tritt hervor, dass dort niedrigere Pneumonieraten beschrieben sind. Dort entstand in 8,2-13,6\% der Fälle nach einem Schlaganfall als Komplikation eine Lungenentzündung (Aslanyan et al. 2004; Dziedzic et al. 2007; Minnerup et al. 2010; Westendorp et al. 2011; Brogan et al. 2014a; Sykora et al. 2015; Westendorp et al. 2016). Diese Analysen beinhalten aber oft sehr heterogene Gruppen. Zum einen wurden sowohl ischämische als auch hämorrhagische Schlaganfälle in die Statistik aufgenommen und zum anderen Patienten mit milden Schlaganfällen eingeschlossen (Brogan et al. 2014a; Westendorp et al. 2016). Im Rahmen dieser Dissertation wurde ein Patientenkollektiv begutachtet, dessen medianer NIHSS-Score bei Aufnahme 16 Punkte betrug, was einer schwersten Beeinträchtigung entspricht (Rundek et al. 2000; Schlegel et al. 2003). Eine hochgradige Betroffenheit durch den Schlaganfall stellt einen Risikofaktor für die Entstehung einer Pneumonie dar (Aslanyan et al. 2004; Walter et al. 2007; Westendorp et al. 2011; Ashour et al. 2016). Auch in dem hier untersuchten Patientenkollektiv waren die Patienten, die eine Pneumonie erlitten, signifikant bzw. tendenziell stärker von dem Schlaganfall beeinträchtigt und wiesen bei Aufnahme höhere NIHSS- (Pneumonie AB p<0,001, Pneumonie LL $\mathrm{p}=0,053$ ) und mRS-Werte (Pneumonie AB $\mathrm{p}<0,001$, Pneumonie LL $\mathrm{p}=0,027)$ auf. Das erhöhte Risiko kann mehrere Gründe haben, die im folgenden Abschnitt besprochen werden. Bei schwer beeinträchtigenden Schlaganfällen ist in der Regel das motorische System mitbetroffen. Die Patienten sind darum eher bettlägerig und immobil. Im Liegen werden die Lungen nicht vollständig entfaltet und die Hustenfunktion ist eingeschränkt. Somit bestehen Umstände, die die Bildung einer Pneumonie begünstigen können (Brogan et al. 2014a). Das Lagern und Bewegen von bettlägerigen Patienten hat sich als protektiv gegenüber der Entwicklung von Komplikationen wie Pneumonien gezeigt, was im Umkehrschluss ein weiteres Indiz für die ungünstige Auswirkung von Immobilität ist (Goldhill et al. 2007). Weiter können schwer betroffene Patienten später extubiert werden. Eine längere Intubationsdauer bedeutet, dass sich das Risiko erhöht, dass über den Tubus pathogene Keime in den Respirationstrakt gelangen und zu einer Pneumonie führen (Leibovitz et al. 2003a; Leibovitz et al. 2003b; Leibovitz et al. 2005). Außerdem sind physiologische Abläufe wie beispielsweise Hustenreflexe, Abtransport von Schleim, Zusammenfallen oder Entfalten kleiner Lungenbläschen gestört und könnten das Risiko erhöhen 
(Kalanuria et al. 2014; Lau et al. 2015). In der multivariaten logistischen Regression war eine kürzere Intubationsdauer mit einem geringeren Risiko des Erleidens einer Pneumonie vergesellschaftet (Pneumonie nach AB OR 0,62, p=0,005; Pneumonie nach LL OR 0,76, $\mathrm{p}=0,004)$. Zusätzlich ist bei einem schweren Schlaganfall die Wahrscheinlichkeit größer, dass die komplexe Koordination des Schluckaktes gestört ist. Dysphagische Patienten weisen ein höheres Aspirationsrisiko auf. Die Dysphagie stellte sich dementsprechend in dem hier untersuchten Kollektiv in der multivariaten logistischen Regression als unabhängiger Risikofaktor für die Entwicklung einer Pneumonie nach Leitlinie heraus. Die Odds-ratio betrug für die Pneumonie LL 10,92 ( $\mathrm{p}=0,031$ ). Für die Pneumonie nach Arztbrief erwies sich die Dysphagie als tendenzieller Prädiktor ( $p=0,058$, OR 3,25). Dieses Ergebnis wird durch weitere Studien unterstützt (Hilker et al. 2003; Walter et al. 2007; Westendorp et al. 2011; Brogan et al. 2014a). Konsekutiv stellte sich in der multivariaten Analyse bei der Pneumonie nach Arztbrief eine naso-gastrale Sonde als signifikanter Risikofaktor heraus ( $p=0,001$, OR 3,93). Der Befund bestätigt bestehende Studien (Vargas et al. 2006; Brogan et al. 2014a; Ashour et al. 2016). Bei dem Vergleich mit Studien, die die Lungenentzündungsraten nach Schlaganfällen für Patienten auf der Intensivstation beschrieben, fiel auf, dass die dort ermittelten Daten die hier vorliegende Analyse gut unterstützen. Westendorp et al. publizierten 2011 eine MetaAnalyse von Post-Schlaganfall-Infektionsratenstudien, in der ein Großteil der Inzidenz von Pneumonien auf Intensivstationen in einem Bereich von 18-38\% lag. Wenn man also, wie vorhin erwähnt, davon ausgeht, dass die Rate nach Leitlinie die wahre Auftretenswahrscheinlichkeit unter- und die Rate nach Arztbrief die wahre Auftretenswahrscheinlichkeit überschätzt, dann entspricht das dieser Dimension. Ein Vergleich mit diesen Studien scheint legitim, da alle Patienten des untersuchten Kollektivs nach der interventionellen Thrombektomie auf einer Intensivstation behandelt wurden. Gleichermaßen könnte die Betroffenheit der Patienten der anderen Studien ähnlich schwer sein, weil ansonsten bei einem Großteil wahrscheinlich keine Intensivtherapie nötig gewesen wäre. Aus diesem Grund kann man davon ausgehen, dass bei diesen Patienten die Risikofaktoren der Aspiration und der Immunmodulation in einem ähnlichen Maß bestehen könnten.

Die Grundüberlegung, ob eine Beta-Blocker-Medikation einen protektiven Einfluss auf die Infektionsrate nach einem Schlaganfall hat, kann für den Endpunkt der Pneumonie nicht bestätigt werden. Das steht im Gegensatz zu einigen veröffentlichen Studien. Zunächst einmal ließ sich der Effekt in experimentellen Mausversuchen demonstrieren (Prass et al. 2003; McCulloch et al. 2017). Jedoch besteht bei diesen Experimenten das Problem, dass in den Versuchsreihen der Beta-Blocker Propranolol verwendet wurde, der unselektiv ist, also sowohl $\beta_{1}$ - als auch $\beta_{2}$-Adrenozeptoren blockiert. Propranolol wird in einer kardialen Indikationssituation (vgl. Kapitel 1.8) nicht als Standardpräparat eingesetzt und daher nur noch sehr selten verwendet. Auch Wong et al. stellten 2011 bei Mäusen den Effekt der Beta-Blocker auf eine möglicherweise entscheidende Immunkaskade in der Leber mithilfe von Propranolol dar. Immunzelltypen exprimieren unterschiedliche und mehrere Arten von Adrenorezeptoren in heterogener Gewichtung, sodass der Einfluss des Sympathikus vermutlich 
nicht auf einen Rezeptortyp beschränkt werden kann (Marino und Cosentino 2013). Es gibt Indizien, dass die Verbindung zwischen sympathischen Nerven- und Immunsystem vor allem über $\beta_{2}$-Adrenozeptoren gesteuert werden könnte (Kohm und Sanders 2001). Heutzutage werden aber in der Regel eher $\beta_{1}$-selektive Beta-Blocker, deren Hauptwirkung gezielter am Herzen liegt, angewendet. Das trifft auch auf dieses Kollektiv zu, in dem der Wirkstoff Propranolol kaum eingenommen wurde. Dementsprechend könnten die maßgeblich beteiligten Adrenozeptoren nur unzureichend blockiert worden sein. Das könnte erklären, warum bei den Beta-Blocker-Patienten die Schwächung des Immunsystems nicht, wie erwartet und erhofft, unterdrückt wurde. Zudem sind theoretische und experimentelle Studienergebnisse, aufgrund des komplexen Zusammenspiels unzähliger Faktoren, nicht immer im menschlichen Körper reproduzierbar. Es wurden aber auch in humanen Studien protektive Eigenschaften von Beta-Blockern auf die Pneumonierate nach einem Schlaganfall beschrieben. In einem von Dziedzic et al. 2007 publizierten Artikel wurde in einem Patientenkollektiv, welches von 1994-97 einen Schlaganfall erlitt, eine signifikante Reduktion der Inzidenz festgestellt. Ein Grund dafür könnte sein, dass damals Beta-Blocker verwendet wurden, die noch nicht so kardioselektiv $\beta_{1}$-Adrenozeptor wirksam wie die heutigen Präparate waren und deshalb einen größeren Einfluss auf das Immunsystems gehabt haben könnten. Sykora et al. stellten 2015 in einer Analyse gleichermaßen fest, dass bei Patienten, die einen Beta-Blocker vor einem Schlaganfall nahmen, die Rate an Pneumonie im Vergleich zu den Patienten, die keinen Beta-Blocker nahmen, reduziert war. In dem untersuchten Kollektiv war der Anteil der unselektiven Beta-Blocker höher als in der Gruppe, die für diese Dissertation untersucht wurde, was einen gewissen Einfluss auf das unterschiedliche Ergebnis hinsichtlich der Infektionsraten gehabt haben könnte. Im Vergleich mit dieser Patientengruppe muss ebenso bemerkt werden, dass die Schlaganfallschwere des dortigen Kollektivs deutlich geringer war.

Weiter existieren Studienergebnisse, die keinen oder einen nachteiligen Effekt einer BetaBlocker-Therapie nach einem Schlaganfall beschreiben. Maier et al. machten in ihrem untersuchten Patientenkollektiv 2015 kaum einen Unterschied zwischen beiden Gruppen in der Entwicklung der Pneumonierate aus. Zu der Vergleichbarkeit mit dem hier analysierten Kollektiv ist aber zu sagen, dass dort sowohl hämorrhagische als auch ischämische Schlaganfälle eingeschlossen wurden und das Patientenkollektiv insgesamt weniger stark beeinträchtigt war. Westendorp et al. protokollierten 2016 ein vergleichbares Ergebnis wie in der hiesigen Untersuchung. Beta-Blocker-Patienten wiesen eine erhöhte Inzidenz an Pneumonien auf. Das dortige Kollektiv stellte eine Patientengruppe dar, die nicht extrem stark von dem Schlaganfall betroffen war und hämorrhagische ebenso wie ischämische Schlaganfälle beinhaltete. Nichtsdestotrotz ist dort bei einer geringeren gesamten Infektionsquote eine ähnliche Tendenz zu beobachten. Außerdem handelte es sich um eine retrospektive Analyse eines bestehenden Datensatzes, in der viele Einflussfaktoren auf die Entwicklung einer Pneumonie, z. B. die Häufigkeit von naso-gastralen Sonden oder einer Intubationssituation, nicht bewertet werden konnten. Eine sichere Beurteilung des Beta-Blocker-Einflusses ist daher nicht möglich. 
Nach aktuellem Stand der Wissenschaft müssen Infarkte im Bereich der A. cerebri media und/ oder dem Bereich der Insula stattfinden, um einen gesteigerten Sympathikustonus auszulösen (Steinhagen et al. 2009; Harms et al. 2011; Walter et al. 2013). Unsere Daten unterstützen diese Beobachtung in der nach ASPECTS-Zonen gewichteten Auswertungen. In den vorangegangenen Studien wurde jedoch nicht nach der Lokalisation gefiltert, sondern Schlaganfälle aller Hirngefäße eingeschlossen. Somit ist unsicher, ob der immunmodulatorische Prozess aufgrund der verstärkten adrenalen Stimulation bei einem Großteil der Patienten stattfand und der Beta-Blocker an dieser Schnittstelle überhaupt wirken konnte. Die Patienten in dem analysierten Kollektiv zeigten hohe NIHSS- und mRS-Werte, was einer hohen Schlaganfallschwere entspricht, sodass ursächlich große Infarktareale und auch der immunmodulatorische Bereich des Gehirns betroffen waren (Walter et al. 2013, vgl. Kapitel 1.7). Bei der Auswertung der Subgruppen zeigt sich passend, dass die Patienten, deren Gebiete des insulären Kortex, der M1 - und M4-Region der A. cerebri media von dem Schlaganfall mitbetroffen waren, eine signifikant höhere Rate an Pneumonien $(\mathrm{p}<0,001)$ aufwiesen.

Wenn man in dieser Untersuchung die Verteilung der Risikofaktoren für die Entwicklung einer Pneumonie betrachtet, können einige Gründe für die erhöhte Inzidenz in der BetaBlocker-Gruppe gefunden werden. Eine wichtige Tatsache stellt dar, dass diese Patienten initial tendenziell stärker betroffen waren (NIHSS-Wert bei Aufnahme $(p=0,095)$ und mRSWert bei Aufnahme ( $p=0,08)$, Aslanyan et al. 2004; Walter et al. 2007; Westendorp et al. 2011; Ashour et al. 2016). Zugleich lag in der Beta-Blocker-Gruppe, mitbedingt durch die Beeinträchtigung, signifikant öfter $(p=0,006)$ eine Dysphagie vor, was wiederum das Aspirationsrisiko steigert und die Folgekomplikationen hervorruft (Hilker et al. 2003; Walter et al. 2007; Westendorp et al. 2011; Brogan et al. 2014a). Dazu konträr ist jedoch die kürzere Intubationsdauer der Patienten, welches per se vor einer Pneumonie schützen kann (Hilker et al. 2003; Walter et al. 2007). In Bezug auf das Alter $(\mathrm{p}<0$,001) und der Komorbiditäten (vgl. Kapitel 3.2.1) lagen zwischen der Beta-Blocker- und Vergleichsgruppe wesentliche Unterschiede vor. Dementsprechend gibt es einige Kofaktoren, die den Nachteil der Beta-BlockerPopulation miterklären können. Die erhöhte Pneumonieanfälligkeit kann aber nicht allein auf das erhöhte Aspirationsrisiko beschränkt werden. Bei Patienten, die nach einem Schlaganfall zum Schutz vor der Aspiration eine naso-gastrale Sonde angelegt bekamen, zeigte sich dieser Schutz nichtsdestotrotz als nur unzureichend (Dziewas et al. 2004). Der Schlauch der Sonde könnte eine Leitstruktur und Eintrittspforte für Keime darstellen. Jedoch lassen diverse Studien vermuten, dass ein gewisser Anteil gesunder Menschen aspiriert, ohne im Verlauf eine Pneumonie zu entwickeln (Huxley et al. 1978; Gleeson et al. 1997). Daher scheint die Immunmodulation als Folge des Schlaganfalls eine gewichtige Rolle bei der Entwicklung einer Lungenentzündung zu spielen.

In dem vorliegenden Patientenkollektiv stand ein rechtshirniger Infarkt öfter, aber nicht signifikant, im Zusammenhang mit der Entwicklung einer Pneumonie als ein linkshirniger Infarkt (Pneumonie AB p=0,082, Pneumonie LL p=0,121). In der multivariaten logistischen Regression stellte sich ein rechtshirniger Infarkt dann als signifikanter bzw. fast tendenzieller 
Prädiktor für die Entwicklung einer Pneumonie heraus (Pneumonie AB p=0,031, OR 2,18; Pneumonie LL p=0,101, OR 1,88). Das unterstützt die These, dass die rechtshirnige Inselregion das Zentrum der gesteigerten autonomen Aktivität und Infektanfälligkeit sei (Sander und Klingelhöfer 1995; Meyer et al. 2004; Kemmling et al. 2013).

\subsection{Harnwegsinfektrate}

Bei 17,3\% der Patienten wurde im Arztbrief eine Harnwegsinfektion beschrieben. In der $\mathrm{BB}(+)$-Gruppe zeigte sich eine höhere Inzidenz als in der BB(-)-Gruppe (20,3\% vs. 14,2\%). Bei der Diagnose nach Leitlinie steigerte sich die Rate im Kollektiv auf gut ein Viertel der Patienten (26,1\%), wobei sie statistisch signifikant häufiger in der Beta-Blocker-vormedizierten Gruppe auftrat ( $p=0,027 ; 31,6 \%$ vs. 20,3\%). Der prozentuale Unterschied zwischen den beiden Endpunkten lässt sich dadurch erklären, dass in der Kategorie der Leitliniendiagnose die asymptomatischen Bakteriurien, ehemals asymptomatische Harnwegsinfekte, aufgenommen wurden, die in den Arztbriefen meist unerwähnt blieben. Aus diesem Grund wird die Harnwegsinfektrate nach Leitlinie eher überschätzt, da nicht jeder bakterielle Befund im Urin Krankheitswert besitzt und die präsentierte Klinik des Patienten eine gewichtige Rolle einnimmt. In anderen Untersuchungen wurde ein Inzidenzspektrum von 10-27,3\% dokumentiert und somit schließt sich die vorliegende Studie diesen Werten an (Aslanyan et al. 2004; Ersoz et al. 2007; Indredavik et al. 2008; Stott et al. 2009; Minnerup et al. 2010; Westendorp et al. 2011; Bogason et al. 2017). Die Meta-Analyse von Westendorp et al. von 2011 stellte einen Mittelwert der Inzidenzrate von 20\% für Patienten, die nach einem Schlaganfall auf einer Intensivstation behandelt werden mussten, fest. Ein Problem bei dem Vergleich mit anderen Studien bleibt die Tatsache, dass die Definition eines Infekts der Harnwege nicht einheitlich verwendet wurde. Damit ist gemeint, dass in manchen Studien eine signifikante Bakteriurie als Harnwegsinfekt gewertet wurde und in anderen Studien die Klinik mit Schmerzen oder häufigem Wasserlassen eine entscheidende Gewichtung erhielt. Vor allen Dingen muss ebenso beachtet werden, dass klinisch eine Unterscheidung zwischen Infekt und asymptomatischer Bakteriurie nicht immer leichtfällt, da die subjektive Einschätzung des Patienten miteinbezogen wird und einige Patienten nach einem Schlaganfall zum Beispiel aufgrund einer aphasischen Störung keine adäquaten Antworten geben können. Im Gegensatz zu der Pneumonierate liegt in diesem Kollektiv, trotz dessen schwerer Beeinträchtigung, keine viel höhere Auftretenswahrscheinlichkeit vor, als bei den Studien, die auch Patienten mit geringerer Beeinträchtigung einschließen. Dies ist insofern überraschend, da größere Infarkte bzw. höhere NIHSS-Werte eigentlich mit einem höheren Harnwegsinfektrisiko assoziiert sind (Aslanyan et al. 2004; Stott et al. 2009). Wie bereits bei der Pneumonie erläutert, ist in dem vorliegenden Patientenkollektiv die Chance höher, dass der Bereich des Gehirns von dem Schlaganfall affiziert ist, der für die anschließende Immunmodulation sorgt. Außerdem kommt es bei volumetrisch großen Schlaganfällen oft durch Mitbeteiligung des frontalen Blasenzentrums zu einer Blasendysfunktion, die die Entwicklung von Harnwegsinfekten 
begünstigt (Kong und Young 2000). Fast alle Patienten dieses Kollektivs (91,4\%) wurden mindestens einmal mit einem transurethralen Katheter versorgt. In diesem Kollektiv erwies sich eine Katheterisierung in der multivariaten logistischen Regression nicht als Risikofaktor für die Entwicklung eines Harnwegsinfekts, doch in anderen Studien konnte ein solcher Zusammenhang mit einem Anstieg der Erkrankungswahrscheinlichkeit mit der Dauer des liegenden Katheters um etwa 3-10\% pro Tag hergestellt werden (Maki und Tambyah 2001; Stott et al. 2009; Gould et al. 2010; Westendorp et al. 2011). Es ist davon auszugehen, dass die Patienten des Kollektivs mehrere Tage, meist mindestens für die Dauer ihres Aufenthalts auf der Intensivstation, einen solchen Katheter besaßen. In weiteren Studien erwiesen sich ein hohes Alter und weibliches Geschlecht als Risikofaktor für die Ausbildung eines Infekts der Harnwege (Aslanyan et al. 2004; Stott et al. 2009; Westendorp et al. 2011). Dieser Zusammenhang konnte in diesem Kollektiv zumindest bezüglich des weiblichen Geschlechts bestätigt werden. In der Betrachtung der möglichen Störfaktoren in dem hier untersuchten Kollektiv fiel außerdem auf, dass die $\mathrm{BB}(+)$-Gruppe häufiger einen transurethralen Katheter ( $p=0,099)$ besaß (Stott et al. 2009; Westendorp et al. 2011; Westendorp et al. 2016).

Im Gegensatz dazu stellte sich in dem von Maier et al. 2015 untersuchten Kollektiv eine statistisch signifikante protektive Rolle des Beta-Blockers auf die Entwicklung eines Harnwegsinfekts heraus. Dort reduzierte die Vormedikation die Inzidenz nach einem Schlaganfall. Die Beta-Blocker-Patienten waren jedoch zusätzlich weniger stark von dem Schlaganfall betroffen und daher könnte die Gruppe auch aus diesem Grund eine niedrigere Infektanfälligkeit besessen haben. Mögliche Konfounder, die in der Studie nicht dokumentiert wurden, wie z. B. ein transurethraler Katheter, könnten das Ergebnis jedoch entscheidend beeinflusst haben. In einer weiteren Untersuchung von Westendorp et al. von 2016 wurde bei einem geringer betroffenem Patientenkollektiv ebenso festgestellt, dass eine Beta-Blocker-Vormedikation die Harnwegsinfektrate nach dem Schlaganfälle erhöhte. Dies steht wieder im Einklang mit dem Resultat des hier untersuchten Kollektivs. Generell stellt sich auch bei den Harnwegsinfekten wieder die Frage, ob die häufig verwendeten $\beta_{1}$-selektiven-Blocker entscheidend in die Immunkaskade eingreifen können und genügend beteiligte Immunzellen ansprechen. Letztlich kann man festhalten, dass der Beta-Blocker die Inzidenz von Harnwegsinfekten in diesem Patientenkollektiv eher erhöhte, was aber ebenso von dem höheren Aufkommen von transurethralen Kathetern, dem höheren Alter, den Komorbiditäten und schwereren Schlaganfällen in dieser Patientengruppe beeinflusst worden sein könnte.

\subsection{Sepsis- und andere Infektionsrate}

Eine Sepsis entwickelte sich in diesem Patientenkollektiv in gut zehn Prozent der Fälle (nach AB 10,1\% und nach LL 13,1\%). Alle Patienten, die eine Sepsis erlitten, zeigten dysphagische Symptome und benötigten einen transurethralen Katheter. Die hochsignifkante Dysphagierate im Vergleich zu den Patienten ohne Sepsis $(p<0,001)$ lässt die Vermutung zu, dass die Sepsis oft über einen pneumogenen Ursprung verfügte (Czupryna et al. 2013; Berger et al. 
2014; Jo et al. 2017). Das wird dadurch unterstützt, dass die Patientengruppe im Vergleich zu den Patienten ohne Sepsis außerdem besonders häufig $(p<0,001)$ und lange $(p<0,001)$ intubiert wurde. Je kürzer die Patienten intubiert waren, desto protektiver war dies in der multivariaten logistischen Regression gegenüber der Entwicklung einer Sepsis (OR nach AB 0,8, $\mathrm{p}=0,001$; OR nach LL 0,8, $\mathrm{p}=0,001)$. Die Beeinflussung des Abwehrsystems könnte eine entscheidende Rolle spielen, weil ein Intubationstubus einen gewissen Schutz vor einer Aspiration darstellt. Andererseits kann der Tubus ebenso eine Leitstruktur und Eintrittspforte für pathogene Keime abbilden. Dazu passt, dass das Pneumonierisiko mit jedem weiteren Tag der Intubation steigt (Chastre und Fagon 2002; Davis 2006). Die Sepsispatienten wiesen eine hohe Rate an langwierigen respiratorischen Problemen auf. Ein Drittel der Patienten wurde tracheotomiert, was im Mittel nach 13,7 Tagen stattfand und dementsprechend geht diesen Patienten eine lange Intubationszeit voraus. Ein Hinweis, dass das Sepsiskollektiv weitere, auf die Prognose einflussnehmende Komorbiditäten aufweist, könnte die Tatsache sein, dass in 37,75\% der Fälle ein weiterer Eingriff, der nicht zur Standardbehandlung des Schlaganfalls gehört, durchgeführt wurde. Jedoch könnte gleichermaßen die Sepsis weitere Operationen oder diagnostische Prozeduren bedingen, sodass dieser Zusammenhang nicht eindeutig interpretiert werden kann. In der multivariaten logistischen Regression der Sepsis nach Arztbrief fiel zudem auf, dass eine immunmodulierende Vormedikation ein Risikofaktor für die Entwicklung einer Sepsis darstellte (OR 4,92, p=0,027). Der Zusammenhang erscheint plausibel, da diese Medikamente das Immunsystem weiter schwächen, welches daraufhin nicht adäquat auf einen pathogenen Keim reagieren kann. Aufgrund der Immunsuppression könnte sich nun leichter eine Sepsis entwickeln.

Darüber hinaus zeigte sich in der Analyse der Subgruppen, dass Patienten mit einem Infarkt, der den Inselkortex und den anteromedialen Kortex in Form des M1- und M4-Gebiets einschließt, signifikant öfter eine Sepsis erlitten (Sepsis AB p=0,031, Sepsis LL p=0,006). Wie bei der Diskussion der Pneumonierate bereits angesprochen, stehen diese Regionen im Verdacht, dass sie eine erhöhte Sympathikusaktivität und damit eine Immunsuppression auslösen könnte (Meyer et al. 2004; Harms et al. 2011; Walter et al. 2013). Andererseits existiert wieder das Problem, dass ein großer Infarkt meist diese Gebiete auch einschließt und aufgrund der starken Beeinträchtigung das Sepsisrisiko erhöht sein könnte. Leider ist ein Vergleich der dezidierten Sepsisrate nach einem Schlaganfall mit anderen Studien schwierig, da sie kaum als einzelner Endpunkt festgehalten wird. Eine Analyse von Berger et al. ergab 2014 jedoch eine ähnliche Inzidenz von 12,6\% für Patienten, die wegen eines ischämischen oder hämorrhagischen Schlaganfalls auf einer Intensivstation behandelt werden mussten. Im Gegensatz dazu berichteten Aslanyan et al. 2004 nebenbefundlich beispielsweise eine Sepsisrate von nur 1,4\%, obwohl es sich um ein stark betroffenes Kollektiv mit einem NIHSS-Mittelwert von 13 Punkten handelte. Eine Erklärung dieses Unterschieds ist erstmal nicht möglich.

Eine Sepsis trat in dem hier untersuchten Kollektiv häufiger in der Beta-Blocker-positiven Gruppe auf (nach AB: $12 \%$ vs. 8,1\%, nach LL 13,9\% vs. 12,2\%). Die Vormedikation ernied- 
rigte somit nicht die Infektionsrate. Jedoch gibt es einige Faktoren, die man in diese Schlussfolgerung einbeziehen muss. Gleichzeitig war diese Gruppe, wie schon mehrfach erwähnt, stärker von dem Schlaganfall betroffen, älter und komorbider und daher generell empfänglicher für Infektionen, die wiederum das Risiko bergen, dass sich im Verlauf eine Sepsis entwickelt (Aslanyan et al. 2004; Walter et al. 2007; Stott et al. 2009; Westendorp et al. 2011; Ashour et al. 2016). Das wird durch die Tatsache bestätigt, dass in der Beta-Blocker-positiven Gruppe häufiger Pneumonien aufgetreten sind, die zugleich einen häufigen Ursprung der Sepsis darstellen (Czupryna et al. 2013; Jo et al. 2017). Das Gleiche gilt für die Harnwegsinfekte. Nichtsdestotrotz passt nicht ganz in das Bild, dass die Beta-Blocker-Gruppe seltener und kürzer intubiert war, was eigentlich das Risiko einer Sepsis erniedrigen sollte. In einigen Studien wurde zudem berichtet, dass eine regelmäßige Beta-Blocker-Einnahme die Mortalität bei Entwicklung einer Sepsis reduzierte (Ackland et al. 2010; Macchia et al. 2012). Die Theorie konnte in diesem Patientenkollektiv nicht bestätigt werden.

In der Sammelkategorie aller weiteren Infektionen ist die Beta-Blocker-Gruppe seltener als die Nicht-Beta-Blocker-Gruppe betroffen (7\% vs. 9,5\%). Diese Aussage wird jedoch deutlich eingeschränkt, da dieser Endpunkt alle weiteren, sehr heterogenen Infektionen- von einer Meningitis bis zu einer Bindehautentzündung- beinhaltet und deshalb die korrekte Assoziation zwischen Beta-Blocker, Immunmodulation und Infektion schwierig möglich ist. Alle eventuellen Störfaktoren auf die mannigfaltigen Infektionen können nicht dokumentiert und einbezogen werden. Auf diese Weise kann maximal spekuliert werden, ob hier unter Umständen der immunmodulative Effekt des Beta-Blockers eine Schwächung des Abwehrsystems abmilderte oder, was wahrscheinlicher erscheint, zufälligerweise die Beta-BlockerGruppe weniger betroffen war. In dieser heterogenen Rubrik liegt der Verdacht nahe, dass es sich eher um schwer betroffene Patienten handelt. Als Hinweise darauf könnten das statistisch signifikant häufigere Auftreten von Dysphagie und naso-gastraler Sonde gelten. Zudem benötigten hier ebenfalls alle betroffenen Patienten einen Katheter sowie ein hoher Prozentsatz von $80 \%$ eine Intubation, die signifikant länger als in der nicht betroffenen Gruppe bestand ( $p=0,011$ bei 6,85 vs. 3,71 Tage). Das könnte die These unterstützen, dass die Patienten aufgrund des immunmodulatorischen Effekts des Schlaganfalls generell empfänglicher für Infektionen waren. Es fiel in der logistischen Regression, passend zu der Annahme einer Rechtshirnigkeit des sympathischen Zentrums, auf, dass rechtshirnige Infarkte unabhängige Risikofaktor für die Entwicklung einer anderen Infektion darstellten (OR 3,89, p =0,01, Sander und Klingelhöfer 1995; Meyer et al. 2004; Kemmling et al. 2013). Das Risiko könnte folglich auf diesen Mechanismus mitbegründet sein. Die Sepsis wird bei dem Großteil der Studien zu dem Sammelendpunkt aller anderen Infektionen gerechnet. Wenn man nun die Inzidenz von Sepsis und anderen Infektionen in diesem Kollektiv zusammenrechnet, kommt man in dieser Kategorie auf eine Rate von 18,3-21,3\%. Dieses Ergebnis würde sich in die Resultate von bestehenden Untersuchungen einreihen, wo in 2,5-19\% der Fälle eine solche, sonst nicht weiter kategorisierte Infektion auftrat (Langhorne et al. 2000; Minnerup et al. 2010; Westendorp et al. 2016). 


\subsection{Mortalität}

In dem hier untersuchten Kollektiv lag die Mortalitätsrate bei 20,9\%. Es fiel auf, dass die verstorbene Patientengruppe bereits bei der Aufnahme einen höheren NIHSS- $(p=0,002)$ sowie mRS-Wert $(p=0,067)$ als die überlebenden Patienten besaßen. Zum Zeitpunkt der Einlieferung bestand folglich ein hohes neurologisches Defizit und möglicherweise ein großes, gefährdetes oder auch bereits infarziertes Hirngebiet. Die ungünstige Prognose deutete sich demnach schon initial an. Sie wird dadurch verstärkt, dass bei diesen Patienten die Therapieversuche zu einem signifikant größeren Anteil fehlschlugen $(p<0,001)$ und die klinische Situation nicht verbessert werden konnte. Eine interventionelle Rekanalisation stellt bei proximal gelegenen Verschlüssen oft die einzige vielversprechende therapeutische Möglichkeit dar, da die Effektivität der intravenösen Lysetherapie leider eingeschränkt ist (Rha und Saver 2007; Chen et al. 2015). Gerade in dem vorliegenden Patientenkollektiv, wo bei allen Patienten ein Verschluss vorlag, der endovaskulär versorgt werden musste, ist die Thrombektomie das entscheidende therapeutische Mittel und spielt daher in der Behandlung eine übergeordnete Rolle. In dem posttherapeutisch wesentlich höherem NIHSS (23,03 vs. 13,2 Punkte, $\mathrm{p}<0,001)$ in der verstorbenen Gruppe spiegelten sich die unvorteilhafte klinische Entwicklung und frustranen Therapieversuchen wider. Die verstorbenen Patienten mussten signifikant öfter intubiert $(\mathrm{p}=0,002)$ werden und wiesen signifikant häufiger eine Dysphagie $(p<0,001)$ und transurethralen Katheter $(p=0,022)$ auf. Außerdem fiel auf, dass die verstorbenen Patienten signifikant älter waren $(p=0,003)$ und daher vermutlich eine höhere Anzahl von Komorbiditäten besaßen, sodass sie die Folgen des Schlaganfalls schlechter kompensieren konnten. Die multivariate logistische Regression des Endpunkts der Mortalität bei Entlassung stützt die Erkenntnisse. Eine erfolgreiche Rekanalisation (OR 0,38, p=0,018) und ein jüngeres Alter ( $\mathrm{p}=0,04$, OR 0,96$)$ stellten sich signifikant protektiv dar. Zudem wurde eine naso-gastrale Sonde als schützender Faktor identifiziert ( $\mathrm{p}<0,001$, OR 0,24). Es muss jedoch beachtet werden, dass bei einigen Patienten, deren Prognose von Anfang an ungünstig erschien und die nach wenigen Tagen verstarben, ein palliatives Behandlungskonzept durchgeführt wurde und daher auf das Anlegen einer naso-gastralen Sonde verzichtet wurde, auch wenn aufgrund einer hochgradigen Dysphagie eine Indikation bestanden hätte. Dieser Umstand kann das Ergebnis beeinflusst haben. Die Todesursachen wurden nicht genau protokolliert, aber die starke Beeinträchtigung könnte für eine hohe Anfälligkeit gegenüber Infektionen sorgen. Das Hauptrisiko nach einem Schlaganfall zu versterben, liegt in der komplikationsreichen ersten Phase nach dem Ereignis. Diese These wird von diesem Patientenkollektiv dadurch unterstützt, dass die verstorbenen Patienten eine signifikant kürzere Aufenthaltsdauer im Krankenhaus aufwiesen $(p<0,001)$, weil ein Großteil in der ersten Woche nach dem Schlaganfall verstarb. In der Analyse der Mortalitätsrate fiel beim Vergleich der rechtsund linkshirnigen Infarkte auf, dass Patienten mit linkshirnigem Infarkt tendenziell häufiger verstarben $(p=0,061)$. Für die Feststellung kann so erstmal keine Erklärung gefunden werden. Eine Idee wäre, dass bei solchen Infarkten mit einer Aphasie zu rechnen ist und ggf. 
mittels vorliegender Patientenverfügung und Wunsch der Angehörigen ein palliatives Behandlungskonzept beschlossen wurde.

Weiter wurden bei der Analyse der bestehenden Publikationen für die Sterblichkeit während des Krankenhausaufenthalts Raten von 6,6-14,9\% beobachtet (Nimptsch und Mansky 2014; Phelan et al. 2015; Westendorp et al. 2016). Die hier ermittelte höhere Mortalität in den ersten Wochen kann leicht mit der stärkeren Beeinträchtigung sowie der Abhängigkeit von einer erfolgreichen interventionellen Therapie begründet werden. Es handelte sich in dem untersuchten Kollektiv um ein stark gefährdetes Kollektiv. In weiteren, vergleichbaren Studien liegt die Mortalität nach 90 Tagen in ähnlichen Bereichen bei 11,4-17,5\% (Sykora et al. 2015; Westendorp et al. 2016).

Beim Vergleich der Mortalitätsrate bei Entlassung aus dem Krankenhaus zwischen den beiden Gruppen fiel ein nicht signifikanter Unterschied zuungunsten der Beta-Blocker-Patienten auf (24,1 vs. 17,6\%, p=0,206). Dieses Ergebnis ist fast etwas überraschend, da in der ersten Phase nach dem Schlaganfall in der Beta-Blocker-Gruppe häufiger Komplikationen wie Pneumonie, Harnwegsinfekt oder Sepsis vorlagen. Die Schwere des Schlaganfalls spielt zudem eine wichtige prognostische Rolle und diese Gruppe war initial stärker von dem Schlaganfall betroffen. Die Beta-Blocker-Patienten besaßen ebenso mehr Komorbiditäten und waren älter. Somit besitzt die Gruppe formal mehrere prognostisch ungünstige Risikofaktoren, die sich jedoch nicht so deutlich in der Mortalitätsrate abbilden, wie man es eventuell vermuten könnte. Das könnte den Schluss zulassen, dass die Behandlung nach dem Schlaganfall heutzutage auf einem Stand ist, dass die entstehenden Komplikationen relativ gut behandelt werden können. In einer Untersuchung, die Maier et al. 2015 publiziert haben, unterschieden sich die Beta-Blocker- und Nicht-Beta-Blocker-Gruppe analog zu der hiesigen Studie kaum in der 7-Tage-Mortalität, was aber der Tatsache geschuldet sein könnte, dass die Beta-Blocker-Patienten insgesamt weniger stark von dem Schlaganfall betroffen waren und daher in den ersten Tagen weniger mortalitätsgefährdet gewesen sein könnten. Im weiteren Krankheitsverlauf wurde dort festgestellt, dass in der die Beta-Blocker-Gruppe eine signifikant höhere 30 Tage-Mortalität bestand. Die Beta-Blocker-Gruppe war dort zusätzlich signifikant älter und besaß mehr Komorbiditäten, sodass weitere Faktoren existieren, die in die Prognose entscheidend miteinwirken und eine Beurteilung erschweren. Westendorp et al. berichteten 2016 ebenso in ihrem untersuchten Patientenkollektiv von einer erhöhten Mortalität der Beta-Blocker-Patienten bei Entlassung aus dem Krankenhaus und nach 90 Tagen. Es ist jedoch wieder festzuhalten, dass die Patienten, die einen Beta-Blocker einnahmen, sowohl älter waren als auch eine höhere Anzahl von Komorbiditäten aufwiesen. Weiterhin existieren jedoch auch Berichte, die eine Senkung der Mortalität nach einem Schlaganfall bei Patienten mit Beta-Blocker-Medikation dokumentiert haben. Dziedzic et al. beschrieben 2007 etwa in ihrem Patientenkollektiv eine signifikant reduzierte Mortalität nach 30 Tagen. Des Weiteren stellten Phelan et al. 2015 fest, dass die Patienten, die vor und nach dem Schlaganfall durchgängigen ihren Beta-Blocker einnahmen, eine reduzierte Sterblichkeit während des Krankenhausaufenthaltes aufwiesen. Ein Großteil der dortigen Patienten war aber eher 
mild betroffen und daher wahrscheinlich keinem so großem Komplikationsrisiko in den ersten Tagen nach dem zerebrovaskulärem Ereignis ausgesetzt. Sykora et al. fanden 2015 heraus, dass eine Neuverordnung von Beta-Blockern nach einem Schlaganfall das Mortalitätsrisiko nach 90 Tagen reduzierte. Eine Beta-Blocker-Therapie, die vor dem Schlaganfall bestand und fortgeführt wurde, hatte in diesem Patientenkollektiv keine Wirkung auf die 90-TageMortalität. Diese Patienten besaßen eine leicht höhere Sterblichkeit, während sie aber auch älter waren und eine höhere Rate an Komorbiditäten aufwiesen. Insgesamt betrachtet könnten die unterschiedlichen Ergebnisse bezüglich der Sterblichkeit in der Heterogenität der jeweilig untersuchten Patientengruppe begründet und aus diesem Grund von einigen Störfaktoren wie dem Alter, der Komorbiditäten oder Betroffenheit nach dem Schlaganfall beeinflusst worden sein.

\subsection{Lokalisation des Schlaganfalls}

In dem hier untersuchten Patientenkollektiv ließ sich im Vergleich der rechts- und linkshirnigen Schlaganfällen keine signifikanten Unterschiede in der Anfälligkeit für Infektionen feststellen. Bei dem Vergleich der Beta-Blocker-positiven und -negativen Gruppe fiel jedoch auf, dass bei den Beta-Blockern einnehmenden Patienten rechtshirnige Infarkte signifikant öfter als linkshirnige Infarkte zu einer Pneumonie nach Arztbrief $(p=0,013)$ führten. In der Population ohne Beta-Blocker-Medikation wurde festgestellt, dass bei rechtshirnigen Infarkten signifikant häufiger eine andere Infektion vorherrschte $(p=0,001)$. Die rechte Hemisphäre des Gehirns wird nach aktueller Studienlage bei einer Schädigung mit einer erhöhten Sympathikusaktivität in Verbindung gebracht (Sander und Klingelhöfer 1995; Meyer et al. 2004). In dem hier untersuchten Patientenkollektiv konnte eine Beta-Blocker-Vormedikation die Immunmodulation vermutlich nicht unterbinden. In anderen Studien konnte keine Region mit erhöhtem Infektionsrisiko identifizieren werden (Minnerup et al. 2010). Eine Schädigung des insulären Kortex und des vorderen Stromgebietes der A. cerebri media könnten nach aktueller Studienlage besonders im Zusammenhang mit dieser Immunmodulation stehen (Meyer et al. 2004; Harms et al. 2011; Kemmling et al. 2013; Walter et al. 2013). Diese These wird von der Subgruppenanalyse in dem vorliegenden Kollektiv unterstützt. Patienten mit einem Infarkt, der das Gebiet der Insel und/ oder M1- bzw. M4-Gebiet der A. cerebri media einschließt, erlitten sowohl eine Pneumonie als auch eine Sepsis statistisch signifikant öfter (siehe Kapitel 3.5.2 für die jeweiligen p-Werte). Bei dem Vergleich der Infektionsrate von Beta-Blocker-positiven und -negativen Patienten wurden jedoch keine signifikanten Unterschiede festgestellt. Ein schützender Effekt des Beta-Blockers konnte folglich auch in diesem Bezug nicht dargestellt werden. Es lässt sich lediglich beobachten, dass im Vergleich zu der Gesamtpopulation Patienten mit Beta-Blocker-Medikation seltener als Patienten ohne Beta-Blocker-Medikation in der Subgruppe mit Schädigung der Insel eine Pneumonie nach Leitlinie bekamen $(p=0,206)$. In der Gesamtpopulation war die Inzidenz sehr ausgeglichen 
$(p=0,898)$. Es könnte folglich einen Effekt der Beta-Blocker-Medikation geben. Dieser erreicht jedoch keine statistische Signifikanz und kann daher nicht sicher verwendet und beurteilt werden.

\subsection{Schwere des Schlaganfalls}

Es stellt sich auch die Frage, ob eine Beta-Blocker-Vormedikation einen Einfluss auf die Schwere des Schlaganfalls hat. In der Untersuchung dieses Patientenkollektivs ließ sich feststellen, dass die Beta-Blocker-Gruppe gemessen an NIHSS- und mRS-Werten initial signifikant bzw. tendenziell schwerer betroffen waren (NIHSS bei Aufnahme $\mathrm{p}=0,095$, mRS bei Aufnahme $\mathrm{p}=0$,08). Die Beta-Blocker-Patienten waren jedoch älter und besaßen mehr Komorbiditäten. Im zeitlichen Verlauf glich sich die Betroffenheit der beiden Gruppen jedoch an. Posttherapeutisch, während in den zwei Gruppen die Rekanalisation ähnlich oft gelang $(p=0,521)$ bestand noch ein signifikanter Unterschied hinsichtlich des NIHSS-Wertes $(p=0,016)$, der bei Entlassung keine Signifikanz mehr aufwies $(p=0,142)$. Die Statistik wird allerdings dadurch beeinflusst, dass die verstorbenen Patienten, die vermutlich eine stärkere Beeinträchtigung aufwiesen und in der Beta-Blocker-Gruppe leicht häufiger auftraten, aus dem Ergebnis herausfallen. Es bestehen aber auch weitere Faktoren, die diese Assoziation stören könnten. So ließ sich in Studien beispielsweise darstellen, dass ein Zusammenhang zwischen einer Einnahme von Angiotensin Converting Ensyme-Hemmern oder Angiotensin-1 Rezeptor-Antagonisten und milderen Schlaganfällen besteht (Selim et al. 2005; Miyamoto et al. 2012). In der leitliniengerechten Standardtherapie der Herzinsuffizienz wird diese Wirkstoffgruppe oft gemeinsam mit Beta-Blockern verabreicht, was auf das Ergebnis einwirken könnte und eine singuläre Beurteilung erschwert (Ponikowski et al. 2016). Die Studien der letzten Jahre geben folglich kein einheitliches Bild ab (Dziedzic et al. 2007; Laowattana und Oppenheimer 2007; Dowlatshahi et al. 2009; De Raedt et al. 2012; Maier et al. 2015; Phelan et al. 2015; Westendorp et al. 2016).

\subsection{Laborparameter}

Zudem wurden die Serumwerte der beiden Patientengruppen hinsichtlich der Parameter Leukozyten, C-reaktives Protein (CRP) und Prokalzitonin (PCT), die allesamt bei einer entzündlichen Erkrankung erhöht sein können, verglichen. Dabei stellte sich heraus, dass eine Beta-Blocker-Vormedikation in diesem Kollektiv keinen Einfluss auf diese Größen hatte. Ein Unterschied hätte eine Erklärung für eine höhere Infektionsanfälligkeit einer der zwei Gruppen liefern können. Eine weitere Grundidee zu dieser Analyse bestand darin, dass eine erhöhte Sympathikusaktivität die Leukozytenanzahl verändern könnte und das Abwehrsystem auf diese Art geschwächt werden könnte. Eine Beta-Blocker-Medikation hätte dann eventuell den Effekt haben können, dass sie diese Veränderung verhindert hätte. Anzumerken ist dennoch, dass die Laborparameter sich nicht wesentlich unterschieden, obwohl in der Beta-Blocker-Gruppe häufiger Infekte auftraten. 


\subsection{Limitationen und Ausblick}

Als erstes muss festgehalten werden, dass es sich hier um eine Studie mit einem retrospektiven Design handelt. In Bezug auf die Erhebung der Infektionsraten bedeutet dies, dass lediglich auf die Dokumentation in den Arztbriefen oder im PDMS-System zurückgegriffen werden konnte. Der klinische Zustand der Patienten, der für die Entscheidung pro oder kontra der Diagnose einer Infektion wichtig ist, konnte folglich nur über diese Parameter berücksichtigt werden. Des Weiteren trifft dasselbe auf die Erfassung des NIHSS-Werts der Patienten zu. Hier kommt noch besonders hinzu, dass einige Merkmale durch das wechselnde ärztliche Personal uneinheitlich gewertet werden sein könnten. Grundsätzlich ist ein weiterer Kritikpunkt, dass in dem Patientenkollektiv nicht notiert ist, ob initial bei der Aufnahme eine Infektion vorlag. Dies könnte die Infektionsstatistik verfälschen, da eine solche Infektion eigentlich unabhängig von dem Schlaganfall und seiner Komplikationsrate betrachtet werden müsste. Weiter war es unmöglich die gesamte Vormedikation jedes Patienten in die Analyse einzuschließen, was weiteren Raum für störende Einflussfaktoren lässt. Es kann nicht ausgeschlossen werden, dass weitere Medikamente, wie zum Beispiel Lipidsenker oder Antihypertensiva, das Immunsystem und damit auch die Infektionsrate nach einem Schlaganfall beeinflussen könnten.

Außerdem war bei der Diagnose einer Dysphagie keine Differenzierung in einzelne Schweregrade möglich. Dies hätte jedoch eine wichtige Rolle gespielt, da es hinsichtlich des Aspirationsrisikos einen Unterschied macht, ob der Patient nichts, nur eingedickte Speisen oder auch Dysphagiekost schlucken kann. Ein ähnliches Problem stellt sich bei der Einbeziehung des Faktors des transurethralen Katheters da. Hier konnte nicht voneinander abgegrenzt werden, ob die Patienten den Katheter für einen oder mehrere Tage besessen haben. Je länger ein Katheter jedoch liegt, desto mehr steigt das Risiko der Entwicklung eines Harnwegsinfekts und daher hätte diese Abgrenzung eine wichtige Rolle gespielt. Generell sind die Endpunkte dieser Studie sehr multifaktorielle Geschehen und daher liegt das allgemeine Problem vor, dass es nahezu unmöglich ist, alle entsprechenden Einflussgrößen einzubeziehen.

Wenn zukünftige Studien dem Zusammenhang zwischen der Immunmodulation nach einem Schlaganfall und einer Beta-Blocker-Medikation nachgehen wollen, wäre es eine weitere Möglichkeit, dass man bei den Patienten die Sympathikusaktivität bestimmt. Dazu könnte man im Serum die Meta- oder Norepinephrinspiegel messen und ab einem gewissen Grenzwert die Aktivität als erhöht werten. Das könnte eine genaue Aussage erlauben, bei welchen Patienten der Schlaganfall wirklich eine Stimulation des Sympathikus hervorruft. In der jetzigen Situation kann man durch die Subanalyse der Gruppe mit Infarkten im Media- und/ oder Insel-Stromgebiet lediglich annehmen, dass eine solche Verbindung stattgefunden hat. Nur wenn dieser Mechanismus gegeben ist, hätte die Beta-Blocker-Vormedikation eine Möglichkeit in die systemische Immunmodulation einzugreifen. Konsequenterweise könnte man in diesem hier untersuchten Kollektiv die protektive Funktion der Beta-Blocker-Medikation hinsichtlich der Infektionsentwicklung übersehen, da sich diese Wirkung nur auf einen noch 
kleineren Teil der Schlaganfallpatienten beziehen könnte. Eine weitere Option wäre, Patienten zu untersuchen, die einen $\beta_{2}$-Rezeptor affineren Beta-Blocker einnehmen und diese dann mit einer Kontrollgruppe hinsichtlich der Infektionsrate zu vergleichen. Diese Überlegung beruht auf der Grundlage, dass die entscheidenden Immunsubzelltypen eher von $\beta_{2}$-Rezeptoren reguliert werden und dadurch durch die heutzutage gebräuchlichen Beta-Blocker nicht genügend angesprochen werden. 


\section{$5 \quad$ Zusammenfassung}

In der vorliegenden Analyse wurde bei 306 Patienten, die in der UMG wegen eines ischämischen Schlaganfalls mit einer interventionellen Thrombektomie behandelt wurden, die Infektionsraten erhoben und dann analysiert, ob eine Beta-Blocker-Medikation einen Einfluss auf die selbigen nimmt.

Dabei zeigte sich eine hohe Inzidenz an Infektionen. Die Patienten in dem hiesigen Kollektiv waren sowohl durch die starke Beeinträchtigung als Folge des Schlaganfalls als auch über den immunsuppressiven Mechanismus durch eine gesteigerte Sympathikusaktivität, die man für den Großteil des Kollektivs annehmen kann, hochgefährdet. Patienten, deren Schlaganfall das Gebiet des insulären Kortex und/ oder die M1- und M4-Gebiete des A. cerebri media Stromgebietes nach dem ASPECTS, zeigten signifikant höhere Pneumonie- und Sepsisraten. Das Ergebnis unterstützt die bisher bestehende These, dass ein Schaden in dieser Region eine erhöhte Aktivität des Sympathikus bewirkt, die wiederum das Immunsystem modulieren und schwächen könnte. Vor allem Infarkte der rechten Hemisphäre erhöhten das Risiko für eine Pneumonie und zeigten sich als signifikante bzw. tendenzielle Prädiktoren für deren Entwicklung.

In dem hier untersuchten Patientenkollektiv zeigte sich jedoch keine niedrigere Inzidenzrate von Infektionen bei Patienten, die einen Beta-Blocker einnahmen. In dieser Patientenpopulation kam es sogar eher öfter zu Infektionen. Dafür könnten mehrere Gründe ursächlich sein. Zuallererst waren die Beta-Blocker-Patienten schon initial stärker als die Patienten ohne Beta-Blocker von dem Schlaganfall beeinträchtigt und damit einem höheren Risiko ausgesetzt, eine Infektion zu erleiden. Des Weiteren erhöhte sich das Risiko durch die Tatsache weiter, dass die Beta-Blocker-Gruppe signifikant älter war und wesentlich mehr Komorbiditäten aufwies. Das sind alles Faktoren, die die Anfälligkeit gegenüber Infektionen steigern und die Prognose der Patienten entscheidend beeinflussen. Zusätzlich werden heutzutage vor allem kardioselektive Beta-Blocker eingesetzt, die eher an den $\beta_{1}$-Rezeptoren als an anderen $\beta$-Rezeptoren wirken. Dadurch könnten die verantwortlichen Rezeptoren auf den Immunzellen nicht ausreichend blockiert und aus diesem Grund die sympathische Immunmodulation nicht unterdrückt werden können.

Alles in allem konnte der protektive Effekt eines Beta-Blockers, der sich vor allem in experimentellen Studien gezeigt hatte, gegenüber der Entwicklung von Infekten nach einem Schlaganfall in diesem Patientenkollektiv nicht bestätigt werden. Jedoch kann festgestellt werden, dass der Gebrauch von Beta-Blockern in einem schwerst beeinträchtigten Kollektiv sicher ist und die Infektionsraten sowie die Mortalität nicht erhöht. 


\section{$6 \quad$ Literaturverzeichnis}

Ackland GL, Yao ST, Rudiger A, Dyson A, Stidwill R, Poputnikov D, Singer M, Gourine AV (2010): Cardioprotection, attenuated systemic inflammation, and survival benefit of $\beta 1$-adrenoceptor blockade in severe sepsis in rats*. Crit Care Med $\underline{38}, 388-394$

Adams HP, Bendixen BH, Kappelle LJ, Biller J, Love BB, Gordon DL, Marsh EE (1993): Classification of subtype of acute ischemic stroke. Definitions for use in a multicenter clinical trial. TOAST. Trial of Org 10172 in Acute Stroke Treatment. Stroke 24, 35-41

Ahmed N, Wahlgren N, Brainin M, Castillo J, Ford GA, Kaste M, Lees KR, Toni D, SITS Investigators (2009): Relationship of Blood Pressure, Antihypertensive Therapy, and Outcome in Ischemic Stroke Treated With Intravenous Thrombolysis Retrospective Analysis From Safe Implementation of Thrombolysis in Stroke-International Stroke Thrombolysis Register (SITS-ISTR). Stroke $\underline{40}$, 2442-2449

An C, Shi Y, Li P, Hu X, Gan Y, Stetler RA, Leak RK, Gao Y, Sun B-L, Zheng P, Chen J (2014): Molecular dialogues between the ischemic brain and the peripheral immune system: Dualistic roles in injury and repair. Prog Neurobiol 115, 6-24

Ashour W, Al-Anwar A, Kamel A, Aidaros M (2016): Predictors of early infection in cerebral ischemic stroke. J Med Life 9, 163-169

Aslanyan S, Weir CJ, Diener H-C, Kaste M, Lees KR (2004): Pneumonia and urinary tract infection after acute ischaemic stroke: a tertiary analysis of the GAIN International trial. Eur J Neurol 11, 49-53

Asplund K, Karvanen J, Giampaoli S, Jousilahti P, Niemelä M, Broda G, Cesana G, Dallongeville J, Ducimetriere P, Evans A, et al. (2009): Relative Risks for Stroke by Age, Sex, and Population Based on Follow-Up of 18 European Populations in the MORGAM Project. Stroke 40, 2319-2326

Astrup J, Siesjö BK, Symon L (1981): Thresholds in cerebral ischemia - the ischemic penumbra. Stroke $\underline{12}, 723-725$

ATLANTIS, ECASS, and NINDS rt-PA Study Group Investigators (2004): Association of outcome with early stroke treatment: pooled analysis of ATLANTIS, ECASS, and NINDS rt-PA stroke trials. Lancet $363,768-774$

AWMF-Leitlinie 2016 zur Behandlung von erwachsenen Patienten mit ambulant erworbener Pneumonie und Prävention. Leitlinie der Arbeitsgemeinschaft der Wissenschaftlichen Medizinischen Fachgesellschaften. Version vom 25.02.2016 (https://www.awmf.org/uploads/tx_szleitlinien/020-0201_S3_ambulant_erworbene_Pneumonie_Behandlung_Praevention_2016-02-2.pdf) abgerufen am 25.09.2018 AWMF-Leitlinie 2017 zur Epidemiologie, Diagnostik, Therapie, Prävention und Management unkomplizierter, bakterieller, ambulant erworbener Harnwegsinfektionen bei 
erwachsenen Patienten. Leitlinie der Arbeitsgemeinschaft der Wissenschaftlichen Medizinischen Fachgesellschaften. Version vom 04/2017 (https://www.awmf.org/uploads/tx_szleitlinien/043-0441_S3_Harnwegsinfektionen_2017-05.pdf) abgerufen am 25.09.2018

Bae H-J, Yoon D-S, Lee J, Kim B-K, Koo J-S, Kwon O, Park J-M (2005): In-Hospital Medical Complications and Long-Term Mortality After Ischemic Stroke. Stroke $\underline{36}$, $2441-2445$

Barber PA, Demchuk AM, Zhang J, Buchan AM (2000): Validity and reliability of a quantitative computed tomography score in predicting outcome of hyperacute stroke before thrombolytic therapy. Lancet $\underline{355}, 1670-1674$

Barer DH, Cruickshank JM, Ebrahim SB, Mitchell JRA (1988): Low dose $\beta$ blockade in acute stroke ("BEST” trial): an evaluation. Br Med J Clin Res Ed 296, 737-741

Baron JL, Madri JA, Ruddle NH, Hashim G, Janeway CA (1993): Surface expression of alpha 4 integrin by CD4 T cells is required for their entry into brain parenchyma. J Exp Med 177, 57-68

Basi SK, Marrie TJ, Huang JQ, Majumdar SR (2004): Patients admitted to hospital with suspected pneumonia and normal chest radiographs: Epidemiology, microbiology, and outcomes. Am J Med 117, 305-311

Berger B, Gumbinger C, Steiner T, Sykora M (2014): Epidemiologic features, risk factors, and outcome of sepsis in stroke patients treated on a neurologic intensive care unit. J Crit Care 29, 241-248

Berger K, Weltermann B, Kolominsky-Rabas P, Meves S, Heuschmann P, Böhner J, Neundörfer B, Hense HW, Büttner T (1999): Untersuchung zur Reliabilität von Schlaganfallskalen. Die deutschen Versionen von NIHSS, ESS und Rankin Scale. Fortschr Neurol Psychiatr $\underline{67}, 81-86$

Bergmann M, Sautner T (2002): Immunomodulatory effects of vasoactive catecholamines. Wien Klin Wochenschr 114, 752-761

Berkhemer OA, Fransen PSS, Beumer D, van den Berg LA, Lingsma HF, Yoo AJ, Schonewille WJ, Vos JA, Nederkoorn PJ, Wermer MJH, et al. (2015): A Randomized Trial of Intraarterial Treatment for Acute Ischemic Stroke. N Engl J Med 372, 11-20

Bogason E, Morrison K, Zalatimo O, Ermak DM, Lehman E, Markley E, Cockroft K (2017): Urinary Tract Infections in Hospitalized Ischemic Stroke Patients: Source and Impact on Outcome. Cureus $\underline{9}$, e1014

BQS-Institut.http://www.bqs-outcome.de/2005/ergebnisse/leistungsbereiche/karo-

tis/buaw/index_html/0006_Def_Modifizierte_Rankin-Skala_zur_Qualif.html; Zugriff am 11.07.2017 
Brogan E, Langdon C, Brookes K, Budgeon C, Blacker D (2014a): Dysphagia and Factors Associated with Respiratory Infections in the First Week Post Stroke. Neuroepidemiology $\underline{43}, 140-144$

Brogan E, Langdon C, Brookes K, Budgeon C, Blacker D (2014b): Respiratory infections in acute stroke: nasogastric tubes and immobility are stronger predictors than dysphagia. Dysphagia 29, 340-345

Brott T, Adams HP, Olinger CP, Marler JR, Barsan WG, Biller J, Spilker J, Holleran R, Eberle R, Hertzberg V (1989): Measurements of acute cerebral infarction: a clinical examination scale. Stroke 20, 864-870

Buck BH, Liebeskind DS, Saver JL, Bang OY, Yun SW, Starkman S, Ali LK, Kim D, Villablanca JP, Salamon N, et al. (2008): Early Neutrophilia Is Associated With Volume of Ischemic Tissue in Acute Stroke. Stroke 39, 355-360

Busch DMA, Schienkiewitz A, Nowossadeck E, Gößwald A (2013): Prävalenz des Schlaganfalls bei Erwachsenen im Alter von 40 bis 79 Jahren in Deutschland. Bundesgesundheitsbl $\underline{56}, 656-660$

Campbell BCV, Mitchell PJ, Kleinig TJ, Dewey HM, Churilov L, Yassi N, Yan B, Dowling RJ, Parsons MW, Oxley TJ, et al. (2015): Endovascular Therapy for Ischemic Stroke with Perfusion-Imaging Selection. N Engl J Med 372, 1009-1018

Campos F, Qin T, Castillo J, Seo JH, Arai K, Lo EH, Waeber C (2013): Fingolimod Reduces Hemorrhagic Transformation Associated With Delayed tPA Treatment In A Mouse Thromboembolic Model. Stroke J Cereb Circ 44, 505-511

Chamorro Á, Amaro S, Vargas M, Obach V, Cervera Á, Torres F, Planas AM (2006): Interleukin 10, monocytes and increased risk of early infection in ischaemic stroke. $\mathrm{J}$ Neurol Neurosurg Psychiatry $\underline{77}, 1279-1281$

Chastre J, Fagon J-Y (2002): Ventilator-associated Pneumonia. J Respir 165, 867-903

Chen C-J, Ding D, Starke RM, Mehndiratta P, Crowley RW, Liu KC, Southerland AM, Worrall BB (2015): Endovascular vs medical management of acute ischemic stroke. Neurology $\underline{85}, 1980-1990$

Clausen BH, Lambertsen KL, Babcock AA, Holm TH, Dagnaes-Hansen F, Finsen B (2008): Interleukin-1beta and tumor necrosis factor-alpha are expressed by different subsets of microglia and macrophages after ischemic stroke in mice. J Neuroinflammation $\underline{5}$, 46

Colbert JF, Traystman RJ, Poisson SN, Herson PS, Ginde AA (2016): Sex-Related Differences in the Risk of Hospital-Acquired Sepsis and Pneumonia Post Acute Ischemic Stroke. J Stroke Cerebrovasc Dis 25, 2399-2404 
Czupryna P, Garkowski A, Moniuszko A, Pancewicz S, Ciemerych A, Zajkowska J (2013): Patients with sepsis in infectious diseases department in years 1997-2010 _epidemiology and clinical features. Przegl Epidemiol 67, 429-434

Davis KA (2006): Ventilator-Associated Pneumonia: A Review. J Intensive Care Med 21, 211-226

De Raedt S, Haentjens P, De Smedt A, Brouns R, Uyttenboogaart M, Luijckx GJ, De Keyser J (2012): Pre-stroke use of beta-blockers does not affect ischaemic stroke severity and outcome. Eur J Neurol $\underline{19}, 234-240$

DGN-Leitlinie 2012 zur Akuttherapie des ischämischen Schlaganfalls. Leitlinie der Deutschen Gesellschaft für Neurologie. Version vom 09/2012

(https://www.dgn.org/images/red_leitlinien/LL_2012/pdf/l1_22_2012_akutthera-

pie_des_ischmischen_schlaganfalls_update.pdf) abgerufen am 25.09.2018

DGN-Leitlinie 2015 zur Akuttherapie des ischämischen Schlaganfalls - Ergänzung Rekanalisierende Therapie. Leitlinie der Deutschen Gesellschaft für Neurologie. Version vom 06.10.2015 (https://www.dgn.org/images/red_leitlinien/LL_2015/PDFs_Download/030140_LL_akuter-ischaemischer-schlaganfall_final.pdf) abgerufen am 25.09.2018

Dirnagl U, Klehmet J, Braun JS, Harms H, Meisel C, Ziemssen T, Prass K, Meisel A (2007): Stroke-Induced Immunodepression: Experimental Evidence and Clinical Relevance. Stroke $\underline{38}, 770-773$

NINDS rt-PA Stroke Study Group (1995): Tissue Plasminogen Activator for Acute Ischemic Stroke. N Engl J Med 333, 1581-1588

Dowlatshahi D, Hakim A, Fang J, Sharma M (2009): Pre Admission Antithrombotics are Associated with Improved Outcomes following Ischaemic Stroke: A Cohort from the Registry of the Canadian Stroke Network. Int J Stroke $\underline{4}, 328-334$

Dziedzic T, Slowik A, Pera J, Szczudlik A (2007): Beta-blockers reduce the risk of early death in ischemic stroke. J Neurol Sci $\underline{252}, 53-56$

Dziewas R, Ritter M, Schilling M, Konrad C, Oelenberg S, Nabavi D, Stogbauer F, Ringelstein E, Ludemann P (2004): Pneumonia in acute stroke patients fed by nasogastric tube. J Neurol Neurosurg Psychiatry $\underline{75}$, 852-856

Easton JD, Saver JL, Albers GW, Alberts MJ, Chaturvedi S, Feldmann E, Hatsukami TS, Higashida RT, Johnston SC, Kidwell CS, et al. (2009): Definition and Evaluation of Transient Ischemic Attack. Stroke 40, 2276-2293

Edelstein AI, Kwasny MJ, Suleiman LI, Khakhkhar RH, Moore MA, Beal MD, Manning DW (2015): Can the American College of Surgeons Risk Calculator Predict 30-Day Complications After Knee and Hip Arthroplasty? J Arthroplasty $\underline{30}$, 5-10 
Elenkov IJ, Wilder RL, Chrousos GP, Vizi ES (2000): The sympathetic nerve-an integrative interface between two supersystems: the brain and the immune system. Pharmacol Rev 52, 595-638

Emberson J, Lees KR, Lyden P, Blackwell L, Albers G, Bluhmki E, Brott T, Cohen G, Davis S, Donnan G, et al. (2014): Effect of treatment delay, age, and stroke severity on the effects of intravenous thrombolysis with alteplase for acute ischaemic stroke: a metaanalysis of individual patient data from randomised trials. Lancet 384, 1929-1935

Emsley HCA, Smith CJ, Gavin CM, Georgiou RF, Vail A, Barberan EM, Hallenbeck JM, del Zoppo GJ, Rothwell NJ, Tyrrell PJ, Hopkins SJ (2003): An early and sustained peripheral inflammatory response in acute ischaemic stroke: relationships with infection and atherosclerosis. J Neuroimmunol 139, 93-101

Ersoz M, Ulusoy H, Oktar MA, Akyuz M (2007): Urinary Tract Infection and Bacteriurua in Stroke Patients: Frequencies, Pathogen Microorganisms, and Risk Factors. Am J Phys Med Rehabil 6ㅜ, 734-741

Finlayson O, Kapral M, Hall R, Asllani E, Selchen D, Saposnik G (2011): Risk factors, inpatient care, and outcomes of pneumonia after ischemic stroke. Neurology $\underline{77}, 1338$ 1345

Fransen PS, Berkhemer OA, Lingsma HF, Beumer D, van den Berg LA, Yoo AJ, Schonewille WJ, Vos JA, Nederkoorn PJ, Wermer MJH et al. (2016): Time to reperfusion and treatment effect for acute ischemic stroke: A randomized clinical trial. JAMA Neurol $\underline{73}$, 190-196

Fu Y, Zhang N, Ren L, Yan Y, Sun N, Li Y-J, Han W, Xue R, Liu Q, Hao J, et al. (2014): Impact of an immune modulator fingolimod on acute ischemic stroke. Proc Natl Acad Sci U S A $\underline{111}, 18315-18320$

Gleeson K, Eggli DF, Maxwell SL (1997): Quantitative aspiration during sleep in normal subjects. Chest $\underline{111}, 1266-1272$

Gliem M, Mausberg AK, Lee J-I, Simiantonakis I, van Rooijen N, Hartung H-P, Jander $S$ (2012): Macrophages prevent hemorrhagic infarct transformation in murine stroke models. Ann Neurol 71, 743-752

Goldhill DR, Imhoff M, McLean B, Waldmann C (2007): Rotational Bed Therapy to Prevent and Treat Respiratory Complications: A Review and Meta-Analysis. Am J Crit Care 16, 50-61

Gould CV, Umscheid CA, Agarwal RK, Kuntz G, Pegues DA, Healthcare Infection Control Practices Advisory Committee (2010): Guideline for Prevention of Catheter-Associated Urinary Tract Infections 2009. Infect Control Hosp Epidemiol 31, 319-326

Goyal M, Demchuk AM, Menon BK, Eesa M, Rempel JL, Thornton J, Roy D, Jovin TG, 
Willinsky RA, Sapkota BL, et al. (2015): Randomized Assessment of Rapid Endovascular Treatment of Ischemic Stroke. N Engl J Med 372, 1019-1030

Grau AJ, Weimar C, Buggle F, Heinrich A, Goertler M, Neumaier S, Glahn J, Brandt T, Hacke W, Diener H-C (2001): Risk Factors, Outcome, and Treatment in Subtypes of Ischemic Stroke: The German Stroke Data Bank. Stroke 32, 2559-2566

Hacke W, Kaste M, Bluhmki E, Brozman M, Dávalos A, Guidetti D, Larrue V, Lees KR, Medeghri Z, Machnig T, et al. (2008): Thrombolysis with Alteplase 3 to 4.5 Hours after Acute Ischemic Stroke. N Engl J Med $\underline{359}$, 1317-1329

Hagaman JT, Panos RJ, Rouan GW, Shipley RT (2009): Admission Chest Radiograph Lacks Sensitivity in the Diagnosis of Community-Acquired Pneumonia. Am J Med Sci 337, 236-240

Harms H, Prass K, Meisel C, Klehmet J, Rogge W, Drenckhahn C, Göhler J, Bereswill S, Göbel U, Wernecke KD, et al. (2008): Preventive Antibacterial Therapy in Acute Ischemic Stroke: A Randomized Controlled Trial. PLoS ONE $\underline{3}$, e2158

Harms H, Reimnitz P, Bohner G, Werich T, Klingebiel R, Meisel C, Meisel A (2011): Influence of stroke localization on autonomic activation, immunodepression, and poststroke infection. Cerebrovasc Dis Basel Switz 32, 552-560

Herold G: Innere Medizin 2014: eine vorlesungsorientierte Darstellung; unter Berücksichtigung des Gegenstandskataloges für die Ärztliche Prüfung; mit ICD 10-Schlüssel im Text und Stichwortverzeichnis. Selbstverl, Köln 2014

Hessels AJ, Agarwal M, Liu J, Larson EL (2016): Incidence and Risk Factors for HealthCare Associated Infections after Hip Operation. Surg Infect 17, 761-765

Hilker R, Poetter C, Findeisen N, Sobesky J, Jacobs A, Neveling M, Heiss W-D (2003): Nosocomial Pneumonia After Acute Stroke. Stroke 34, 975-981

Hornsten C, Molander L, Gustafson Y (2012): The prevalence of stroke and the association between stroke and depression among a very old population. Arch Gerontol Geriatr 55, 555-559

Hug A, Liesz A, Muerle B, Zhou W, Ehrenheim J, Lorenz A, Dalpke A, Veltkamp R (2011): Reduced Efficacy of Circulating Costimulatory Cells After Focal Cerebral Ischemia. Stroke $\underline{42}, 3580-3586$

Hurn PD, Subramanian S, Parker SM, Afentoulis ME, Kaler LJ, Vandenbark AA, Offner H (2007): T- and B-cell-deficient mice with experimental stroke have reduced lesion size and inflammation. J Cereb Blood Flow Metab Off J Int Soc Cereb Blood Flow Metab 27, 1798-1805

Huxley EJ, Viroslav J, Gray WR, Pierce AK (1978): Pharyngeal aspiration in normal 
adults and patients with depressed consciousness. Am J Med 64, 564-568

Indredavik B, Rohweder G, Naalsund E, Lydersen S (2008): Medical Complications in a Comprehensive Stroke Unit and an Early Supported Discharge Service. Stroke $\underline{39}, 414$ 420

Iwasaki A, Medzhitov R (2015): Control of adaptive immunity by the innate immune system. Nat Immunol $\underline{16}, 343-353$

Jo S, Jin Y, Lee JB, Jeong T, Yoon J (2017): The reason for death among sepsis and septic shock: Pulmonary origin vs extrapulmonary origin? J Crit Care $\underline{39}, 278$

Kalanuria AA, Zai W, Mirski M (2014): Ventilator-associated pneumonia in the ICU. Crit Care $\underline{18}, 208$

Kalra L, Irshad S, Hodsoll J, Simpson M, Gulliford M, Smithard D, Patel A, RebolloMesa I (2015): Prophylactic antibiotics after acute stroke for reducing pneumonia in patients with dysphagia (STROKE-INF): a prospective, cluster-randomised, open-label, masked endpoint, controlled clinical trial. Lancet $\underline{386}$, 1835-1844

Katzan IL, Cebul RD, Husak SH, Dawson NV, Baker DW (2003): The effect of pneumonia on mortality among patients hospitalized for acute stroke. Neurology $\underline{60}, 620-625$

Kemmling A, Lev MH, Payabvash S, Betensky RA, Qian J, Masrur S, Schwamm LH (2013): Hospital Acquired Pneumonia Is Linked to Right Hemispheric Peri-Insular Stroke. PLoS ONE $\underline{8}$, e71141

Khatri R, McKinney AM, Swenson B, Janardhan V (2012): Blood-brain barrier, reperfusion injury, and hemorrhagic transformation in acute ischemic stroke. Neurology $\underline{79}$, S52-S57

Kinjo Y, Ueno K (2011): iNKT cells in microbial immunity: recognition of microbial glycolipids. Microbiol Immunol 55, 472-482

Klehmet J, Harms H, Richter M, Prass K, Volk HD, Dirnagl U, Meisel A, Meisel C (2009): Stroke-induced immunodepression and post-stroke infections: lessons from the preventive antibacterial therapy in stroke trial. Neuroscience $158,1184-1193$

Kohm AP, Sanders VM (2001): Norepinephrine and $\beta 2$-Adrenergic Receptor Stimulation Regulate CD4+ T and B Lymphocyte Function in Vitro and in Vivo. Pharmacol Rev $\underline{53}$, $487-525$

Kolominsky-Rabas PL, Weber M, Gefeller O, Neundoerfer B, Heuschmann PU (2001): Epidemiology of Ischemic Stroke Subtypes According to TOAST Criteria Incidence, Recurrence, and Long-Term Survival in Ischemic Stroke Subtypes: A Population-Based Study. Stroke 32, 2735-2740 
Kolominsky-Rabas PL, Heuschmann PU, Marschall D, Emmert M, Baltzer N, Neundörfer B, Schöffski O, Krobot KJ (2006): Lifetime Cost of Ischemic Stroke in Germany: Results and National Projections From a Population-Based Stroke Registry: The Erlangen Stroke Project. Stroke 37, 1179-1183

Kong K-H, Young S (2000): Incidence and outcome of poststroke urinary retention: A prospective study. Arch Phys Med Rehabil $\underline{81}$, 1464-1467

Krief S, Lönnqvist F, Raimbault S, Baude B, Spronsen AV, Arner P, Strosberg AD, Ricquier D, Emorine LJ (1993): Tissue distribution of beta 3-adrenergic receptor mRNA in man. J Clin Invest 91, 344-349

Lackland DT, Roccella EJ, Deutsch AF, Fornage M, George MG, Howard G, Kissela BM, Kittner SJ, Lichtman JH, Lisabeth LD, et al. (2014): Factors Influencing the Decline in Stroke Mortality. Stroke $\underline{45}$, 315-353

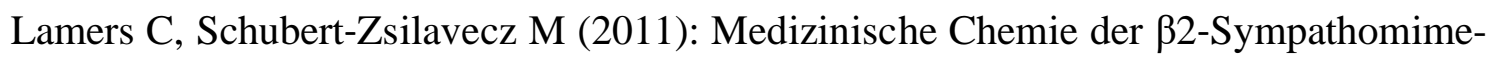
tika. Pharm Unserer Zeit $\underline{40}$, 423-428

Langhauser F, Kraft P, Göb E, Leinweber J, Schuhmann MK, Lorenz K, Gelderblom M, Bittner S, Meuth SG, Wiendl H, et al. (2014): Blocking of $\alpha 4$ Integrin Does Not Protect From Acute Ischemic Stroke in Mice. Stroke 45, 1799-1806

Langhorne P, Stott DJ, Robertson L, MacDonald J, Jones L, McAlpine C, Dick F, Taylor GS, Murray G (2000): Medical Complications After Stroke A Multicenter Study. Stroke $\underline{31}, 1223-1229$

Laowattana S, Oppenheimer SM (2007): Protective effects of beta-blockers in cerebrovascular disease. Neurology $\underline{68}, 509-514$

Lau AC, So H, Tang S, Yeung A, Lam S, Yan W, Hong Kong East Cluster Task Force on Prevention of Ventilator-associated Pneumonia in Critical Care Areas (2015): Prevention of ventilator-associated pneumonia. Hong Kong Med J 21, 61-68

Lees KR, Ford GA, Muir KW, Ahmed N, Dyker AG, Atula S, Kalra L, Warburton EA, Baron J-C, Jenkinson DF, et al. (2008): Thrombolytic therapy for acute stroke in the United Kingdom: experience from the safe implementation of thrombolysis in stroke (SITS) register. QJM Int J Med 101, 863-869

Lees KR, Bluhmki E, von Kummer R, Brott TG, Toni D, Grotta JC, Albers GW, Kaste M, Marler JR, Hamilton SA, et al. (2010): Time to treatment with intravenous alteplase and outcome in stroke: an updated pooled analysis of ECASS, ATLANTIS, NINDS, and EPITHET trials. Lancet $\underline{375}, 1695-1703$

Leibovitz A, Plotnikov G, Habot B, Rosenberg M, Segal R (2003a): Pathogenic colonization of oral flora in frail elderly patients fed by nasogastric tube or percutaneous enterogastric tube. J Gerontol A Biol Sci Med Sci $\underline{58}$, 52-55 
Leibovitz A, Dan M, Zinger J, Carmeli Y, Habot B, Segal R (2003b): Pseudomonas aeruginosa and the Oropharyngeal Ecosystem of Tube-Fed Patients. Emerg Infect Dis $\underline{9}$, 956-959

Leibovitz A, Barmoehl Y, Steinberg D, Segal R (2005): Biodynamics of biofilm formation on nasogastric tubes in elderly patients. Isr Med Assoc $\underline{7}, 428-430$

Leitlinie Harnwegsinfekt s. AWMF-Leitlinie 2017

Leitlinie Pneumonie s. AWMF-Leitlinie 2016

Leitlinie Schlaganfalltherapie s. DGN-Leitlinie 2012

Leitlinie Schlaganfalltherapie- Ergänzung Rekanalisierende Therapie s. DGN-Leitlinie 2015

Liesz A, Zhou W, Mracskó É, Karcher S, Bauer H, Schwarting S, Sun L, Bruder D, Stegemann S, Cerwenka A, et al. (2011): Inhibition of lymphocyte trafficking shields the brain against deleterious neuroinflammation after stroke. Brain 134, 704-720

Llovera G, Hofmann K, Roth S, Salas-Pérdomo A, Ferrer-Ferrer M, Perego C, Zanier ER, Mamrak U, Rex A, Party H, et al. (2015): Results of a preclinical randomized controlled multicenter trial (pRCT): Anti-CD49d treatment for acute brain ischemia. Sci Transl Med 7, 299ra121

Lozano R, Naghavi M, Foreman K, Lim S, Shibuya K, Aboyans V, Abraham J, Adair T, Aggarwal R, Ahn SY, et al. (2012): Global and regional mortality from 235 causes of death for 20 age groups in 1990 and 2010: a systematic analysis for the Global Burden of Disease Study 2010. Lancet $\underline{380}$, 2095-2128

Lv H, Yin P, Long A, Gao Y, Zhao Z, Li J, Zhang L, Zhang L, Tang P (2016): Clinical characteristics and risk factors of postoperative pneumonia after hip fracture surgery: a prospective cohort study. Osteoporos Int 27, 3001-3009

Macchia A, Romero M, Comignani PD, Mariani J, D’ettorre A, Prini N, Santopinto M, Tognoni G (2012): Previous prescription of $\beta$-blockers is associated with reduced mortality among patients hospitalized in intensive care units for sepsis*. Crit Care Med $\underline{40}$, $2768-2772$

Maier IL, Karch A, Mikolajczyk R, Bähr M, Liman J (2015): Effect of Beta-Blocker Therapy on the Risk of Infections and Death after Acute Stroke - A Historical Cohort Study. PLoS ONE $\underline{10}$, e0116836

Maki DG, Tambyah PA (2001): Engineering out the risk for infection with urinary catheters. Emerg Infect Dis $\underline{7}, 342-347$

Marino F, Cosentino M (2013): Adrenergic modulation of immune cells: an update. Amino Acids $\underline{45}, 55-71$ 
Martino R, Foley N, Bhogal S, Diamant N, Speechley M, Teasell R (2005): Dysphagia After Stroke Incidence, Diagnosis, and Pulmonary Complications. Stroke 36, 2756-2763 McCulloch L, Smith CJ, McColl BW (2017): Adrenergic-mediated loss of splenic marginal zone B cells contributes to infection susceptibility after stroke. Nat Commun $\underline{8}$, 15051

Meisel A, Meisel C, Harms H, Hartmann O, Ulm L (2012): Predicting Post-Stroke Infections and Outcome with Blood-Based Immune and Stress Markers. Cerebrovasc Dis $\underline{33}$, 580-588

Meisel C, Schwab JM, Prass K, Meisel A, Dirnagl U (2005): Central nervous system injury-induced immune deficiency syndrome. Nat Rev Neurosci $\underline{6}, 775-786$

Meyer S, Strittmatter M 1 C, Fischer C, Georg T, Schmitz B (2004): Lateralization in autonomic dysfunction in ischemic stroke involving the insular cortex. Neuroreport 15 , 357-361

Michel MC, Ochodnicky P, Summers RJ (2010): Tissue functions mediated by $\beta 3$-adrenoceptors-findings and challenges. Naunyn Schmiedebergs Arch Pharmacol $\underline{382}$, 103-108

Minnerup J, Wersching H, Brokinkel B, Dziewas R, Heuschmann PU, Nabavi DG, Ringelstein EB, Schäbitz W-R, Ritter MA (2010): The impact of lesion location and lesion size on poststroke infection frequency. J Neurol Neurosurg Psychiatry $\underline{81}$, 198-202

Mishra NK, Albers GW, Davis SM, Donnan GA, Furlan AJ, Hacke W, Lees KR (2010): Mismatch-Based Delayed Thrombolysis. Stroke 41, 25-33

Miyamoto N, Tanaka Y, Ueno Y, Tanaka R, Hattori N, Urabe T (2012): Benefits of Prestroke Use of Angiotensin Type 1 Receptor Blockers on Ischemic Stroke Severity. J Stroke Cerebrovasc Dis 21, $363-368$

Mnif H, Koubaa M, Zrig M, Trabelsi R, Abid A (2009): Elderly patient's mortality and morbidity following trochanteric fracture. A hundred cases prospective study. Orthop Traumatol Surg Res 95, 505-510

Mozaffarian D, Benjamin EJ, Go AS, Arnett DK, Blaha MJ, Cushman M, Ferranti S de, Després J-P, Fullerton HJ, Howard VJ, et al. (2015): Heart Disease and Stroke Statistics2015 Update A Report From the American Heart Association. Circulation 131, 29-322

Murray CJL, Vos T, Lozano R, Naghavi M, Flaxman AD, Michaud C, Ezzati M, Shibuya K, Salomon JA, Abdalla S, et al. (2012): Disability-adjusted life years (DALYs) for 291 diseases and injuries in 21 regions, 1990-2010: a systematic analysis for the Global Burden of Disease Study 2010. Lancet $\underline{380}$, 2197-2223

Niklasson J, Lövheim H, Gustafson Y (2014): Morale in very old people who have had a 
stroke. Arch Gerontol Geriatr 58, 408-414

Nimptsch U, Mansky T (2014): Stroke unit care and trends of in-hospital mortality for stroke in Germany 2005-2010. Int J Stroke $\underline{9}, 260-265$

Offner H, Subramanian S, Parker SM, Afentoulis ME, Vandenbark AA, Hurn PD (2006): Experimental Stroke Induces Massive, Rapid Activation of the Peripheral Immune System. J Cereb Blood Flow Metab 26, 654-665

Palm F, Urbanek C, Wolf J, Buggle F, Kleemann T, Hennerici MG, Inselmann G, Hagar M, Safer A, Becher H, Grau AJ (2012): Etiology, Risk Factors and Sex Differences in Ischemic Stroke in the Ludwigshafen Stroke Study, a Population-Based Stroke Registry. Cerebrovasc Dis $\underline{33}, 69-75$

Parker MJ, Pryor GA (1992): The timing of surgery for proximal femoral fractures. J Bone Joint Surg Br 4ㅡ, 203-205

Pexman JHW, Barber PA, Hill MD, Sevick RJ, Demchuk AM, Hudon ME, Hu WY, Buchan AM (2001): Use of the Alberta Stroke Program Early CT Score (ASPECTS) for Assessing CT Scans in Patients with Acute Stroke. Am J Neuroradiol 22, 1534-1542

Phelan C, Alaigh V, Fortunato G, Staff I, Sansing L (2015): Effect of $\beta$-adrenergic antagonists on in-hospital mortality after ischemic stroke. J Stroke Cerebrovasc Dis Off J Natl Stroke Assoc 24, 1998-2004

Ponikowski P, Voors AA, Anker SD, Bueno H, Cleland JGF, Coats AJS, Falk V, González-Juanatey JR, Harjola V-P, Jankowska EA, et al. (2016): 2016 ESC Guidelines for the diagnosis and treatment of acute and chronic heart failureThe Task Force for the diagnosis and treatment of acute and chronic heart failure of the European Society of Cardiology (ESC)Developed with the special contribution of the Heart Failure Association (HFA) of the ESC. Eur Heart J 37, 2129-2200

Popović N, Stefanović-Budimkić M, Mitrović N, Urošević A, Milošević B, Pelemiš M, Jevtović D, Beslać-Bumbaširević L, Jovanović D (2013): The Frequency of Poststroke Infections and Their Impact on Early Stroke Outcome. J Stroke Cerebrovasc Dis $\underline{22}, 424$ 429

Prass K, Meisel C, Höflich C, Braun J, Halle E, Wolf T, Ruscher K, Victorov IV, Priller J, Dirnagl U, et al. (2003): Stroke-induced Immunodeficiency Promotes Spontaneous Bacterial Infections and Is Mediated by Sympathetic Activation Reversal by Poststroke T Helper Cell Type 1-like Immunostimulation. J Exp Med 198, 725-736

Rankin J (1957): Cerebral Vascular Accidents in Patients over the Age of 60: II. Prognosis. Scott Med J 2, 200-215

Rha J-H, Saver JL (2007): The Impact of Recanalization on Ischemic Stroke Outcome: A Meta-Analysis. Stroke $\underline{38}, 967-973$ 
Roth EJ, Lovell L, Harvey RL, Heinemann AW, Semik P, Diaz S (2001): Incidence of and Risk Factors for Medical Complications During Stroke Rehabilitation. Stroke $\underline{32}$, 523-529

Ruhnau J, Schulze K, Gaida B, Langner S, Kessler C, Bröker B, Dressel A, Vogelgesang A (2014): Stroke alters respiratory burst in neutrophils and monocytes. Stroke J Cereb Circ 45, 794-800

Rundek T, Mast H, Hartmann A, Boden-Albala B, Lennihan L, Lin IF, Paik MC, Sacco RL (2000): Predictors of resource use after acute hospitalization: the Northern Manhattan Stroke Study. Neurology 55, 1180-1187

Russo T, Felzani G, Marini C (2011): Stroke in the Very Old: A Systematic Review of Studies on Incidence, Outcome, and Resource Use. J Aging Res 2011, 108785

Sander D, Klingelhöfer J (1995): Changes of circadian blood pressure patterns and cardiovascular parameters indicate lateralization of sympathetic activation following hemispheric brain infarction. J Neurol 242, 313-318

Sander D, Winbeck K, Klingelhofer J, Etgen T, Conrad B (2001): Prognostic relevance of pathological sympathetic activation after acute thromboembolic stroke. Neurology $\underline{57}$, 833-838

Saver JL, Goyal M, Bonafe A, Diener H-C, Levy EI, Pereira VM, Albers GW, Cognard C, Cohen DJ, Hacke W, et al. (2015): Solitaire ${ }^{\mathrm{TM}}$ with the Intention for Thrombectomy as Primary Endovascular Treatment for Acute Ischemic Stroke (SWIFT PRIME) trial: protocol for a randomized, controlled, multicenter study comparing the Solitaire revascularization device with IV tPA with IV tPA alone in acute ischemic stroke. Int J Stroke 10 , 439-448

Schellinger PD, Thomalla G, Fiehler J, Köhrmann M, Molina CA, Neumann-Haefelin T, Ribo M, Singer OC, Zaro-Weber O, Sobesky J (2007): MRI-Based and CT-Based Thrombolytic Therapy in Acute Stroke Within and Beyond Established Time Windows An Analysis of 1210 Patients. Stroke $\underline{38}$, 2640-2645

Schellinger PD, Bryan RN, Caplan LR, Detre JA, Edelman RR, Jaigobin C, Kidwell CS, Mohr JP, Sloan M, Sorensen AG, Warach S (2010): Evidence-based guideline: The role of diffusion and perfusion MRI for the diagnosis of acute ischemic stroke Report of the Therapeutics and Technology Assessment Subcommittee of the American Academy of Neurology. Neurology $\underline{75}, 177-185$

Schlegel D, Kolb SJ, Luciano JM, Tovar JM, Cucchiara BL, Liebeskind DS, Kasner SE (2003): Utility of the NIH Stroke Scale as a Predictor of Hospital Disposition. Stroke $\underline{34}$, 134-137

Schwab SR, Pereira JP, Matloubian M, Xu Y, Huang Y, Cyster JG (2005): Lymphocyte 
Sequestration Through S1P Lyase Inhibition and Disruption of S1P Gradients. Science $\underline{309}, 1735-1739$

Selim M, Savitz S, Linfante I, Caplan L, Schlaug G (2005): Effect of pre-stroke use of ACE inhibitors on ischemic stroke severity. BMC Neurol $\underline{5}, 10$

Singer M, Deutschman CS, Seymour CW, Shankar-Hari M, Annane D, Bauer M, Bellomo R, Bernard GR, Chiche J-D, Coopersmith CM, et al. (2016): The Third International Consensus Definitions for Sepsis and Septic Shock (Sepsis-3). JAMA 315, 801-810

Smektala R, Endres HG, Dasch B, Maier C, Trampisch HJ, Bonnaire F, Pientka L (2008): The effect of time-to-surgery on outcome in elderly patients with proximal femoral fractures. BMC Musculoskelet Disord 9, 171

Steiner MM, Brainin M (2003): The quality of acute stroke units on a nation-wide level: the Austrian Stroke Registry for acute stroke units. Eur J Neurol 10, 353-360

Steinhagen V, Grossmann A, Benecke R, Walter U (2009): Swallowing Disturbance Pattern Relates to Brain Lesion Location in Acute Stroke Patients. Stroke 40, 1903-1906

Stott DJ, Falconer A, Miller H, Tilston JC, Langhorne P (2009): Urinary tract infection after stroke. QJM Int J Med 102, 243-249

Stroke Unit Trialists' Collaboration (2013): Organised inpatient (stroke unit) care for stroke. Cochrane Database Syst Rev 19, CD000197

Swieten JC van, Koudstaal PJ, Visser MC, Schouten HJ, Gijn J van (1988): Interobserver agreement for the assessment of handicap in stroke patients. Stroke $\underline{19}, 604-607$

Sykora M, Siarnik P, Diedler J, for the VISTA Acute Collaborators, VISTA Acute Collaborators, Lees KR, Alexandrov A, Bath PM, Bluhmki E, Bornstein N, et al. (2015): Blockers, Pneumonia, and Outcome After Ischemic Stroke: Evidence From Virtual International Stroke Trials Archive. Stroke 46, 1269-1274

Thapa S. Middle cerebral artery territory in ASPECTS study (radiopedia.org). https://radiopaedia.org/cases/middle-cerebral-artery-territory-in-aspects-study-1; Zugriff am 06.10.2017

Vargas M, Horcajada JP, Obach V, Revilla M, Cervera A, Torres F, Planas AM, Mensa J, Chamorro A (2006): Clinical consequences of infection in patients with acute stroke: is it prime time for further antibiotic trials? Stroke $\underline{37}, 461-465$

Vermeij FH, Reimer WJMS op, Man P de, Oostenbrugge RJ van, Franke CL, Jong G de, Kort PLM de, Dippel DWJ (2009): Stroke-Associated Infection Is an Independent Risk Factor for Poor Outcome after Acute Ischemic Stroke: Data from the Netherlands Stroke Survey. Cerebrovasc Dis 27, 465-471

Vogelgesang A, Grunwald U, Langner S, Jack R, Bröker BM, Kessler C, Dressel A 
(2008): Analysis of Lymphocyte Subsets in Patients With Stroke and Their Influence on Infection After Stroke. Stroke 39, 237-241

Vogelgesang A, May VEL, Grunwald U, Bakkeboe M, Langner S, Wallaschofski H, Kessler C, Bröker BM, Dressel A (2010): Functional Status of Peripheral Blood T-Cells in Ischemic Stroke Patients. PLoS ONE $\underline{5}$, e8718

Walter U, Knoblich R, Steinhagen V, Donat M, Benecke R, Kloth A (2007): Predictors of pneumonia in acute stroke patients admitted to a neurological intensive care unit. $\mathbf{J}$ Neurol 254, 1323-1329

Walter U, Kolbaske S, Patejdl R, Steinhagen V, Abu-Mugheisib M, Grossmann A, Zingler C, Benecke R (2013): Insular stroke is associated with acute sympathetic hyperactivation and immunodepression. Eur J Neurol 20, 153-159

Wei Y, Yemisci M, Kim H-H, Yung LM, Shin HK, Hwang S-K, Guo S, Qin T, Alsharif N, Brinkmann V, et al. (2011): Fingolimod provides long-term protection in rodent models of cerebral ischemia. Ann Neurol 69, 119-129

Weimar C, Roth MP, Zillessen G, Glahn J, Wimmer MLJ, Busse O, Haberl RL, Diener H-C, Collaborators on behalf of the GSDB (2002): Complications following Acute Ischemic Stroke. Eur Neurol 48, 133-140

Westendorp WF, Nederkoorn PJ, Vermeij J-D, Dijkgraaf MG, van de Beek D (2011): Post-stroke infection: A systematic review and meta-analysis. BMC Neurol 11, 110

Westendorp WF, Vermeij J-D, Zock E, Hooijenga IJ, Kruyt ND, Bosboom HJLW, Kwa VIH, Weisfelt M, Remmers MJM, ten Houten R, et al. (2015): The Preventive Antibiotics in Stroke Study (PASS): a pragmatic randomised open-label masked endpoint clinical trial. Lancet $\underline{385}, 1519-1526$

Westendorp WF, Vermeij J-D, Brouwer MC, Roos YBWEM, Nederkoorn PJ, Beek D van de, Investigators for the P (2016): Pre-Stroke Use of Beta-Blockers Does Not Lower Post-Stroke Infection Rate: An Exploratory Analysis of the Preventive Antibiotics in Stroke Study. Cerebrovasc Dis $\underline{42}, 506-511$

Wintermark M, Sanelli PC, Albers GW, Bello JA, Derdeyn CP, Hetts SW, Johnson MH, Kidwell CS, Lev MH, Liebeskind DS, et al. (2013): Imaging Recommendations for Acute Stroke and Transient Ischemic Attack Patients. J Am Coll Radiol 10, 828-832

Wong CHY, Jenne CN, Lee W-Y, Léger C, Kubes P (2011): Functional Innervation of Hepatic iNKT Cells Is Immunosuppressive Following Stroke. Science 334, 101-105

Young M, Marrie TJ (1994): Interobserver variability in the interpretation of chest roentgenograms of patients with possible pneumonia. Arch Intern Med 154, 2729-2732 
Zaidat OO, Yoo AJ, Khatri P, Tomsick TA, von Kummer R, Saver JL, Marks MP, Prabhakaran S, Kallmes DF, Fitzsimmons B-FM, et al. (2013): Recommendations on Angiographic Revascularization Grading Standards for Acute Ischemic Stroke. Stroke J Cereb Circ 44, 2650-2663

Zhu Z, Fu Y, Tian D, Sun N, Han W, Chang G, Dong Y, Xu X, Liu Q, Huang D, Shi FD (2015): Combination of an Immune Modulator Fingolimod with Alteplase in Acute Ischemic Stroke: A Pilot Trial. Circulation 132, 1104-1112 